\title{
الصراعات الداخليت
}

وتمويل التتظيمات الإرهابيت في الوطن العربي الواتي

(دراسة حالة تنظيم داعش)

د. ديبال عز الدين جميل"

مقدمت:

يُعَدُّ واحدًا من المؤشرات الدالَّة على عدم الاستقرار في المنطقة العربية

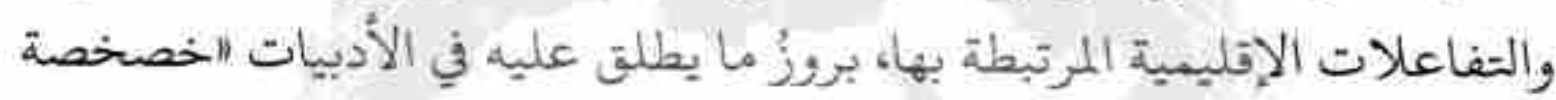
العنف الجهادي"اء إذ أدت موجة الصراعات الداخلية المسـلحة التي شـهدتها

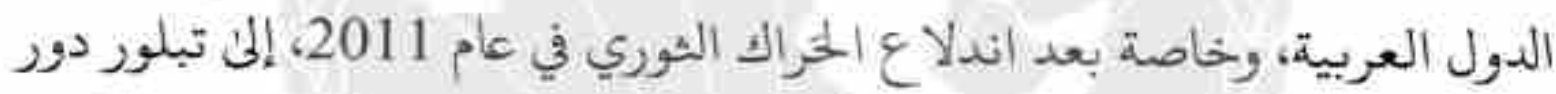

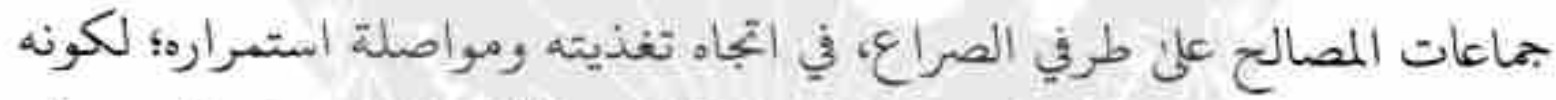

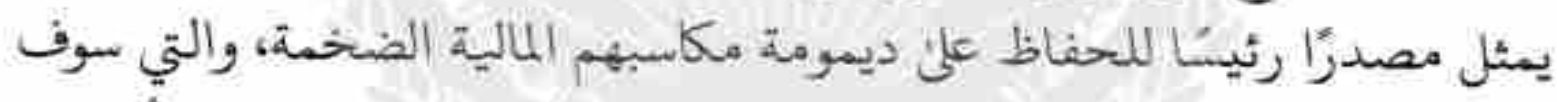

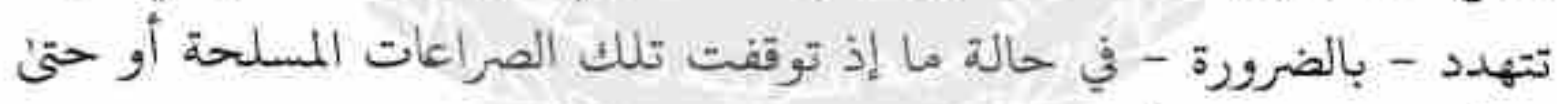

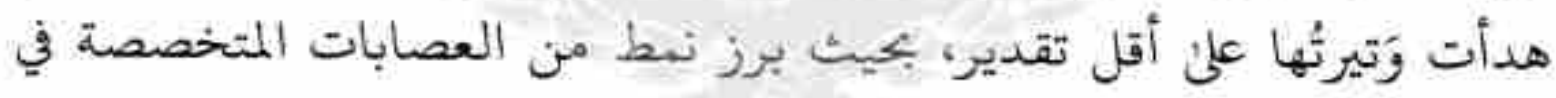

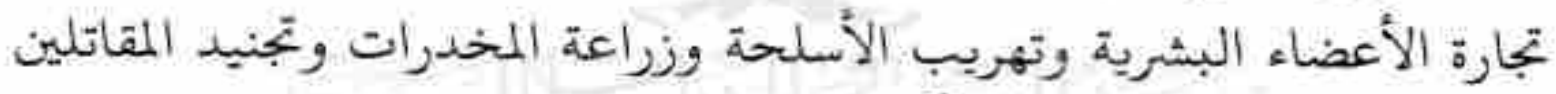

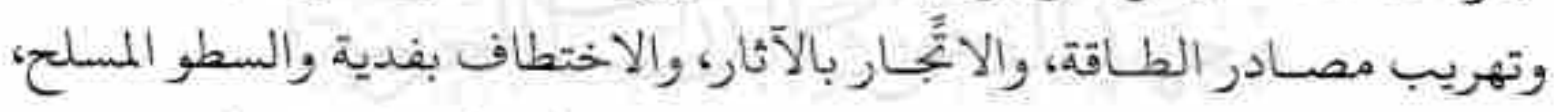
وغيرها من المؤشرات المعبرة عن خصخصة الصراعات الداخلية المسلحة.

وتظل أسباب ظهور تلك الجماعات المقاتِلة العامل الحاسم في انتشارها،

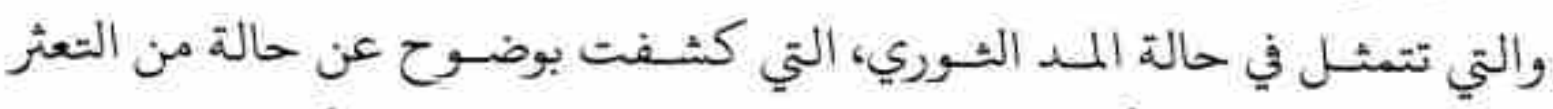

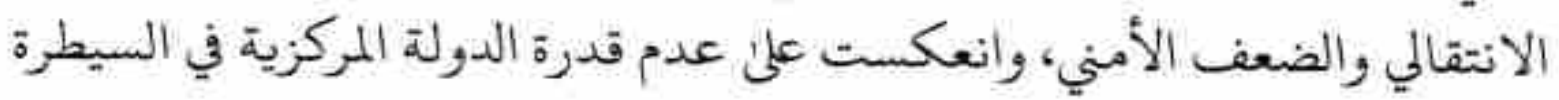

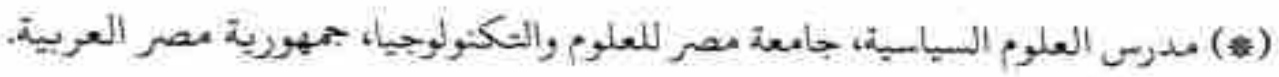


على كامل إقليمها، سواء بشكل كامل؛ أو حتى جزئًاً على بعض المناطق الحدودية، وبعض المناطق الطرفية والهامشية، بحيث تنتعش اقتصاديات الصراعات الداخلية

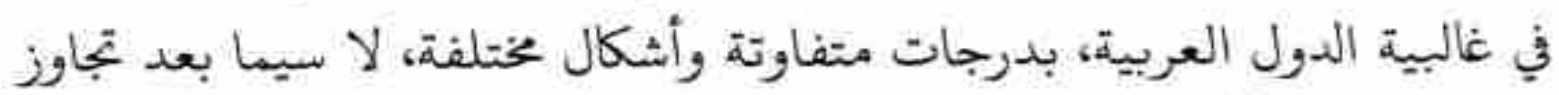

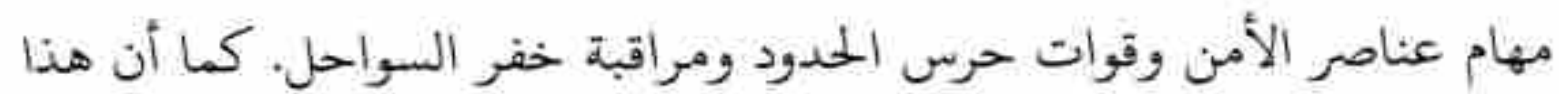

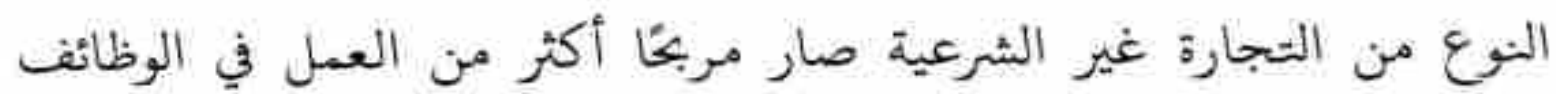

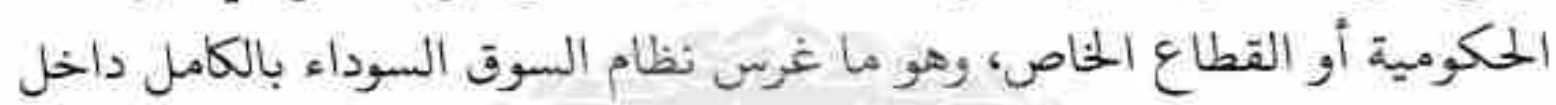
بعض المجتمعات في المنطقة في سيات التفاعلات الصراعية.

وقد أسهمت ظاهرة عدم القدرة على السيطرة الحدودية، وانعكاسها في

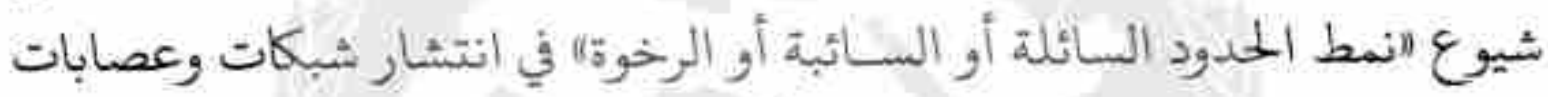

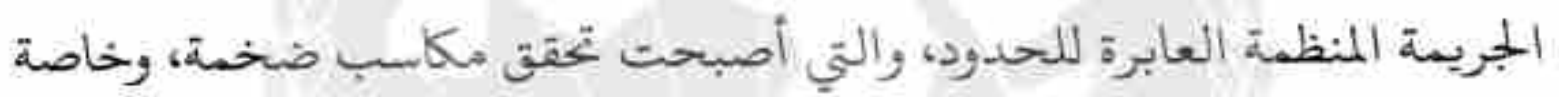

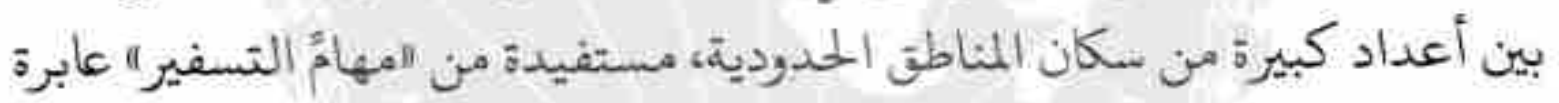

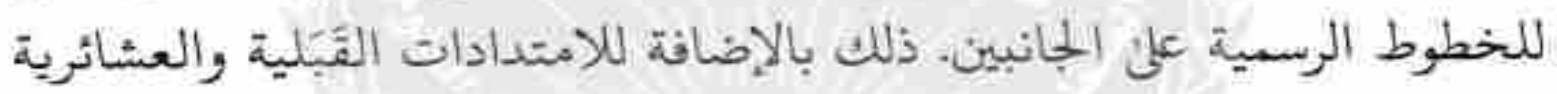

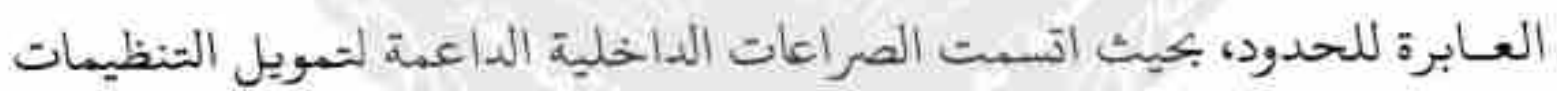

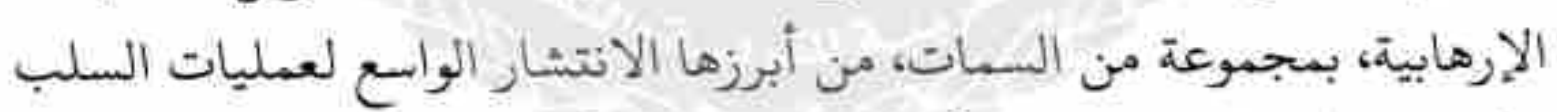

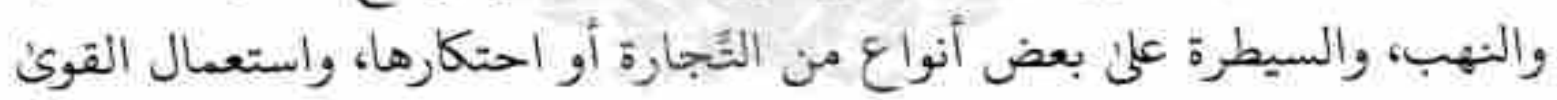

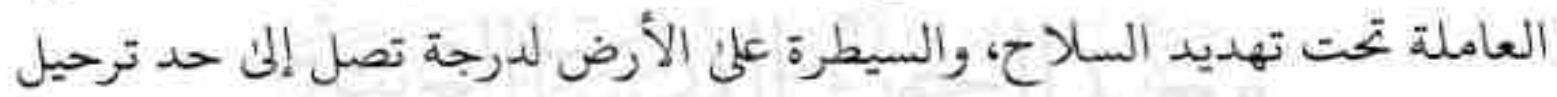

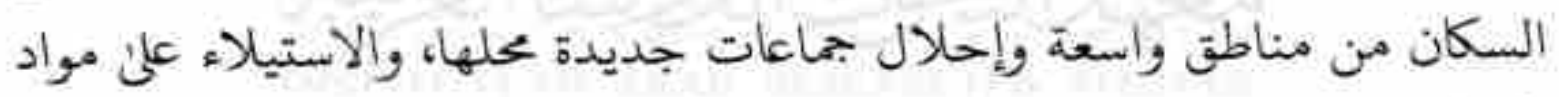

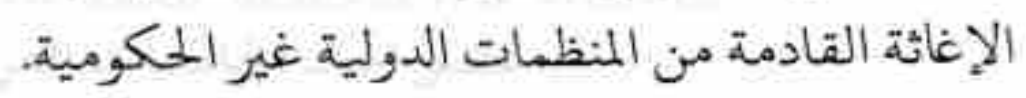

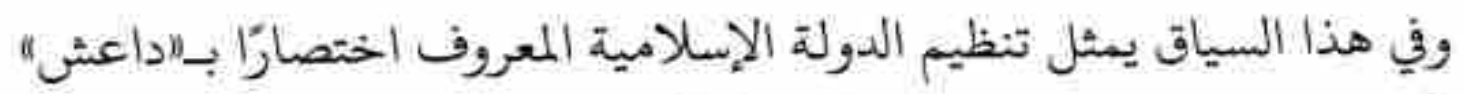

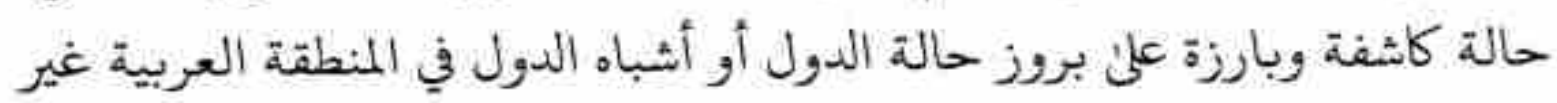

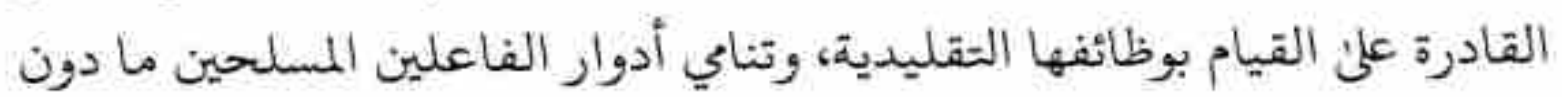

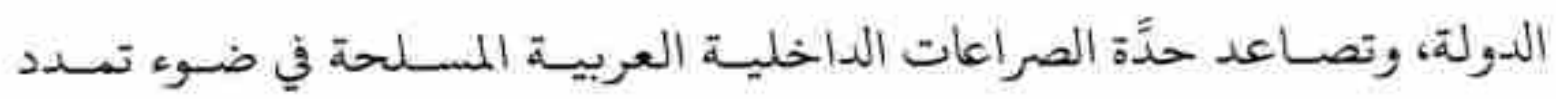


التنظيمات الإرهابية ومحاولتها ليس فقط تقديم نموذج الخلافة الإسلامية وإنما

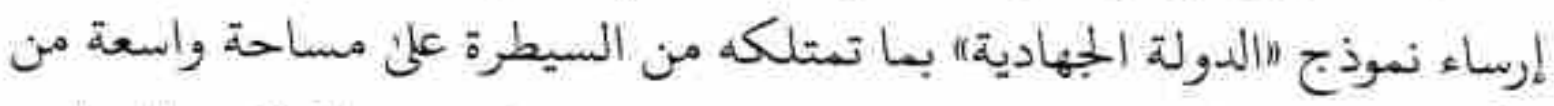

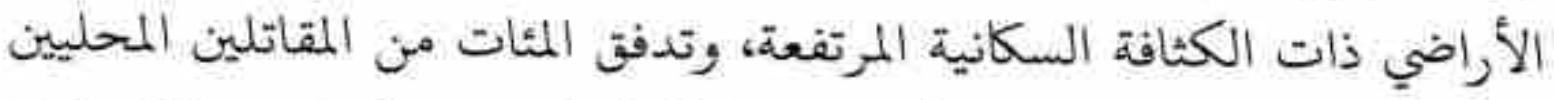

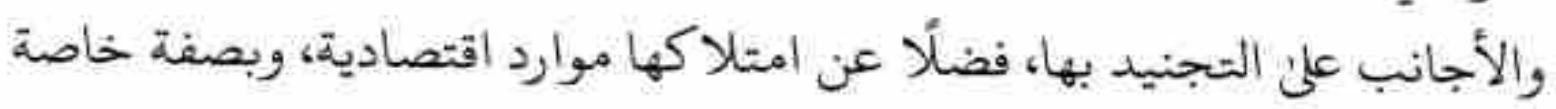
النفط، بخلاف عوائدها المالية من مصادر متعددة، وتعاملات المات اقتصادية بينها

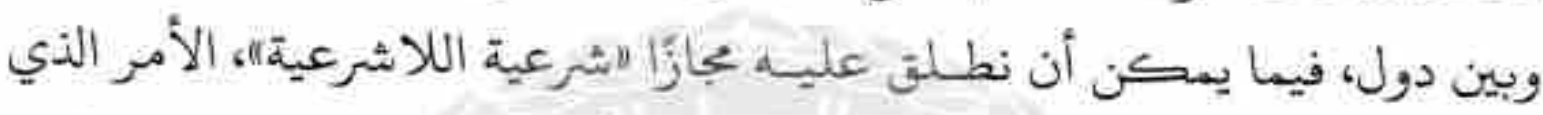

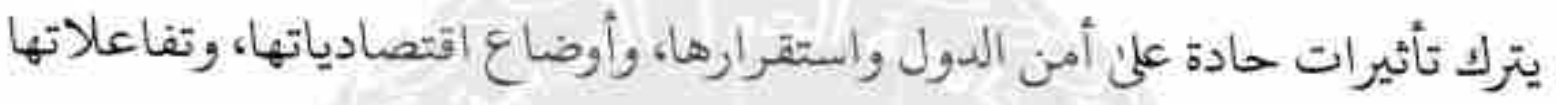
الإقليمية.

وبناء على ما سبق، تناقش هذه الدراسة عدة عناصر أساسية رهي تفسيرات

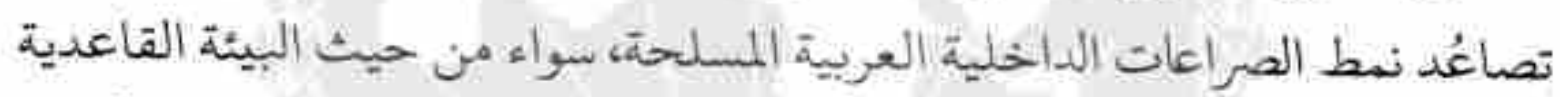

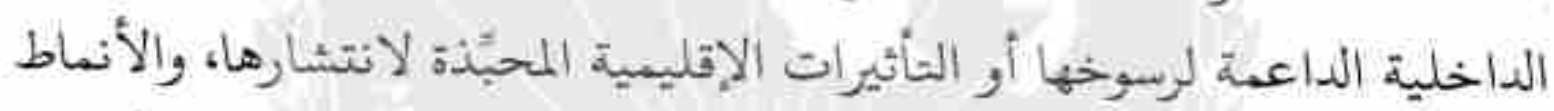

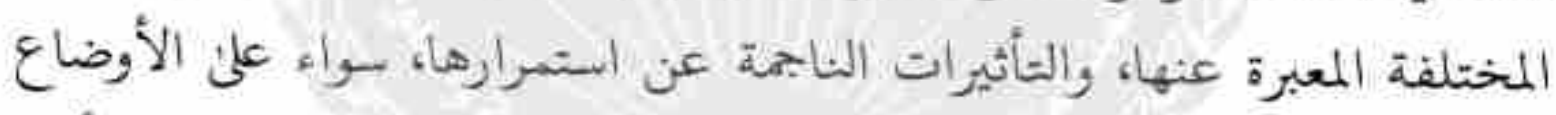

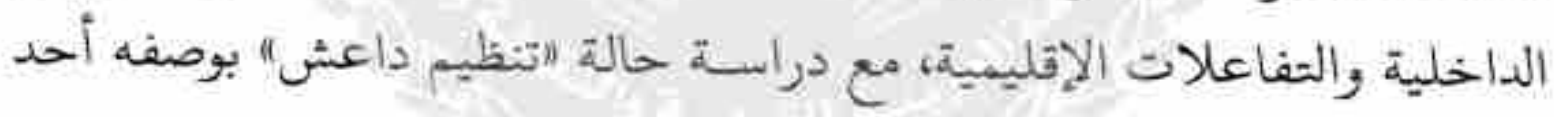

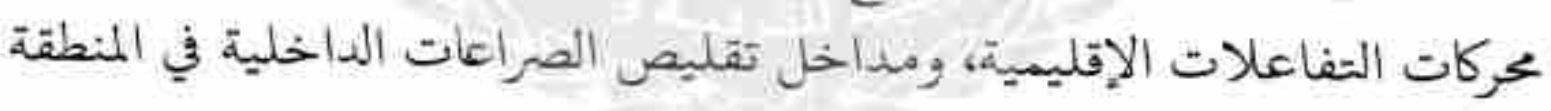

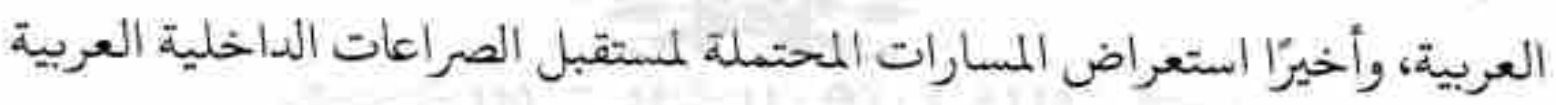

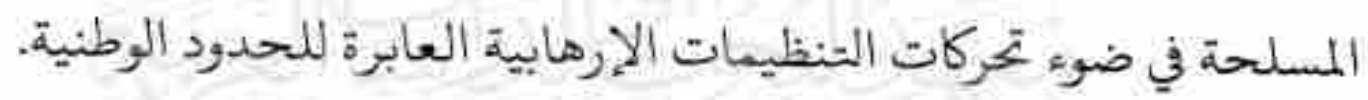

\section{أولاً - أسباب تصاعد حدة الصراعات الداخليت العربيت:}

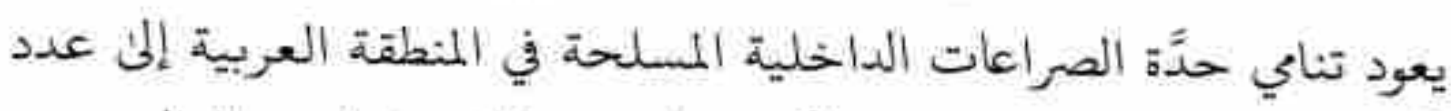

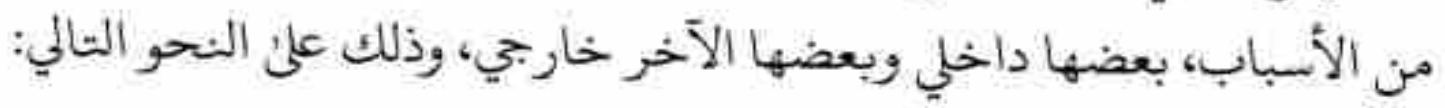

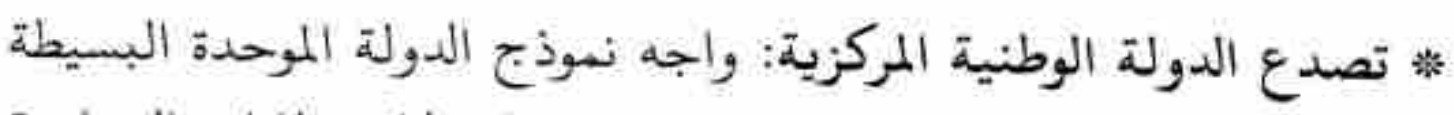

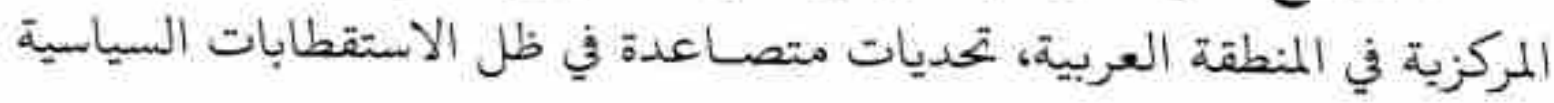


والتصدعات الاجتماعية وشيوع النزعات الانفصالية، لا سيما بعد توابع الثورات

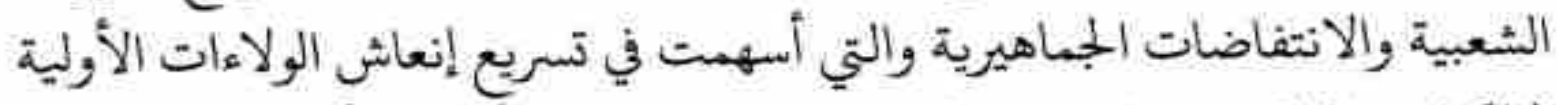

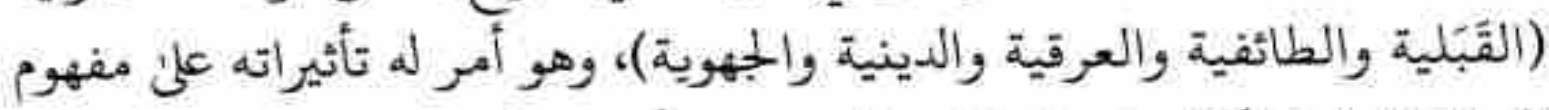

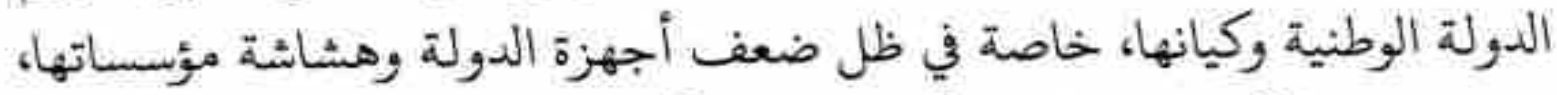

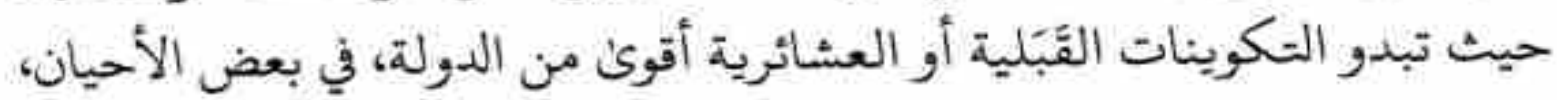

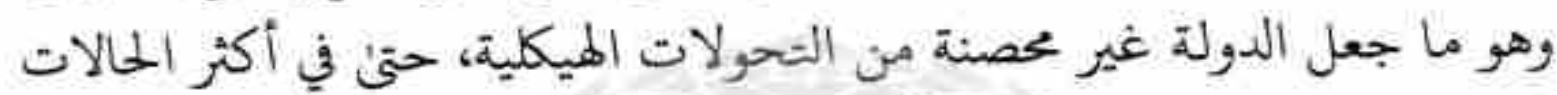

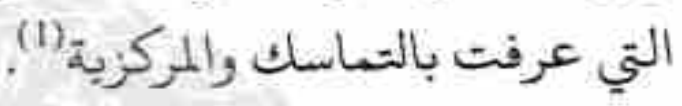

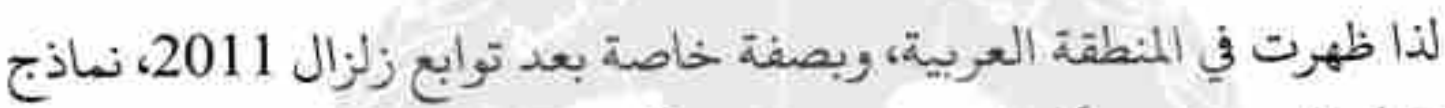

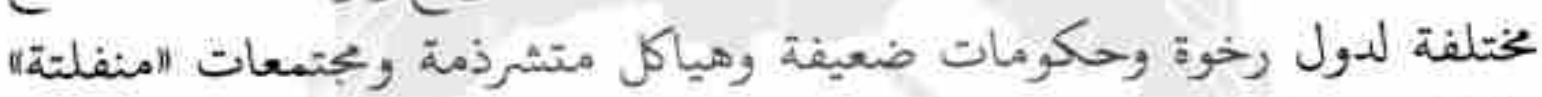

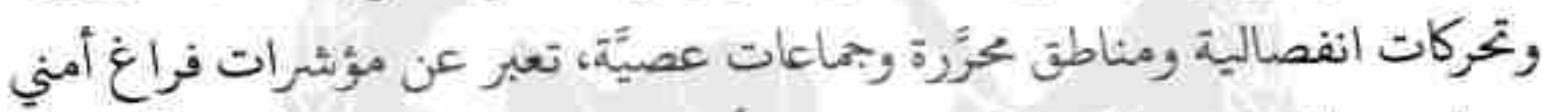

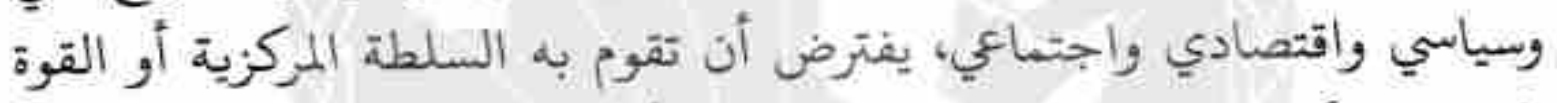

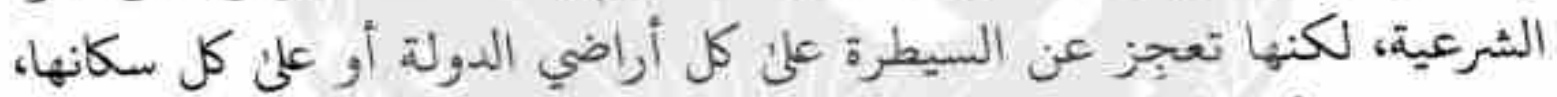

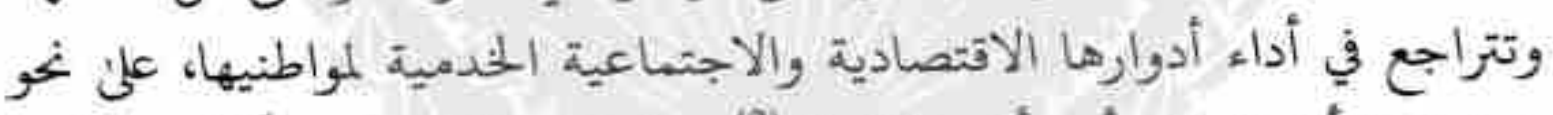

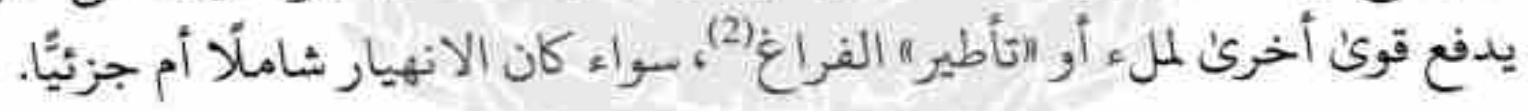
* صعود الفاعلين المسلحين الذين يستخدمون العنف من غير الدول، مثل

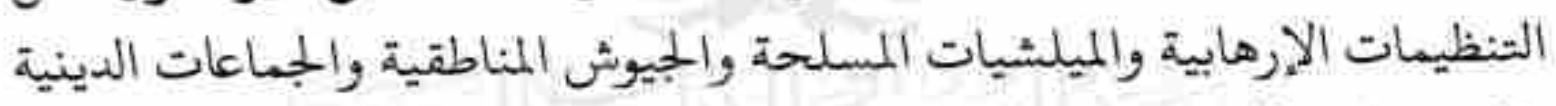

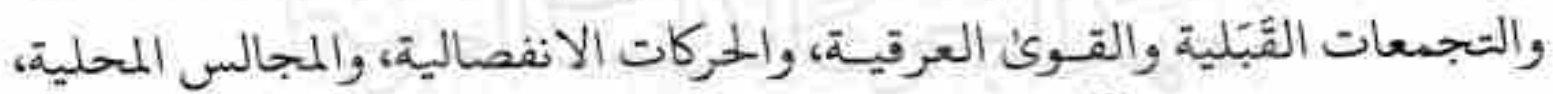

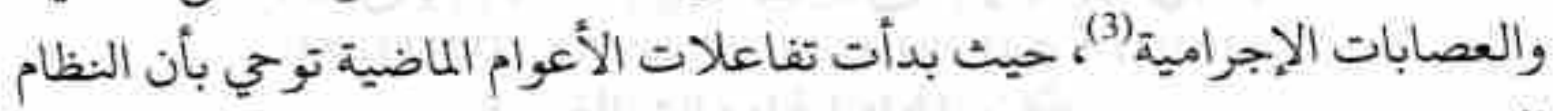

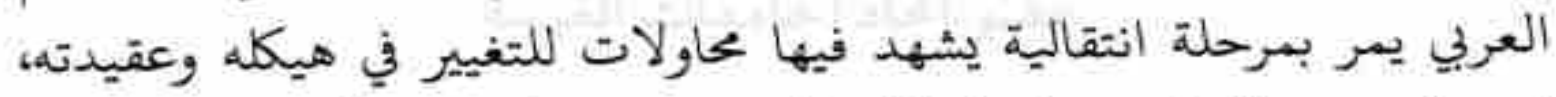

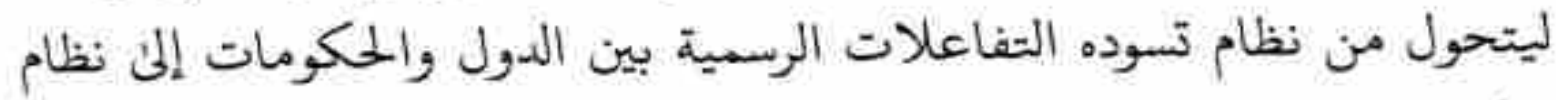

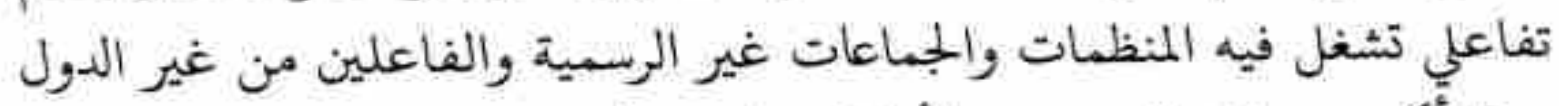

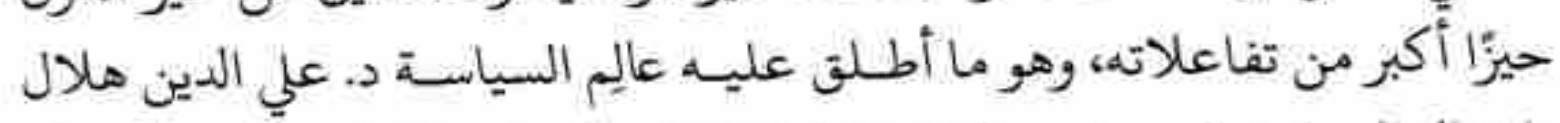

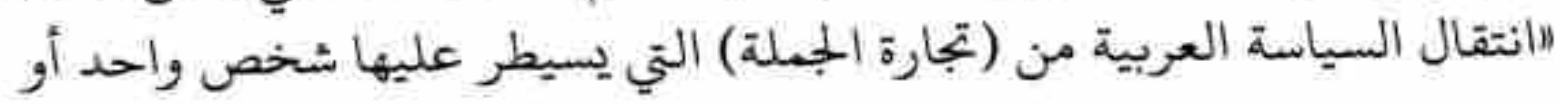


حفنة محدودة من الأفراد إلى (تجارة التجزئة) التي يزداد فيها عدد الفاعلين من

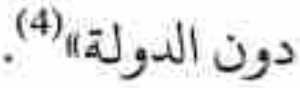
وهنا برز التنافس والتحالف بين التنظيمات الجهادية والجماعات الإرهابية

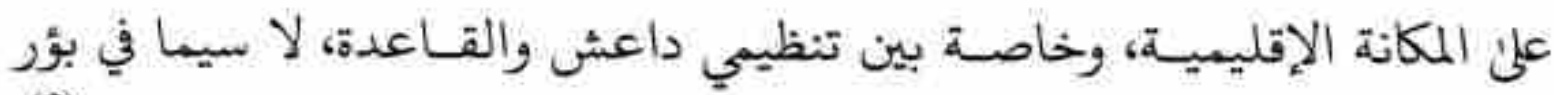

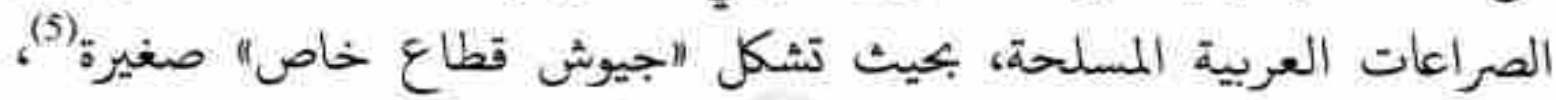

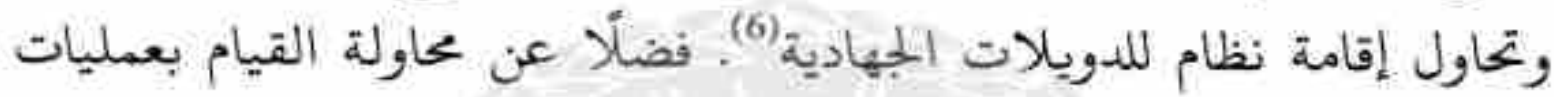

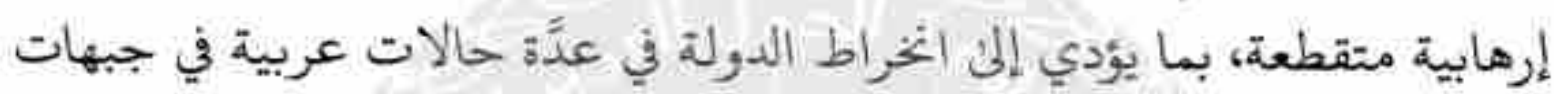

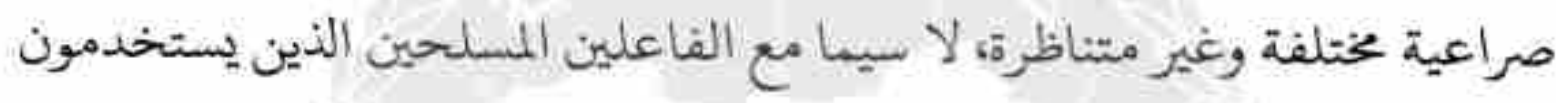
العنف.

* تعثر المراحل الانتقالية لدول الثورات العربية، التي تبدأ منذ انهيار

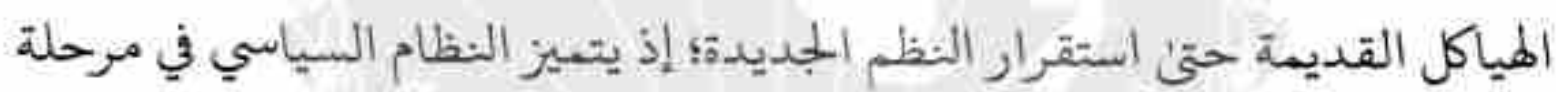

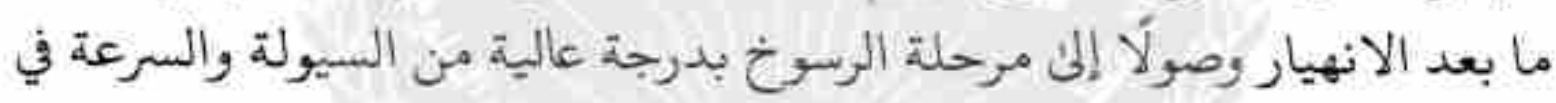

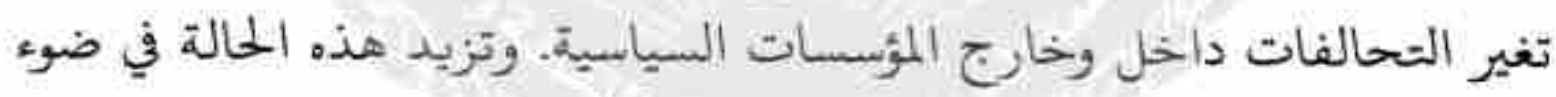

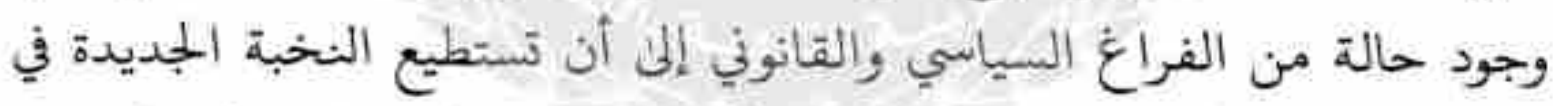

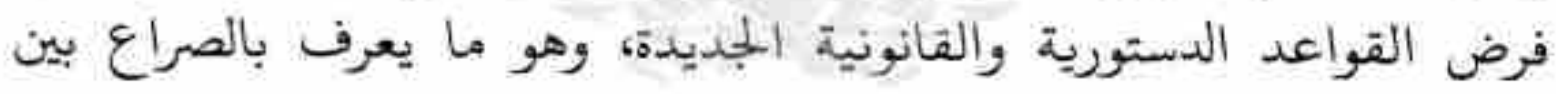

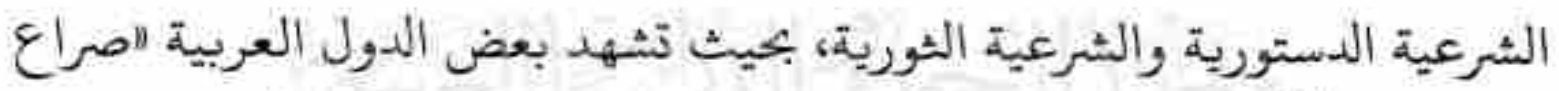

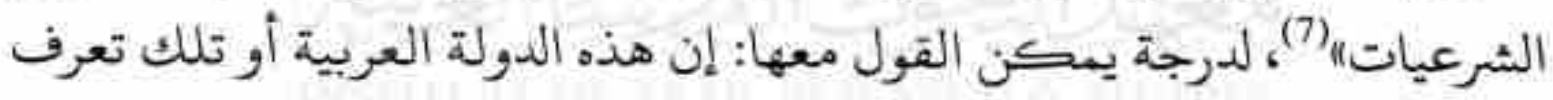

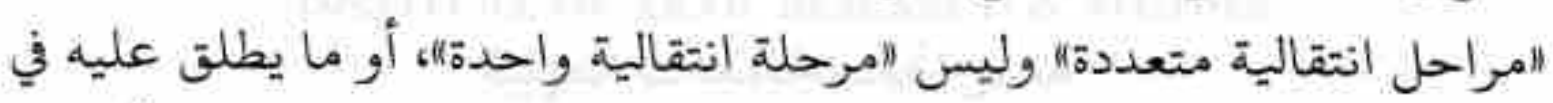

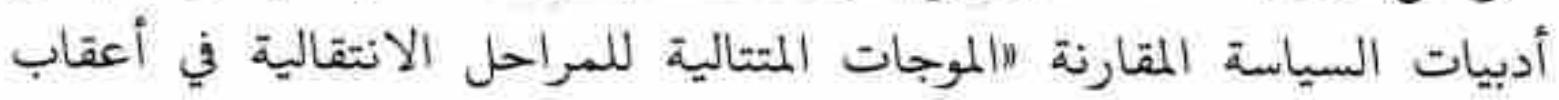

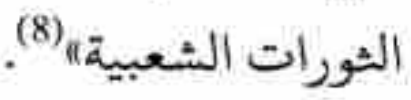
فثمة غياب للتوافق حول تجاوز أزمات مراحل الانتقال في الدول العربية،

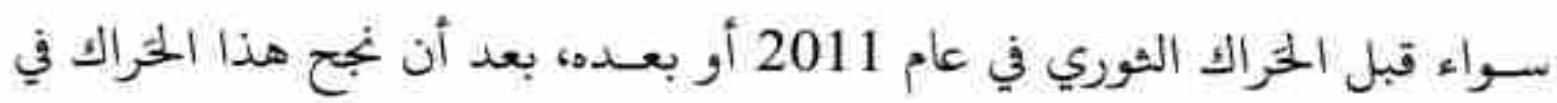


إسـاط أنظمة ووضع أخرى على حافُة السقوط، لا سيما بالنسبة للنُّم التي لا

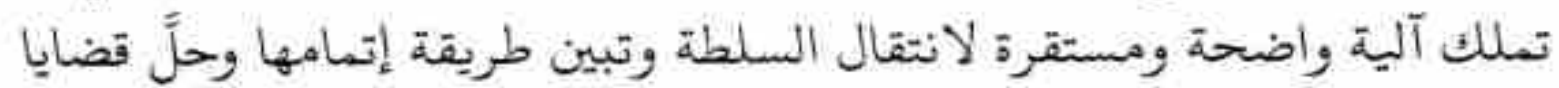

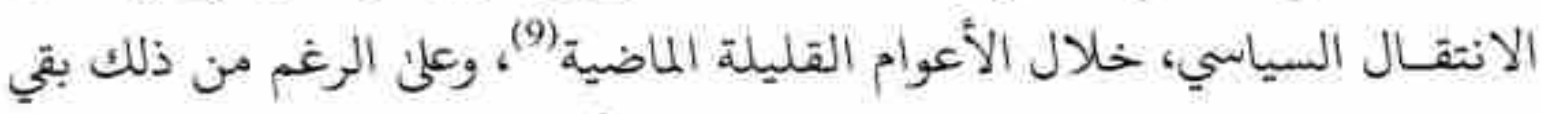

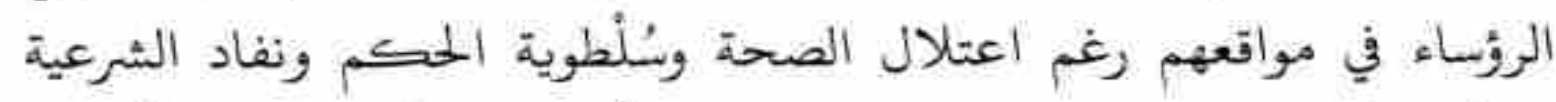

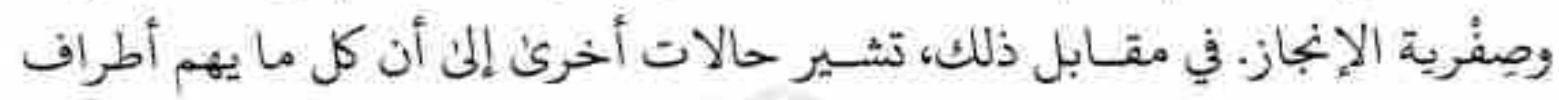

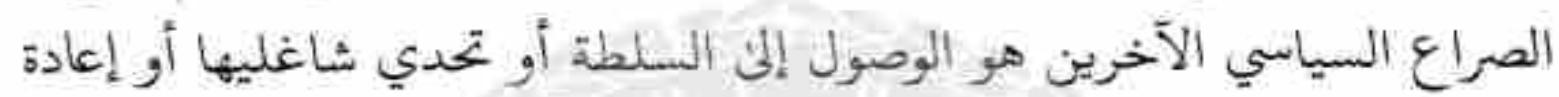

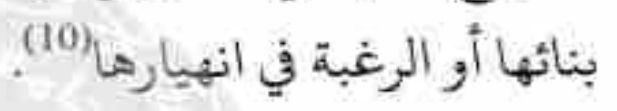

ما الإدارة المزدوجة لأمن المناطق الحدودية، أو ما يعرف بـالامركزية تسيير

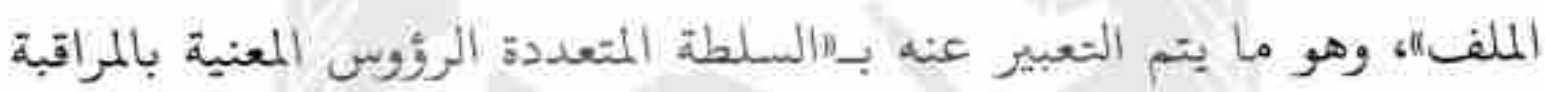

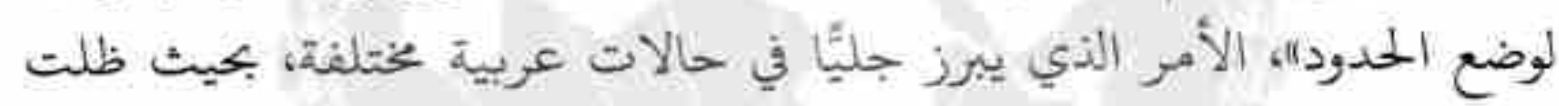

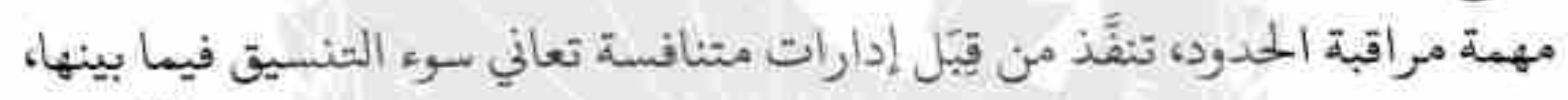

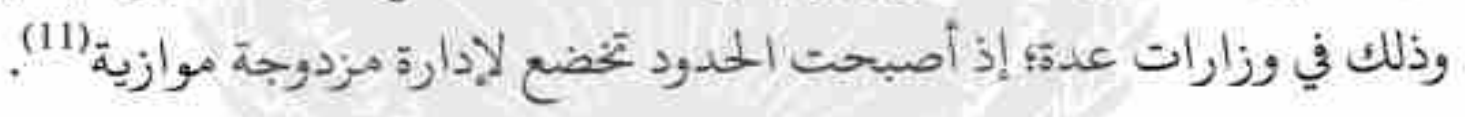

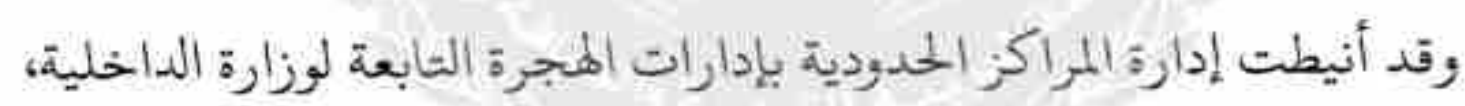

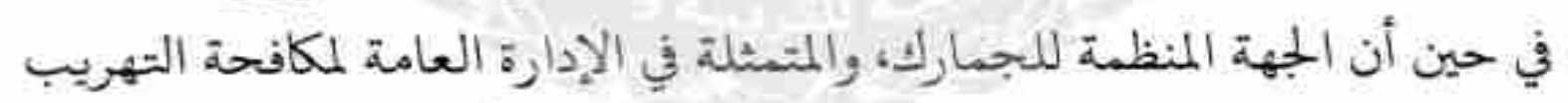

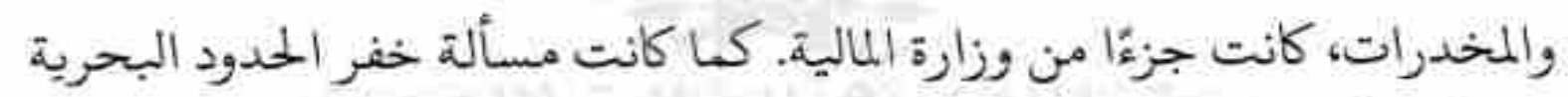

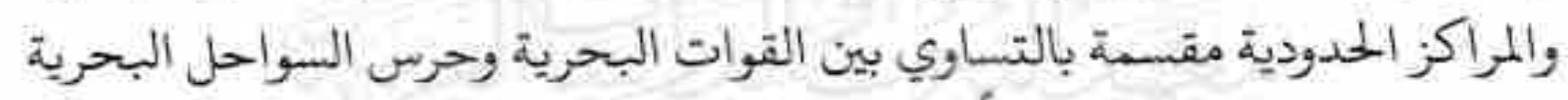

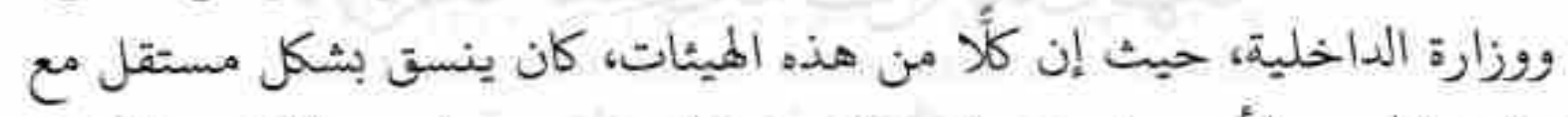

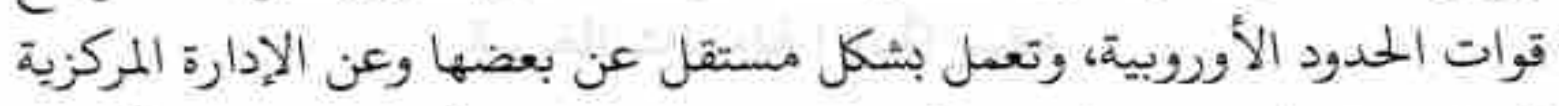

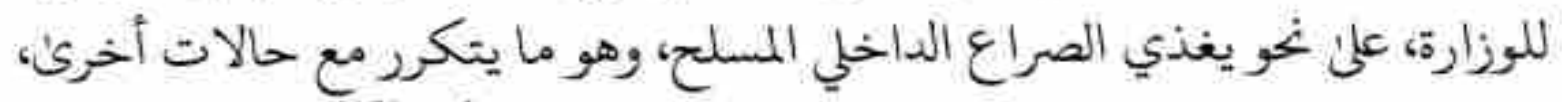
يغلب عليها تداخل اعتبارات الاقتصاد مع إشكليات الأمن (12). ماز التحالف بين التنظيمات الإرهابية والعصابات الإجرامية: تبلورت تجارة

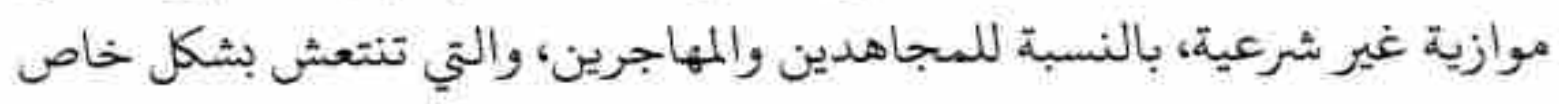




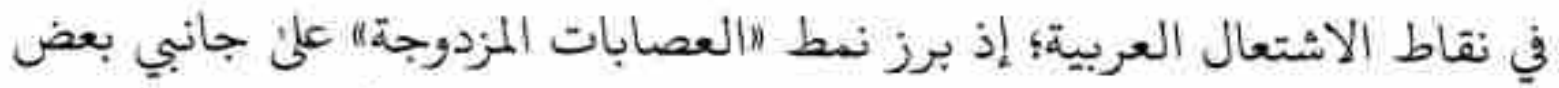

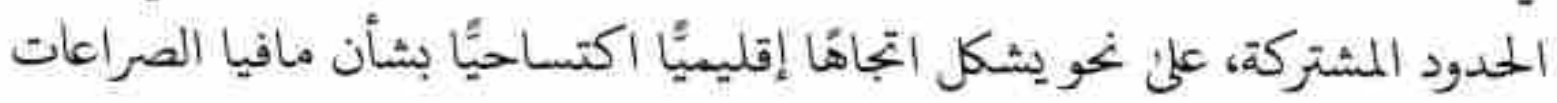

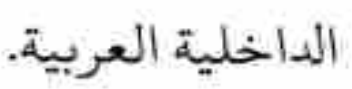

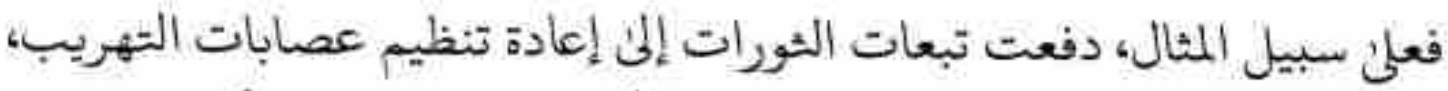

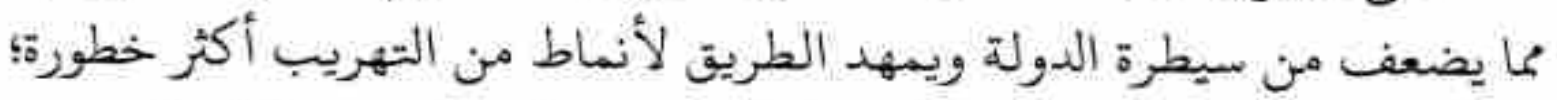

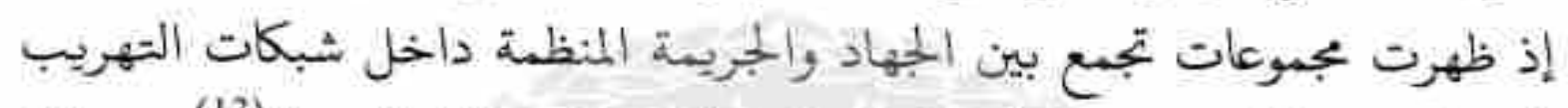

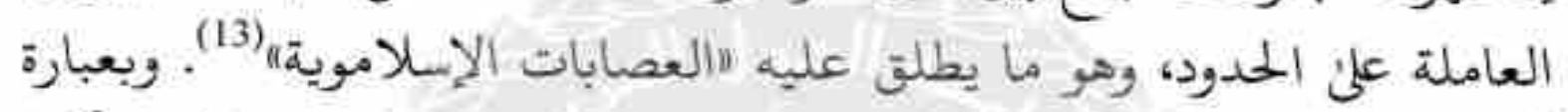

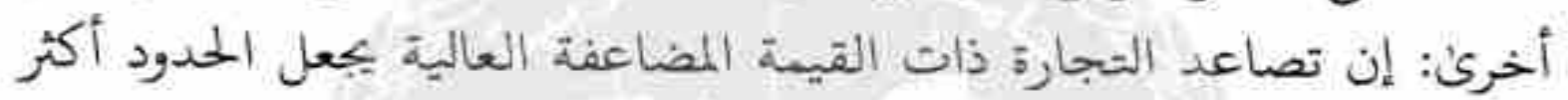
قابلية للاختراق ويجعل الصراعات أصدات الداخلية أكثر حلًّة.

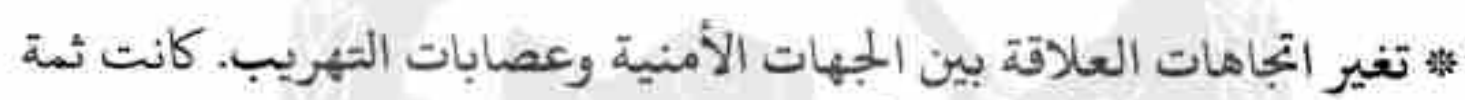

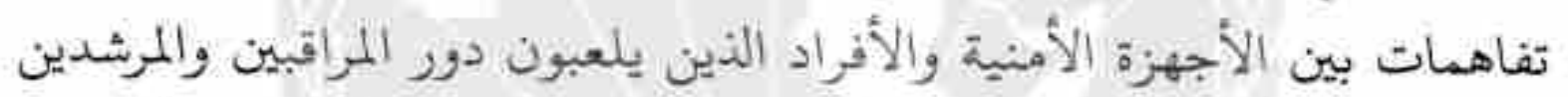

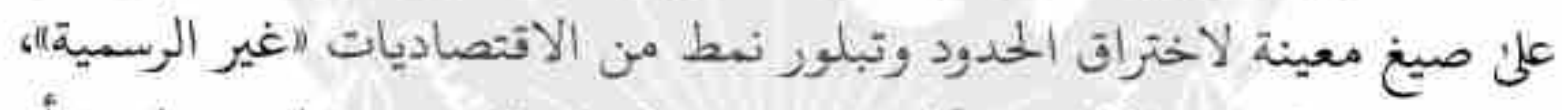

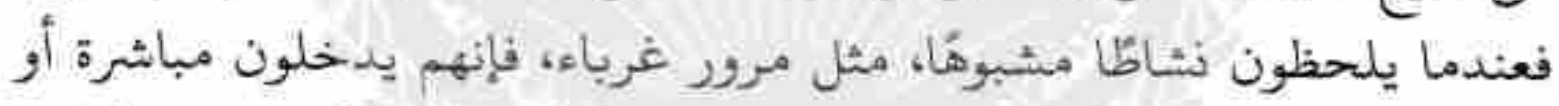

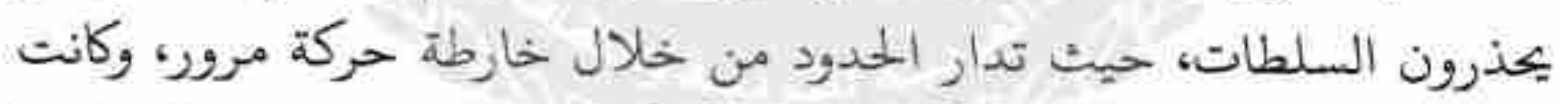

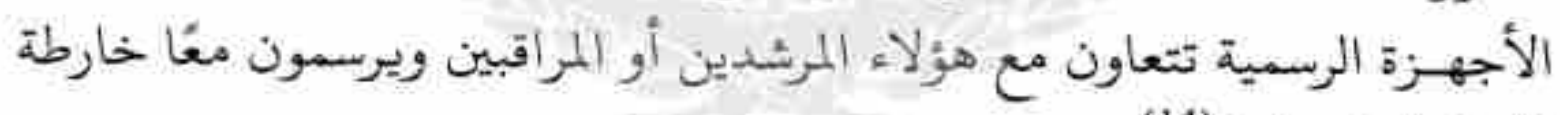

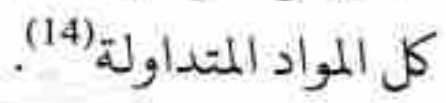

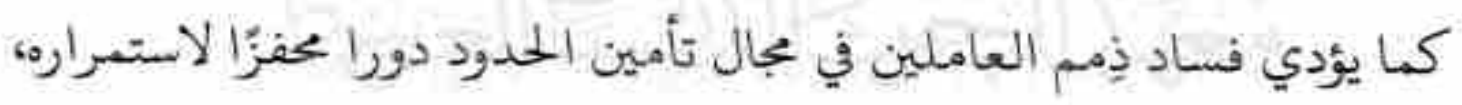

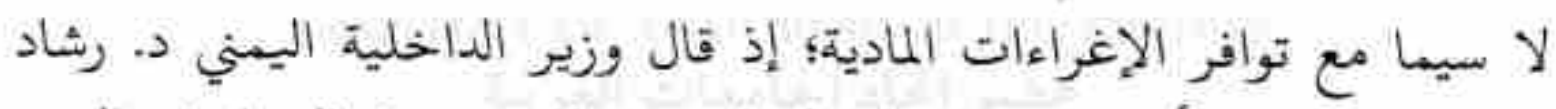

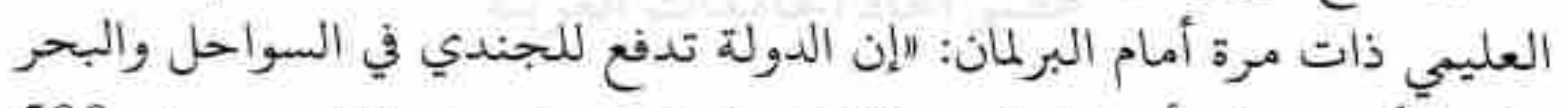

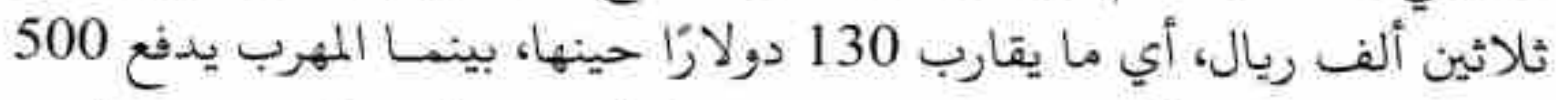

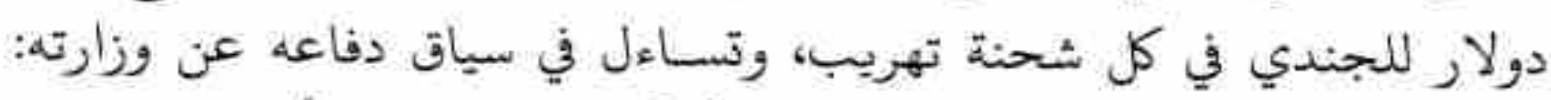

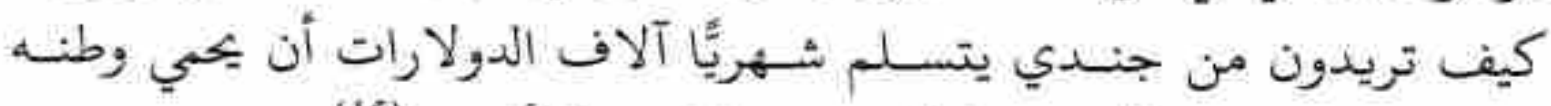
الذي يدفع له ثلاثين ألف ريال لا تكفيف لا هو ولا أسرتها" (15.). 
* تشكل جماعات متخصصة في "مافيا الأنفاق)؛ إذ شهدت أغلب الدول

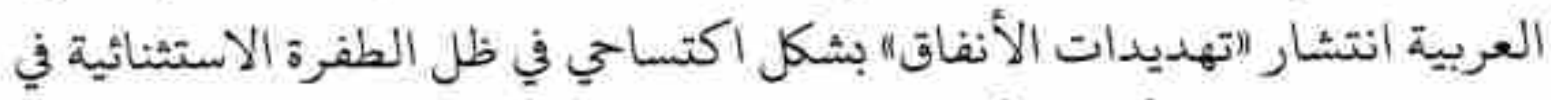

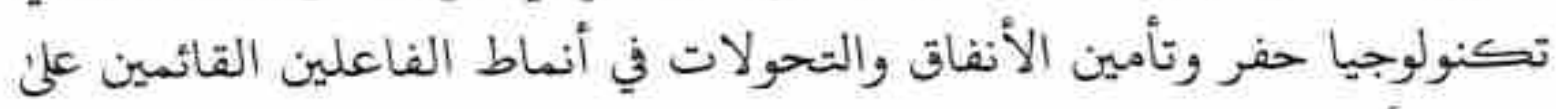

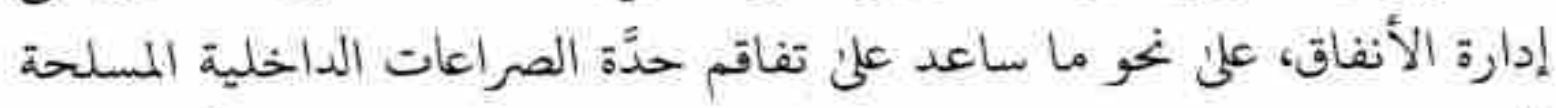

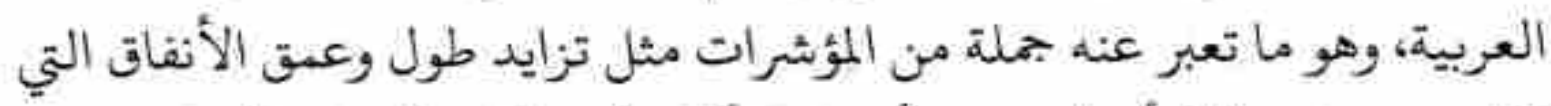

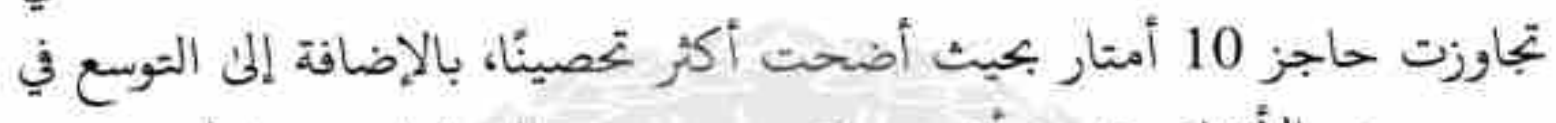

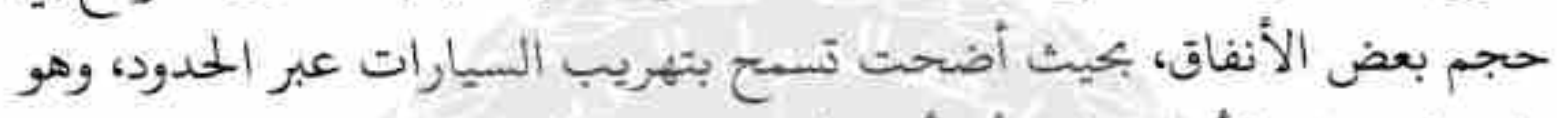

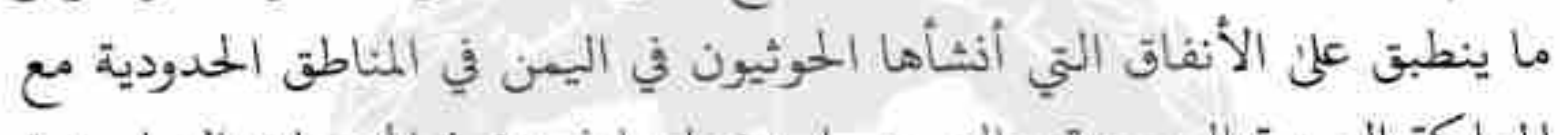

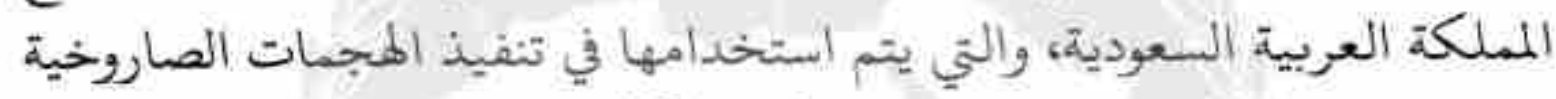

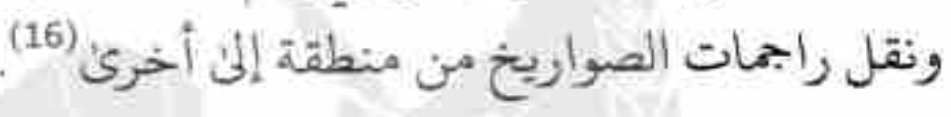

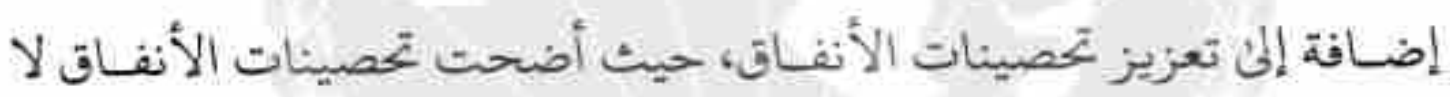

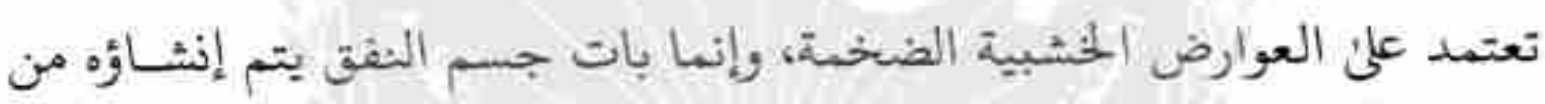

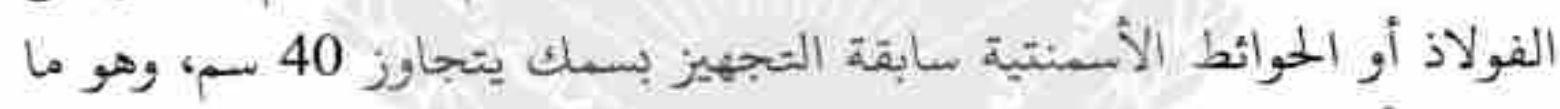

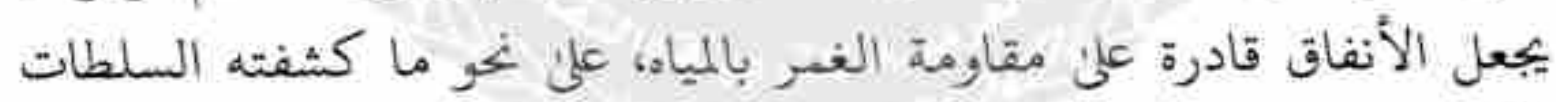

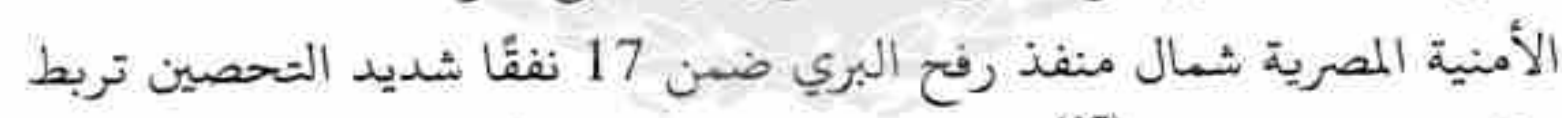

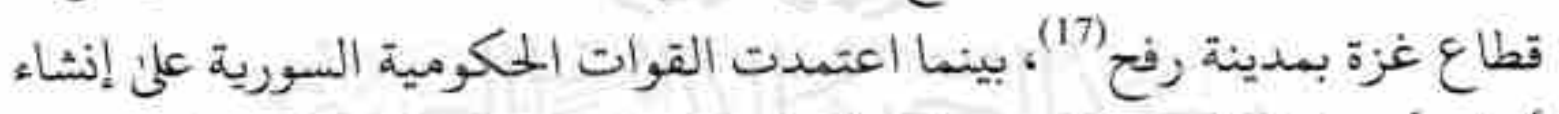

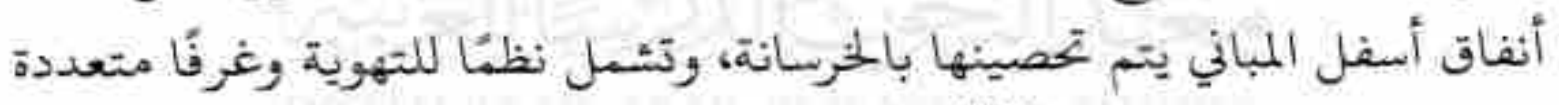

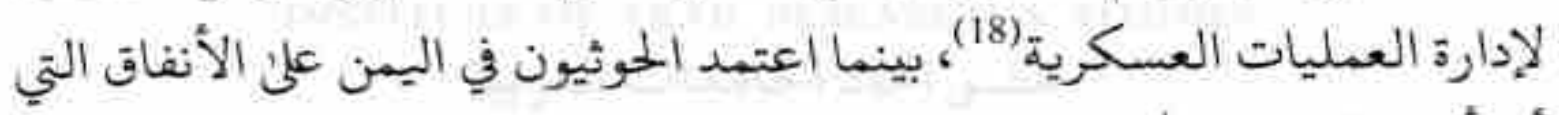

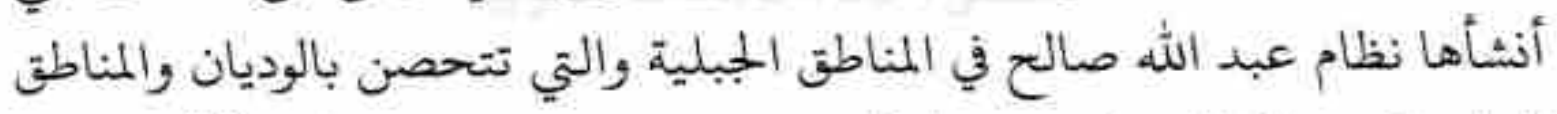

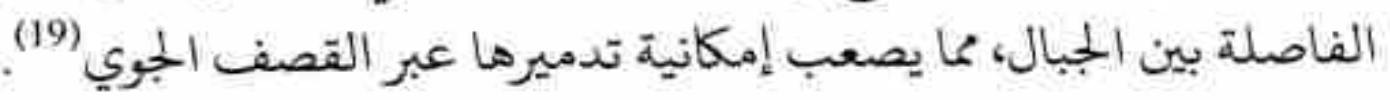

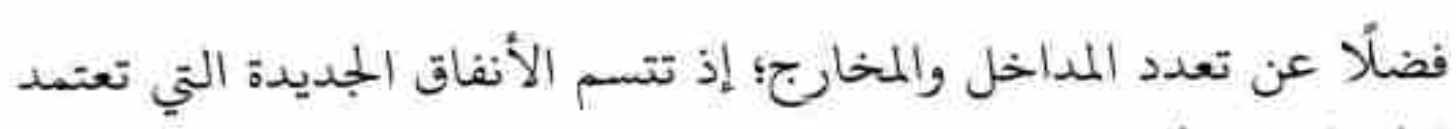

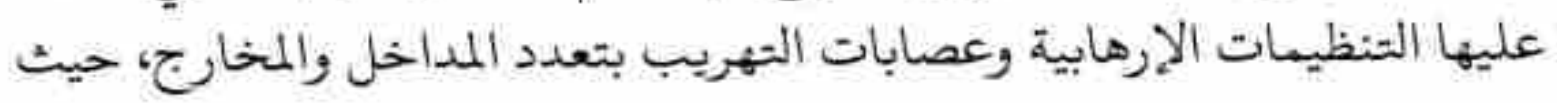


إن النفق الواحد عادة ما يتم إنشاء مداخل ومخارج متعددة على جانبيه، بعضها

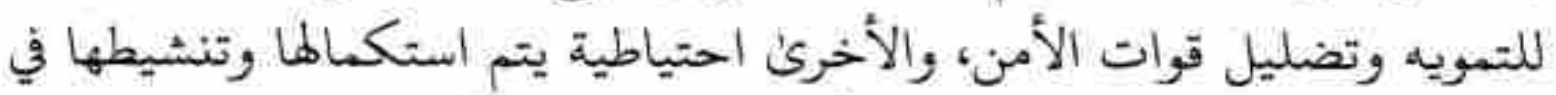

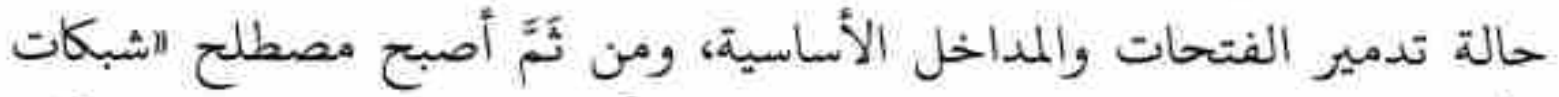

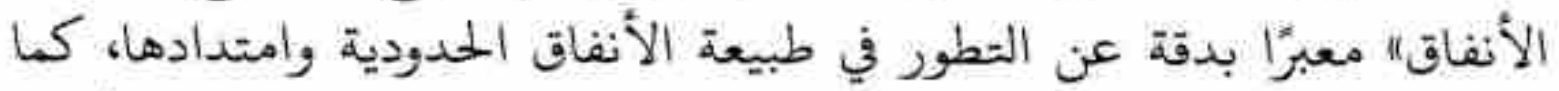

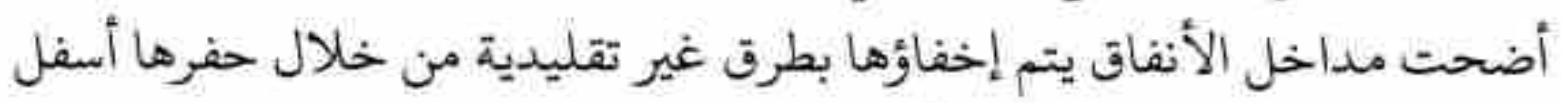

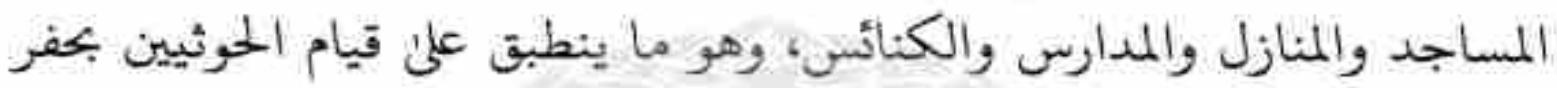
نفق أسفل إحدى المدارس في مدينة صنعاء (20).

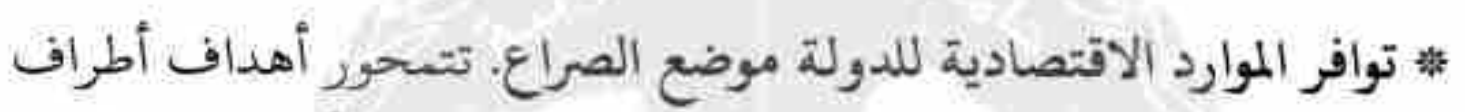

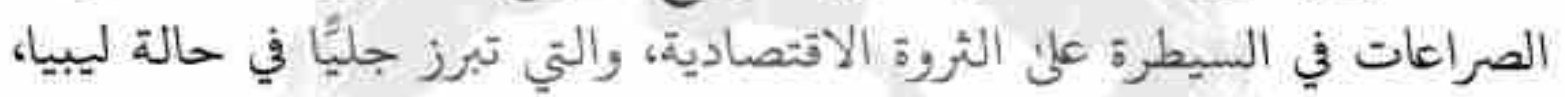

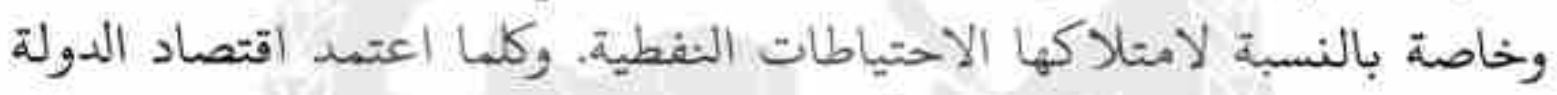

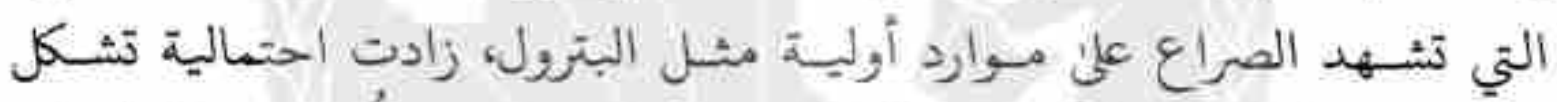

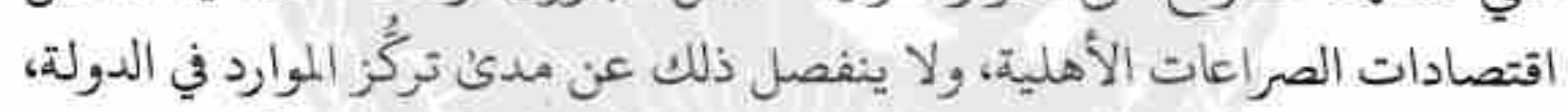

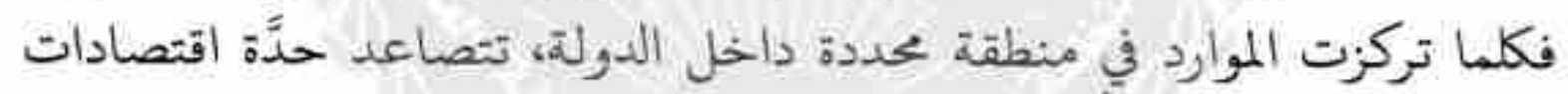

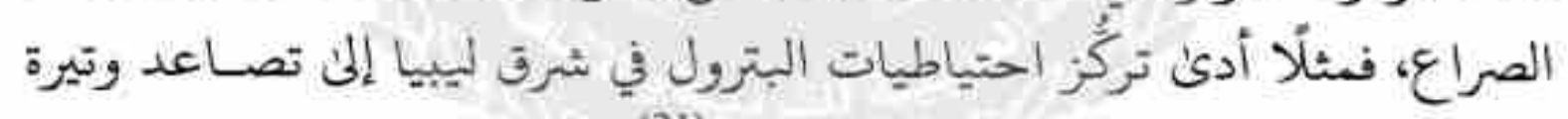

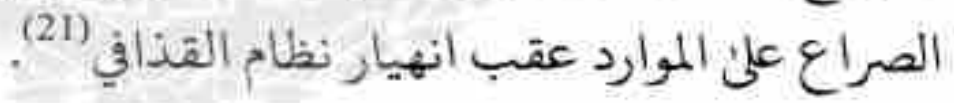

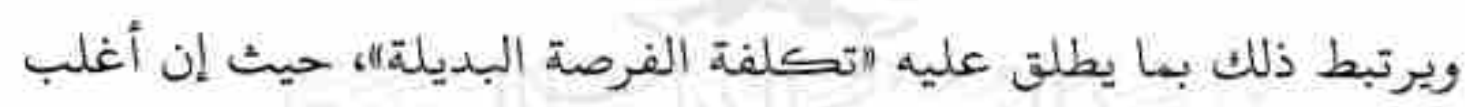

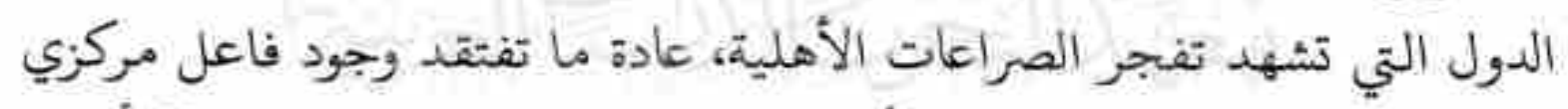

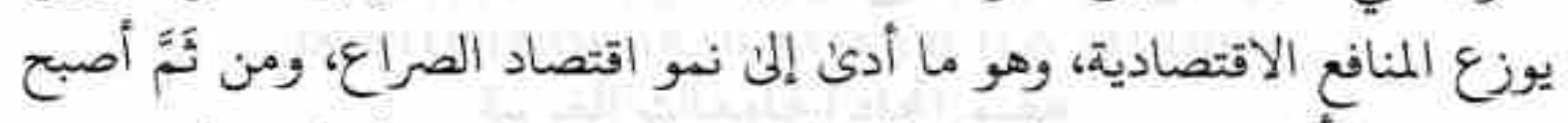

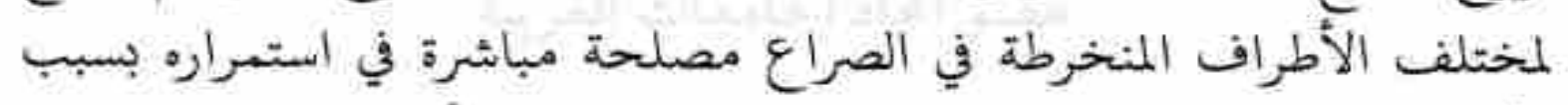

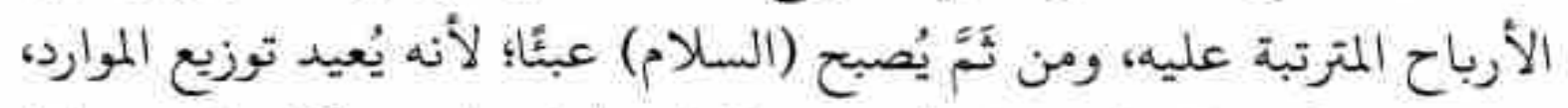

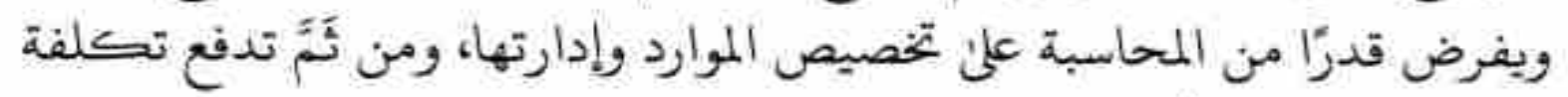

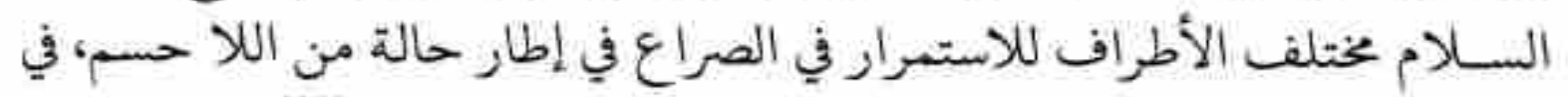

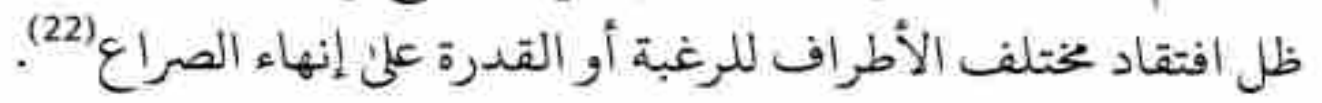


إضافة إلى خصائص مجتمع الصراع؛ إذ يرتبط صعود اقتصادات الصراعات

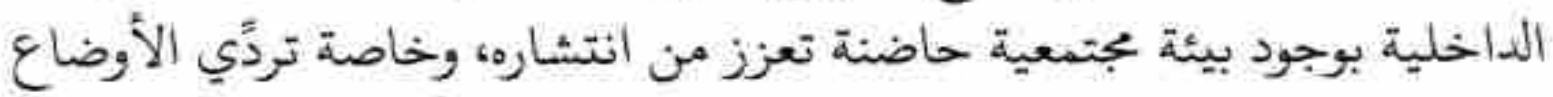

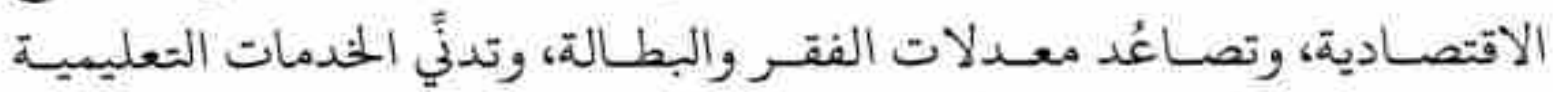

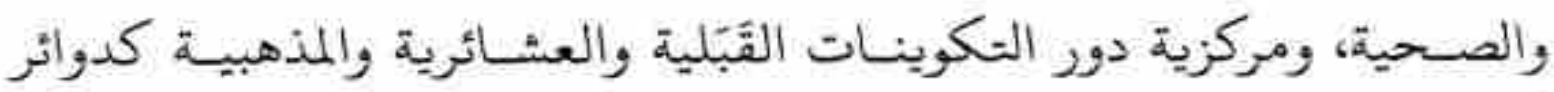

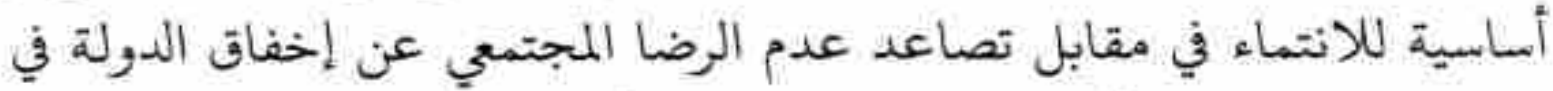

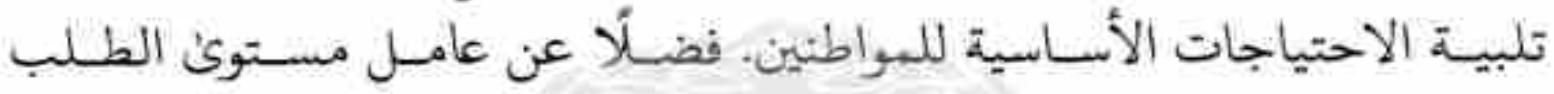

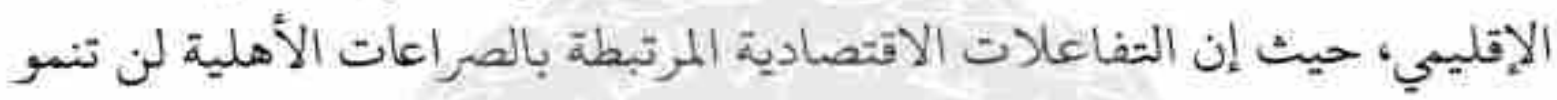

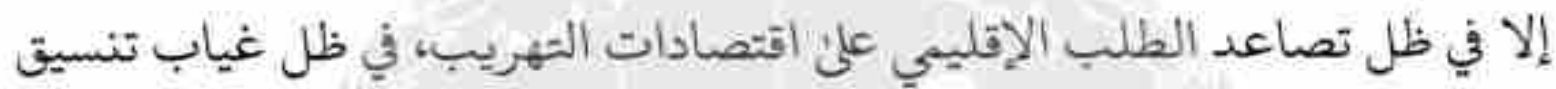

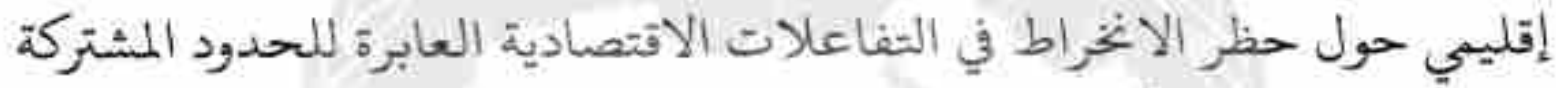

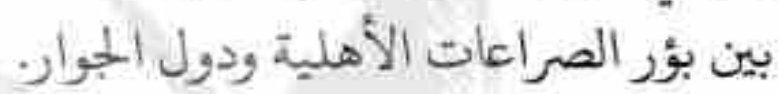
* تزايد الفجوات التنموية (داخل الدول وبينها): حيث تفتقد سياسات

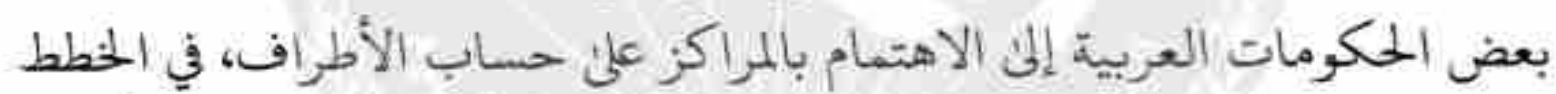

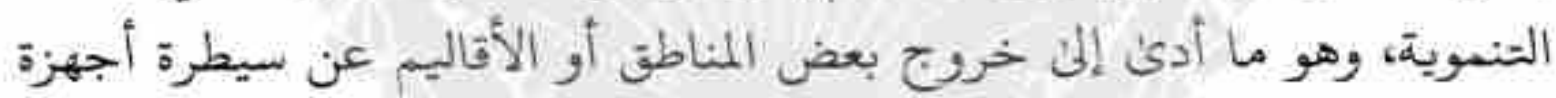

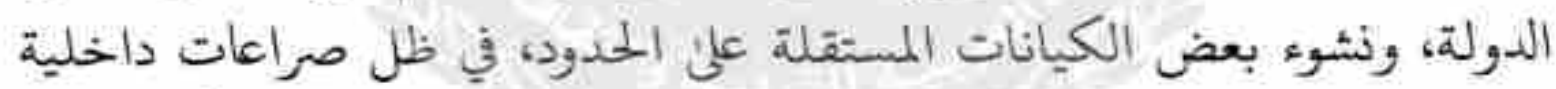

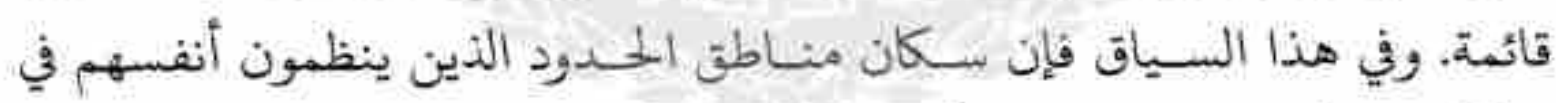

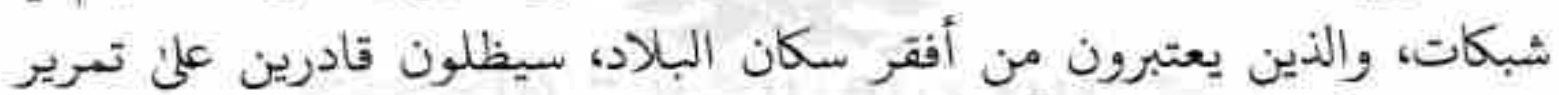

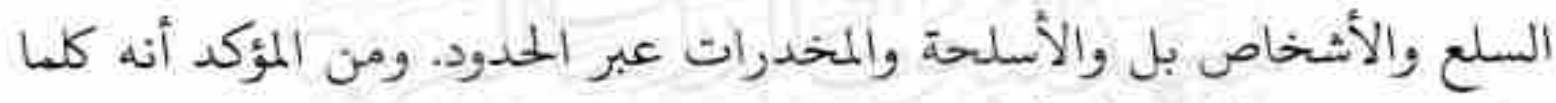

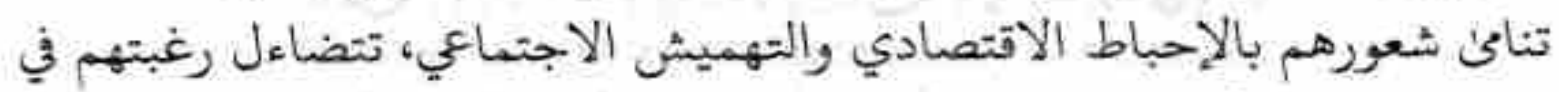

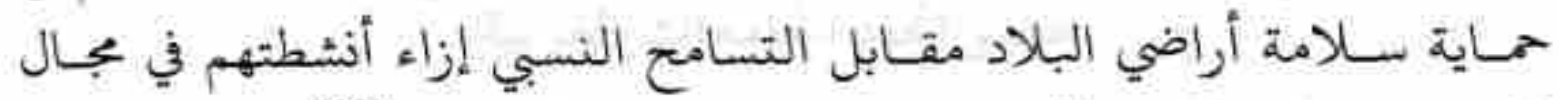

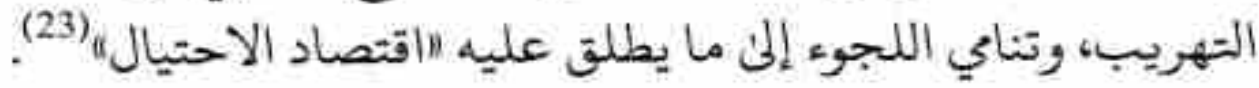

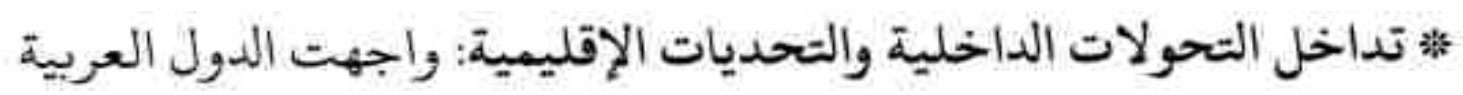

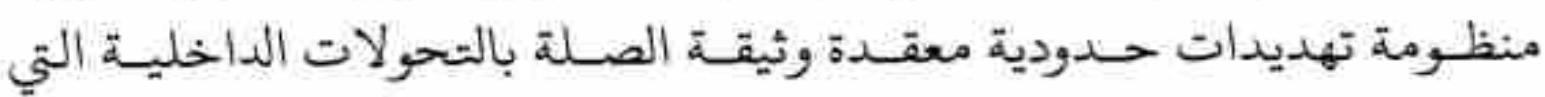

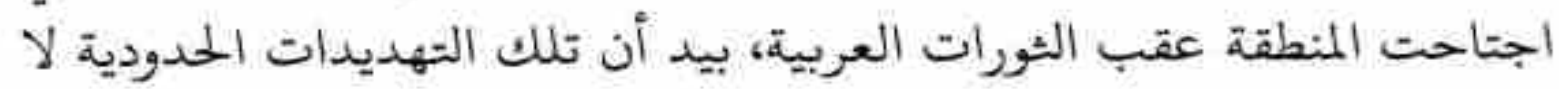


ترجـع جذورها في مراحل سلـابقة، والتي ارتبطت بافتقـاد الحـدود بين الدول

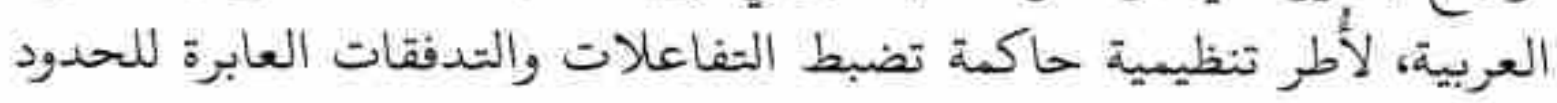
وتداخل الثُخوم الجغرافية والبشرية على الحدود الفاصلة بين الدول، بما جعلها

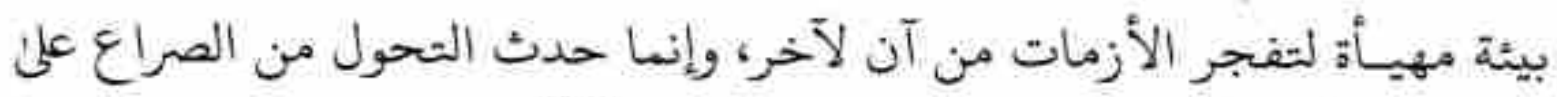

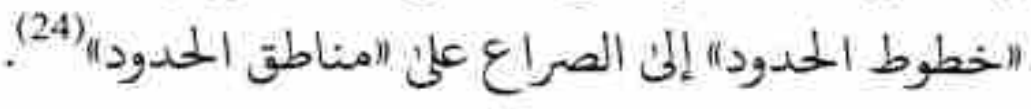

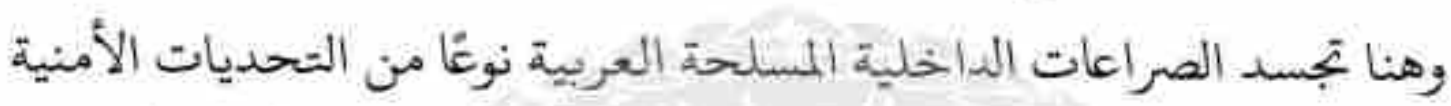

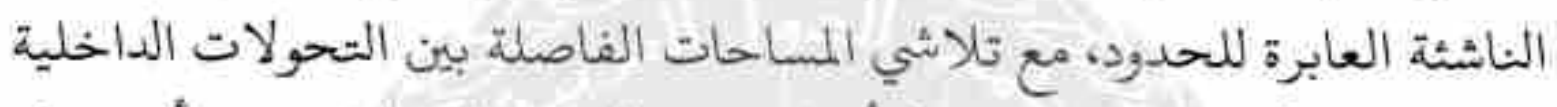

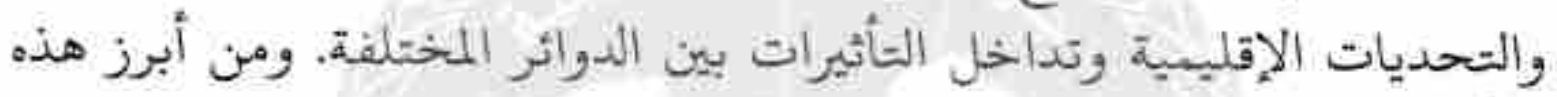

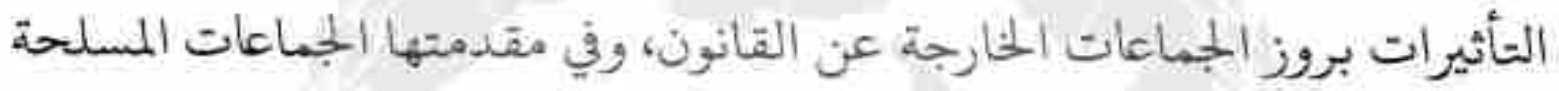

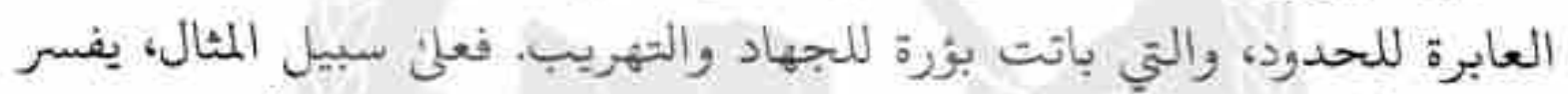

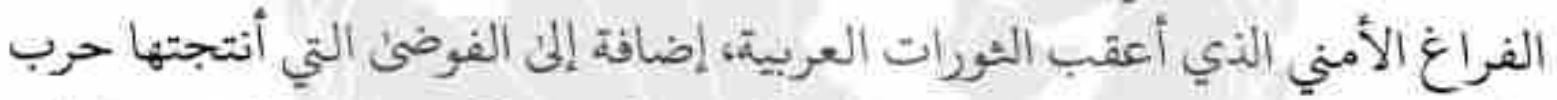

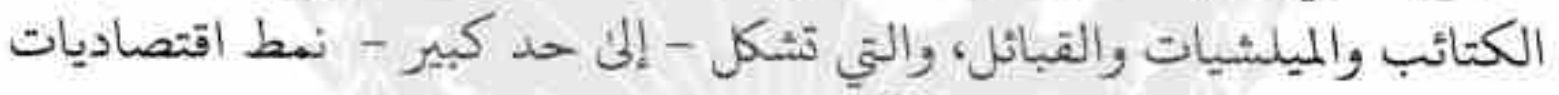
وخصخصة الصراغات الئاخلية (25).

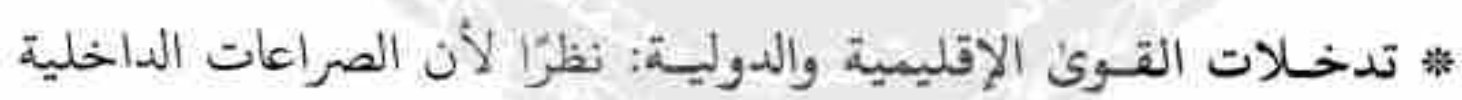

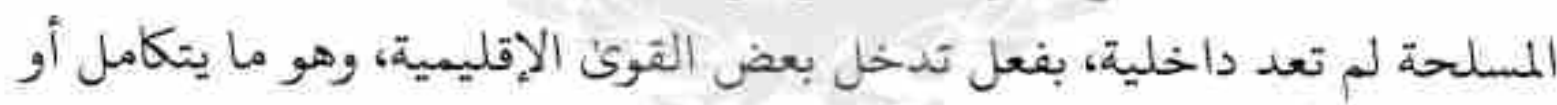

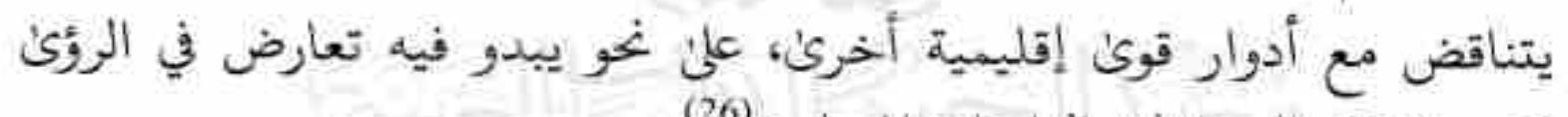

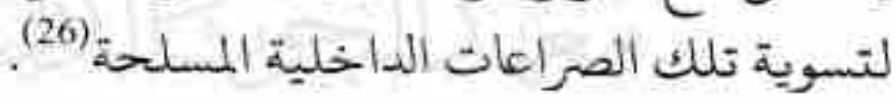

ثانيّا - أنماط توظيف التتظيمات الإرهابيت للصراعات الداخليت

\section{في الوطن العريبي:}

تمكنت التنظيمات الإرهابية العابرة للحدود في المنطقة العربية من

تأسيس اقتصاديات موازية تقوم على شبكات تمويلية تتسم باللامركزية، وإنشاء المباء

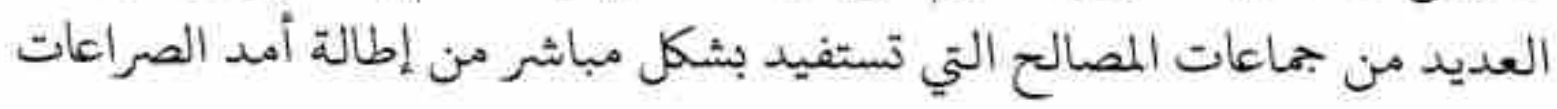


الداخلية في مختلف الدول العربيـة، في ما يطلقلق عليه مسـاعد وزير المزانة

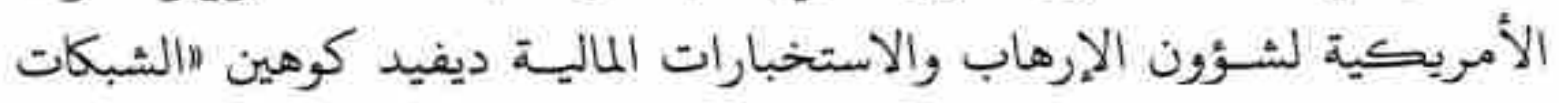

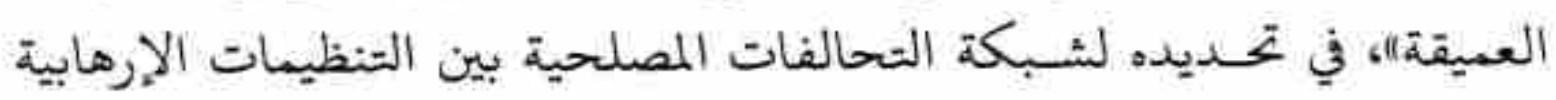

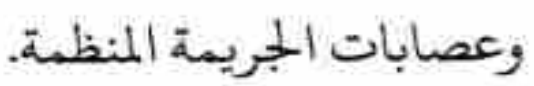

وهنا يمكن الإشارة إلى أبرز أنساط تلك الاقتصادات غير الشرعية في

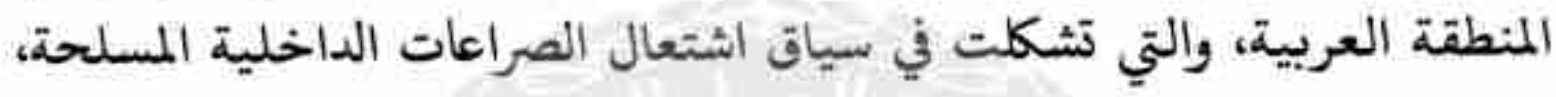
وهي على النحو التالي: - الي

* تهريب الأسلحة: تمثل الأسلحة الوقود الذي يبهـه في إشعال الصراع

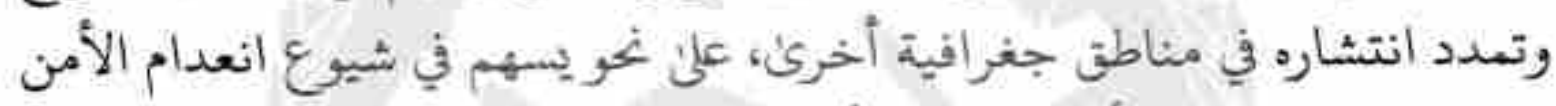

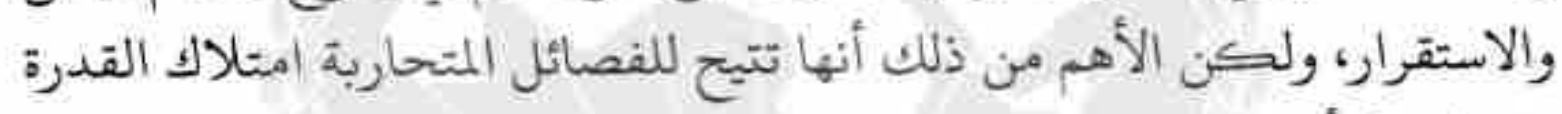

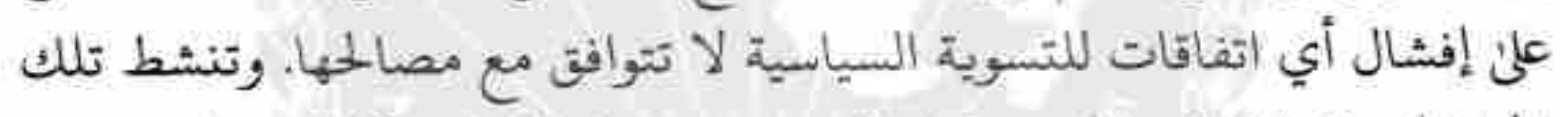

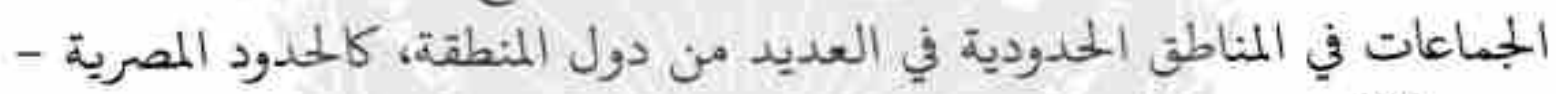
الليبية (27)

كما تنشر أيضا جماعات تهريب الأسلحة على الحدود المصرية السودانية (28)،

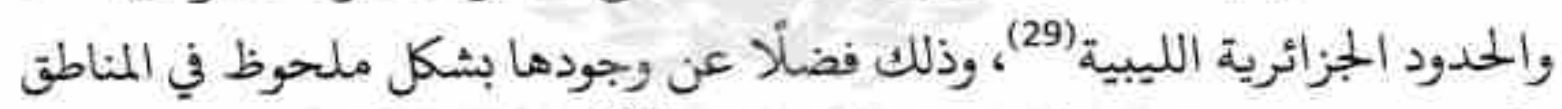

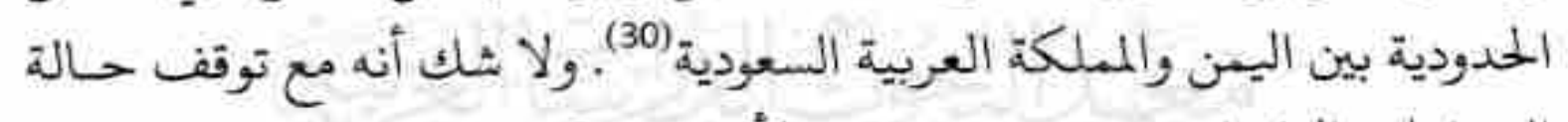

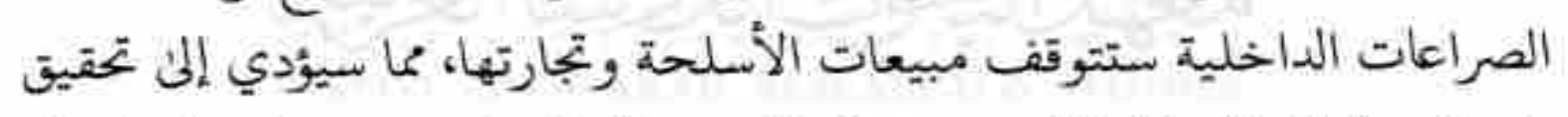

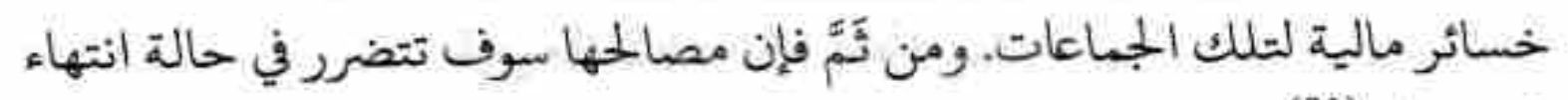
الصراعات (31)

: الاتجار بالمخدرات: إن الاتساع في زراعة المخدرات وتجارتها يسهم في

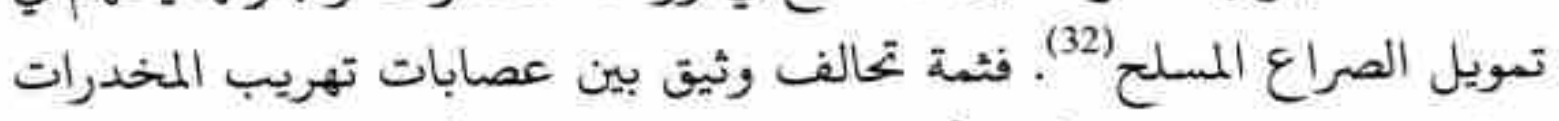

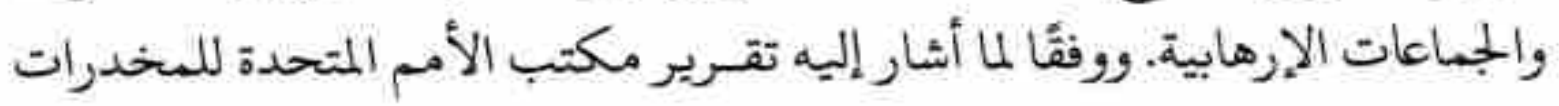


والجريمة لعام 2013، فإن تنظيم القاعدة في بلاد المغرب العربي، وجماعة التوحيد

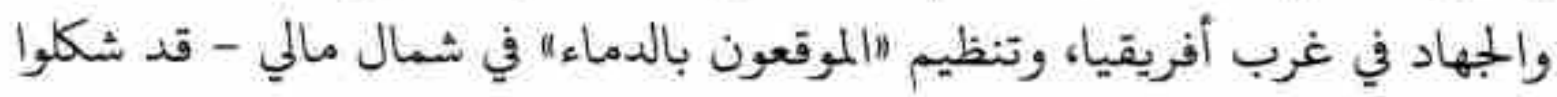

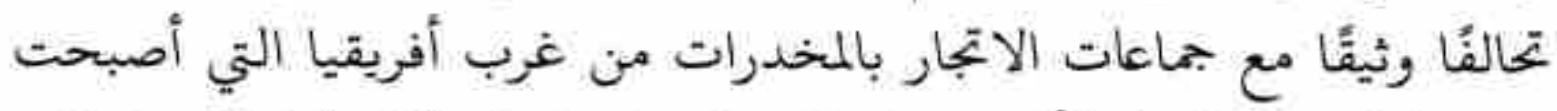

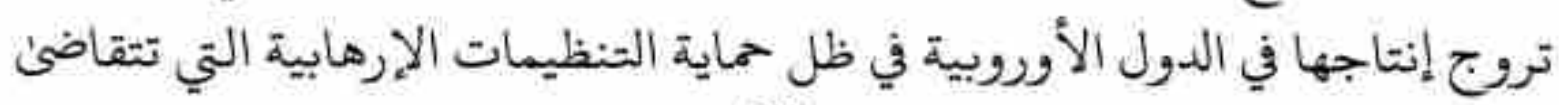

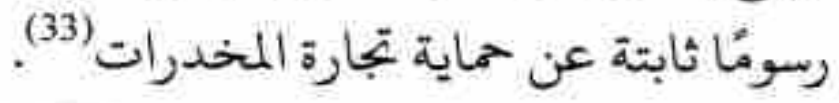

" *جنيد المقاتلين: مع اتساع نطاق الخروب والصراعات الداخلية في دول المنطقة، انتشر نمط شبكات وجماعات تهريب المقاتلين (وخاصة من المدنيين)

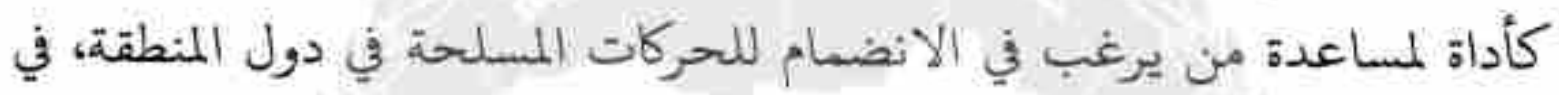

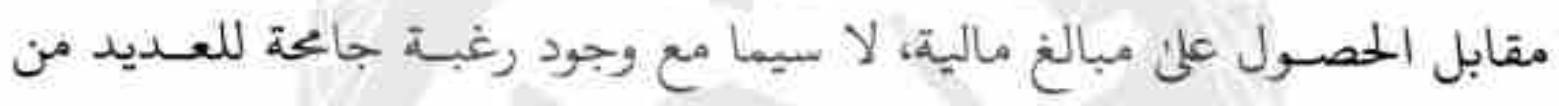

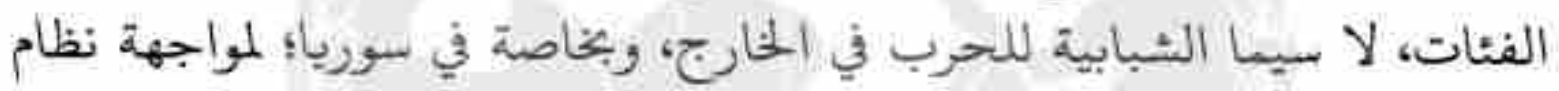

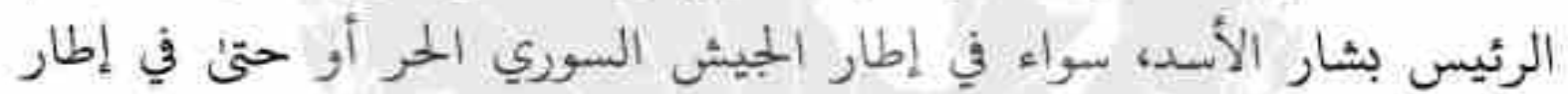

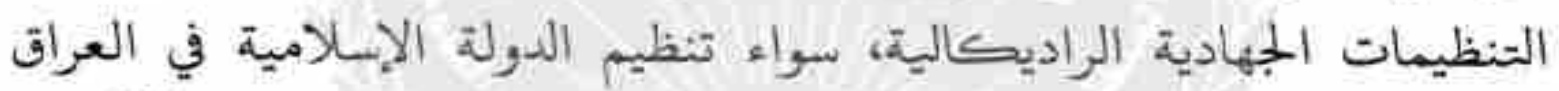

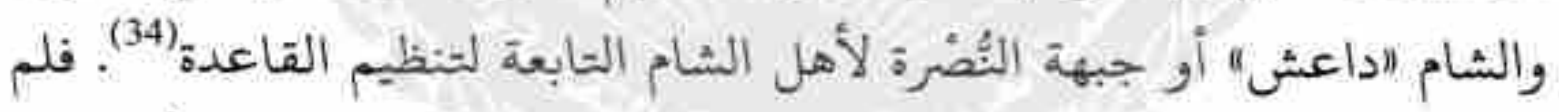

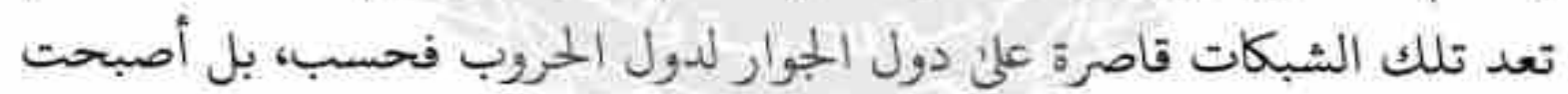
شاملة في غالبية الدول، وذلك للتجنيد في الصراع الإن الاندماجي (35).

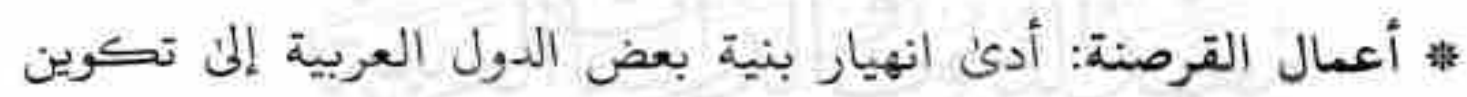

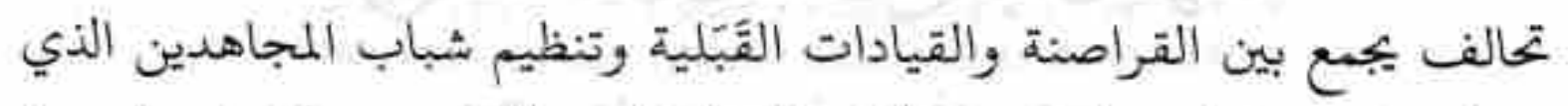

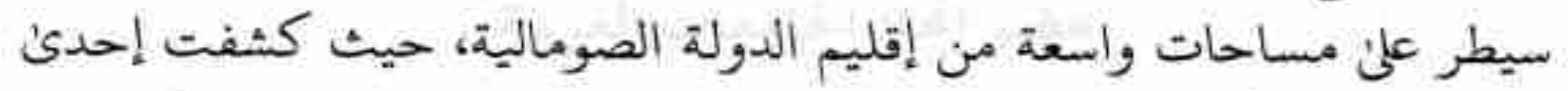

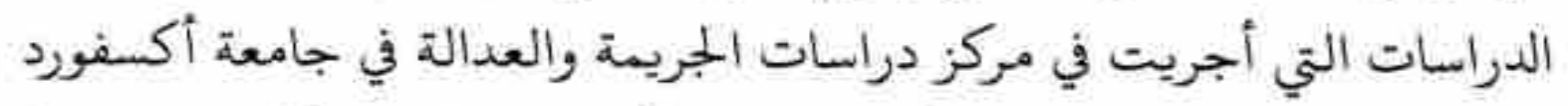

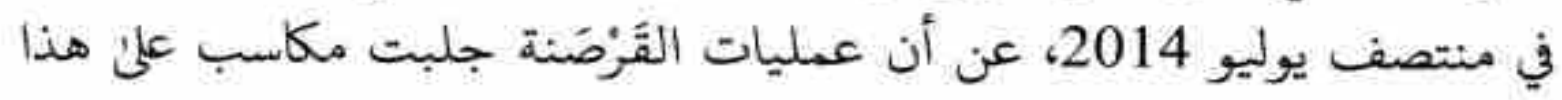
التحـالف قدرت بنحو 400 مليـون دولار خلال الفـترة بين عـاي 2005 
* الاتجار بالبشر: أسهمت حالة عدم الاستقرار السـياسي وغيـاب الأمن

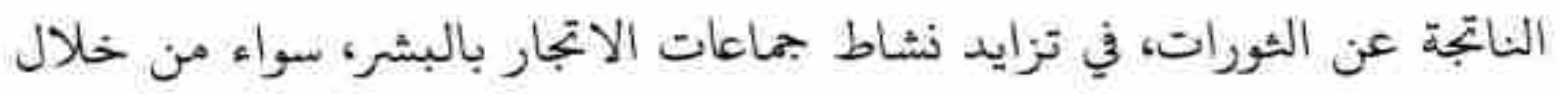

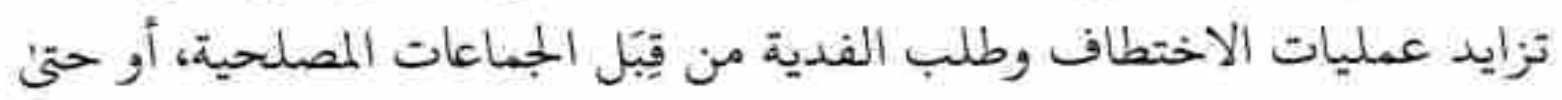

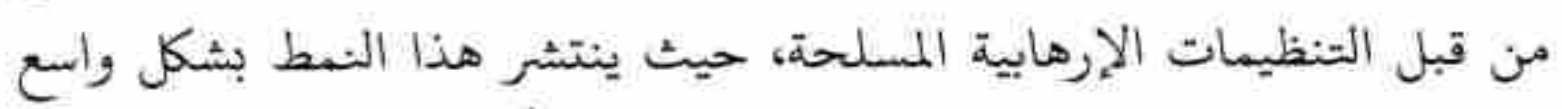

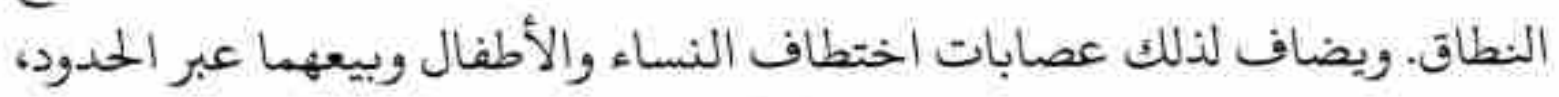

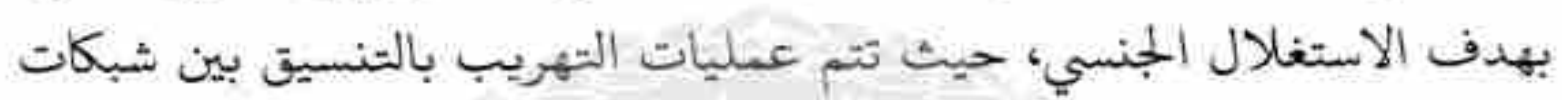

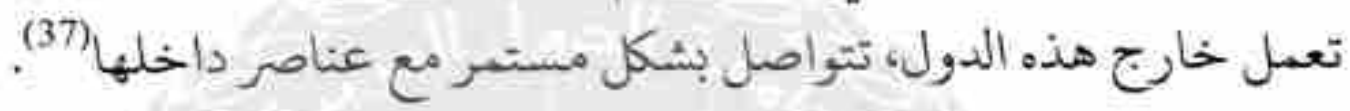

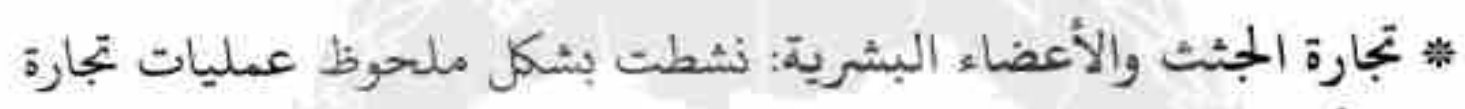

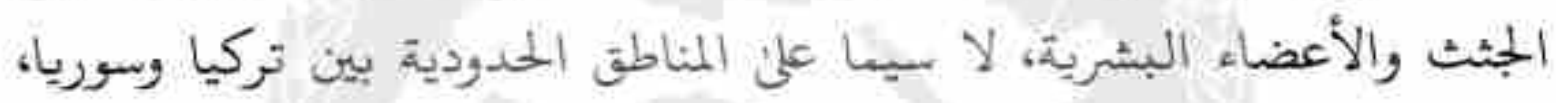

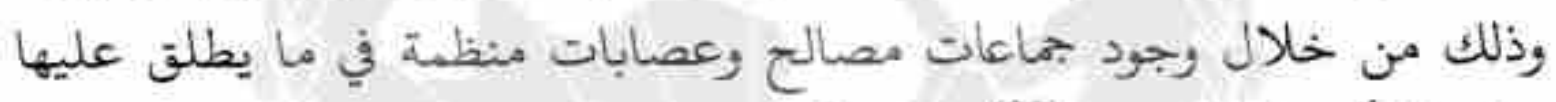

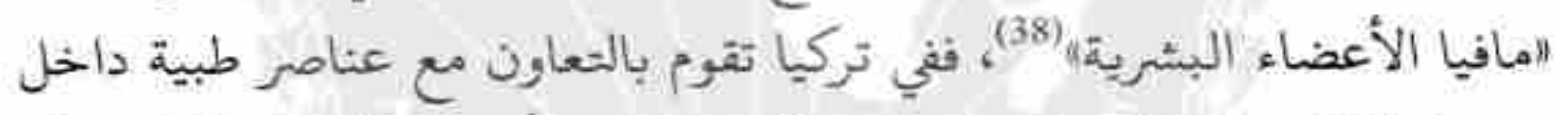

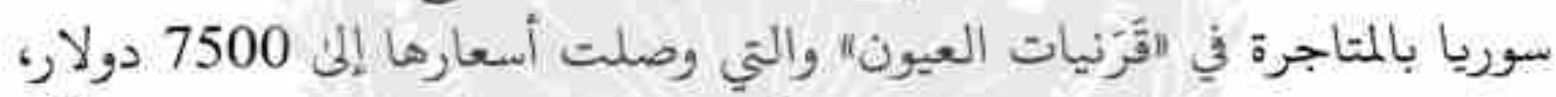

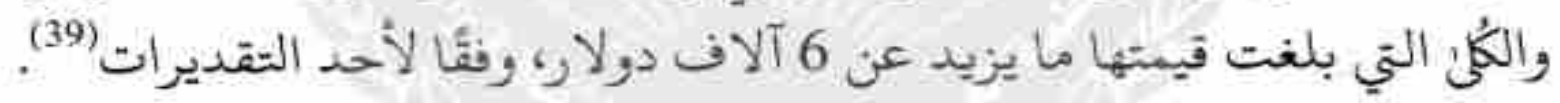

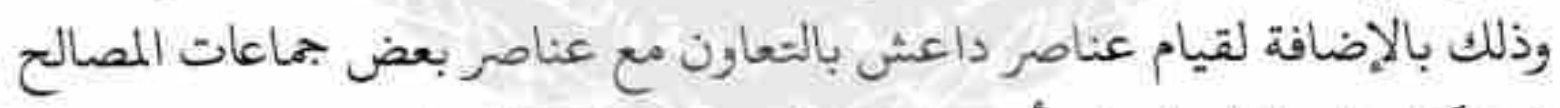

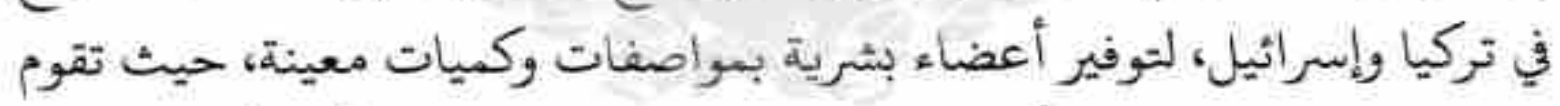

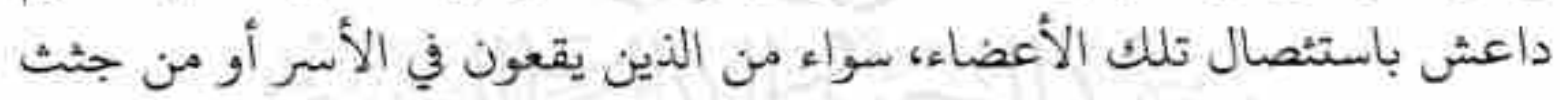

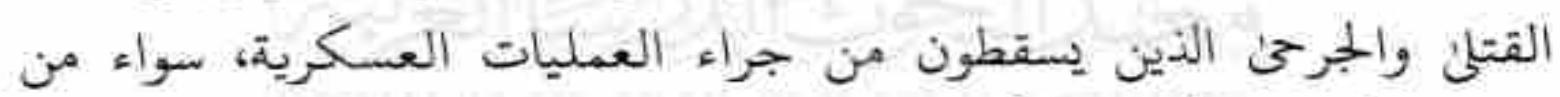

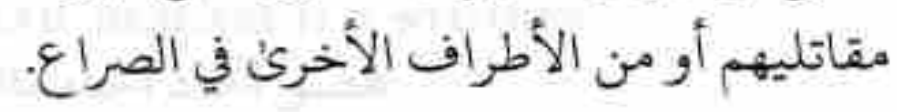

* الاختطاف مقابل الفدية: أصبحت التنظيمات الإرهابية وخاصة في بؤر

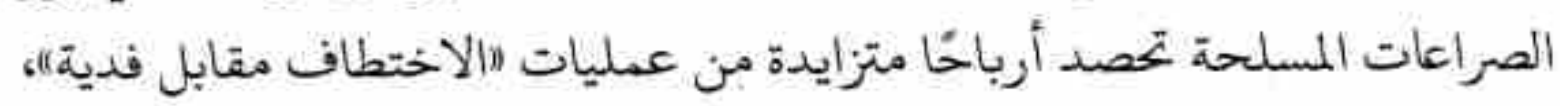

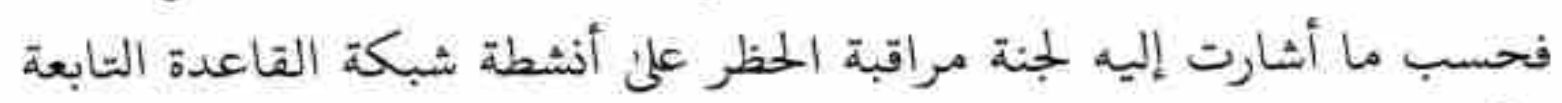

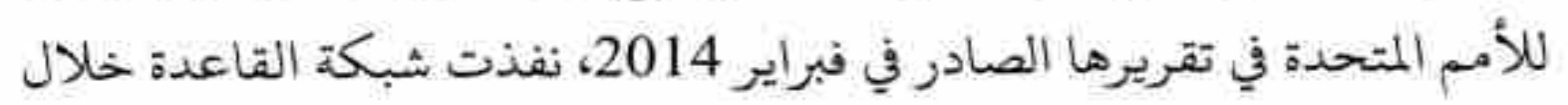


الفترة بين عاي 2004 2012 نحو 1282 عملية اختطاف وجمعت فدية تقدر بـ 120 مليون دولار، وهو ما تركز بصفة رئيسة في اليمن عبر اختطاف

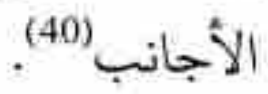

*ثريب مصادر الطاقة: تعتبر حالة جماعات ومهربي الفحم في الصومال

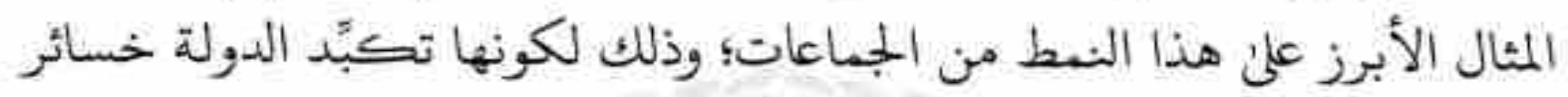

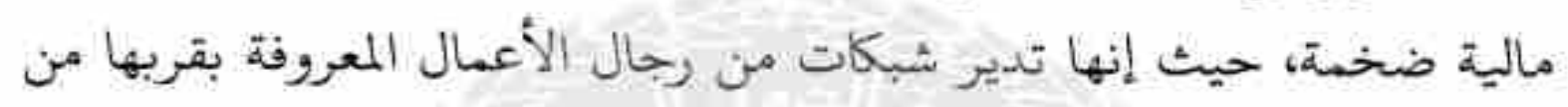

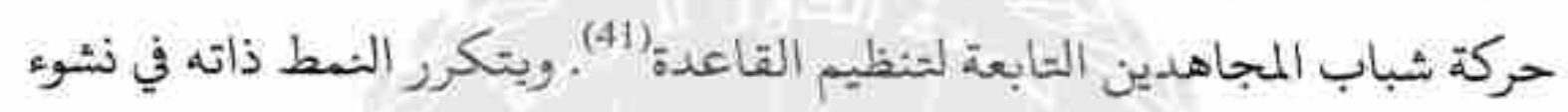

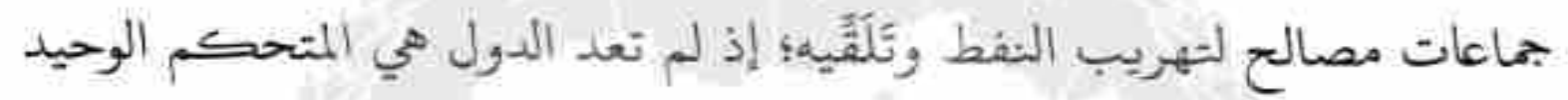

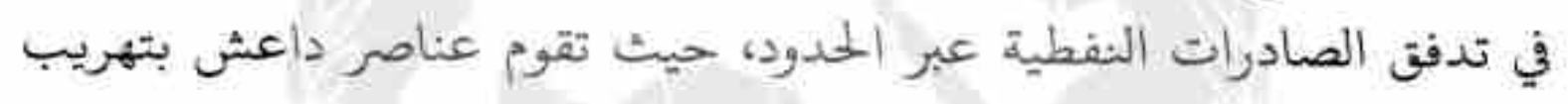

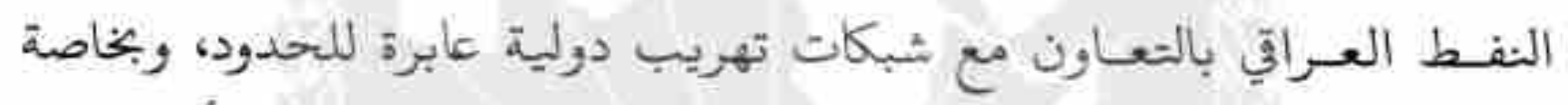

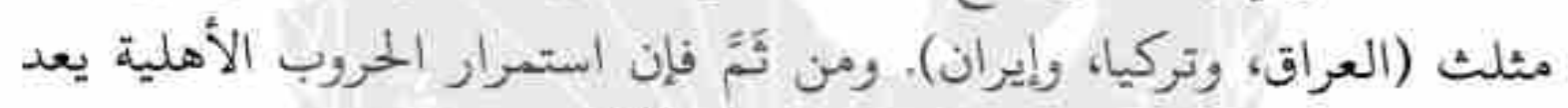
الضامن الوحيد لاستمرار هذه التجارة الرائجة (42).

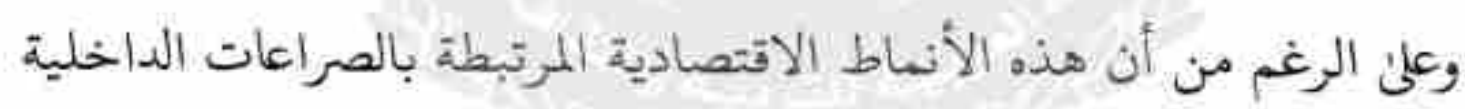

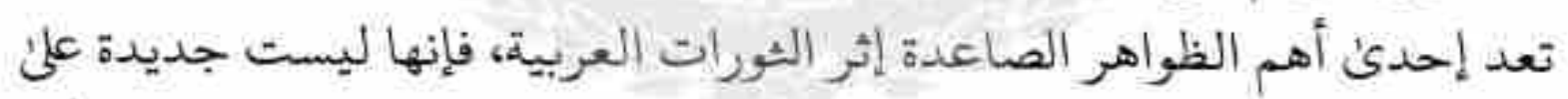

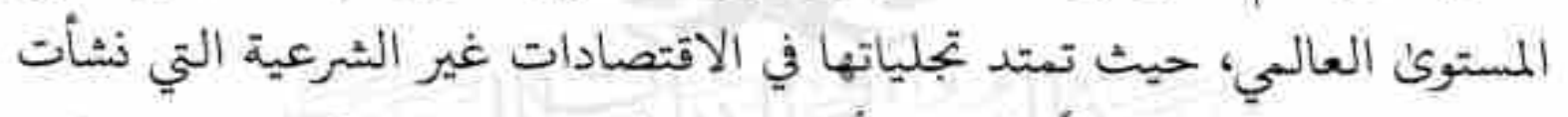

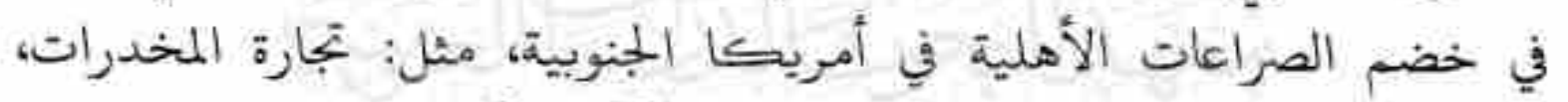

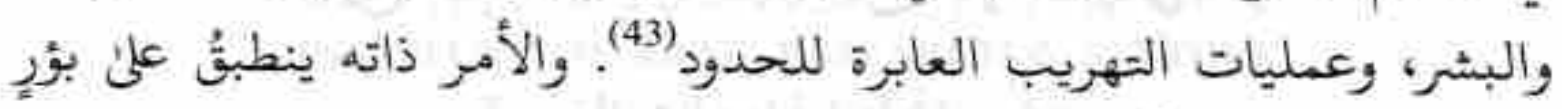

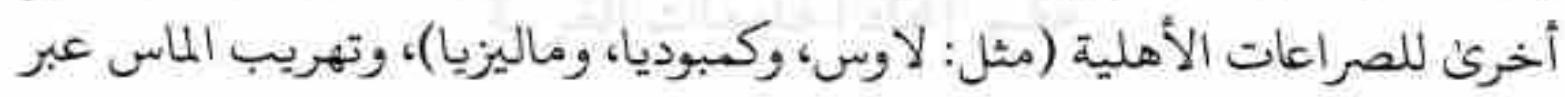

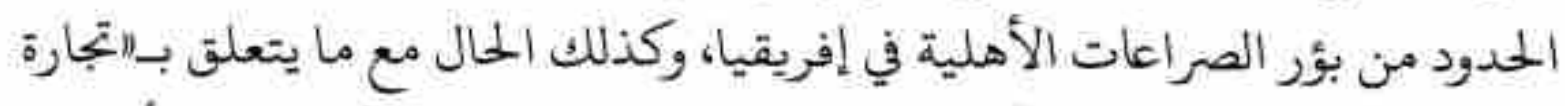

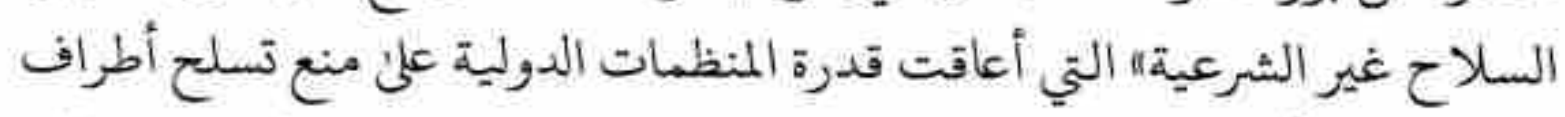

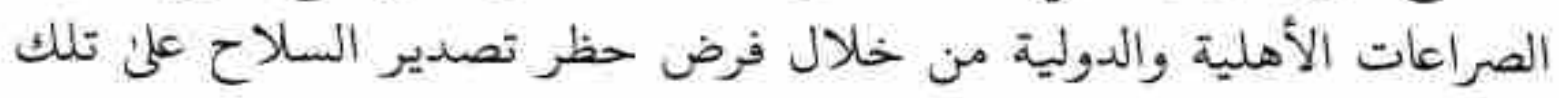
الأطراف. الصراف. 
وفي المقابل تُشير خبرة المنطقة العربية إلى أنه على الرغم من أن الصراعات

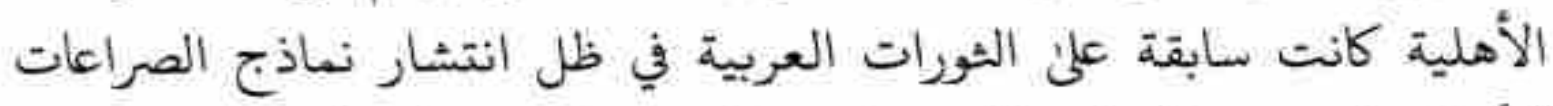

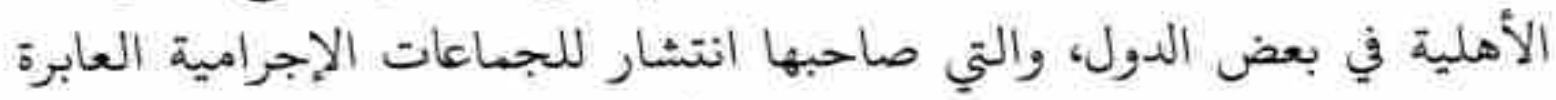

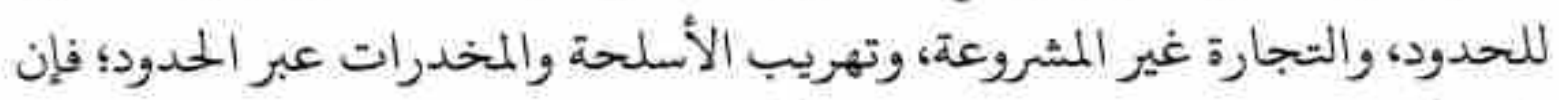

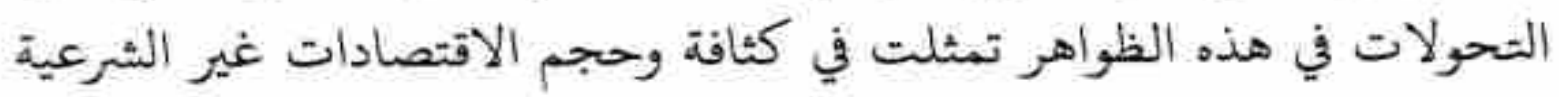

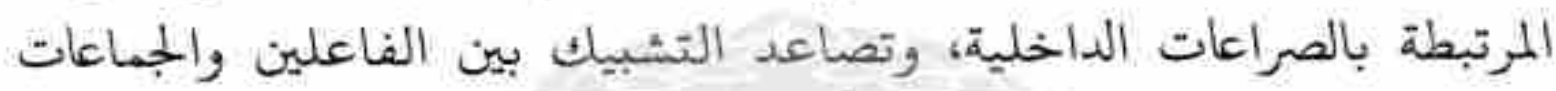
الإجرامية والمنظمات الإرهابية، وتأسيس دورة القتصاتية المادية كاملة ينخرط فيها مختلف الفاعلين (44).

ثالثا - تمويل داعش والصراءعات الداخليت المسلحت العربيتاء

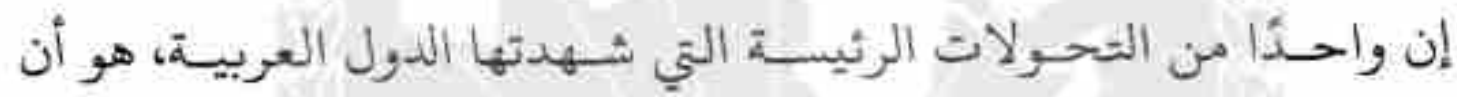

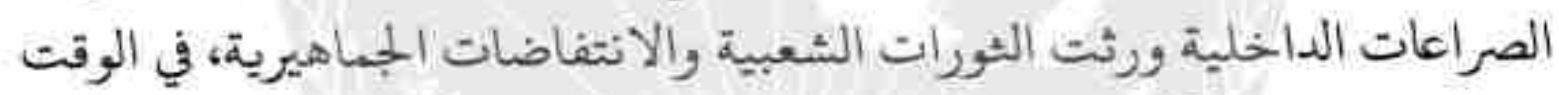

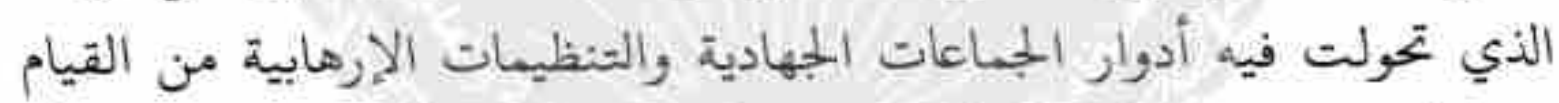

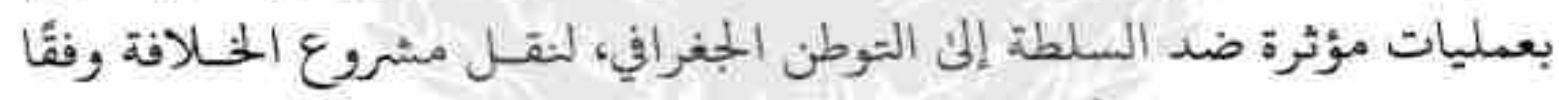

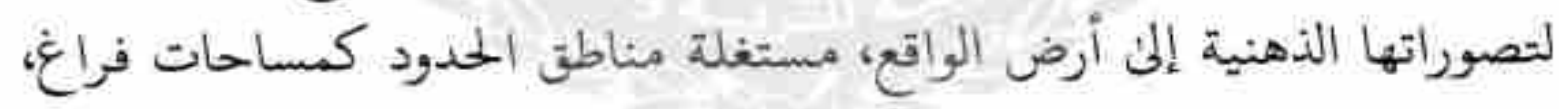

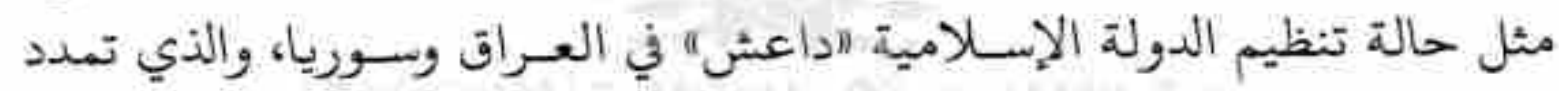

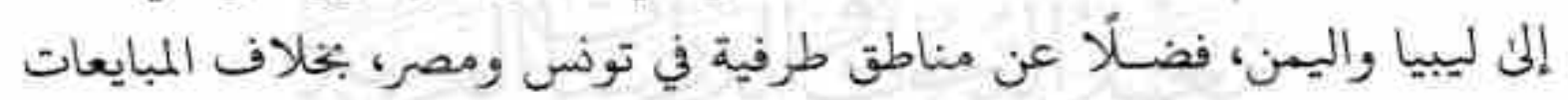

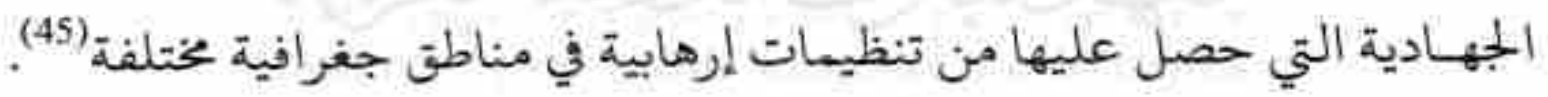

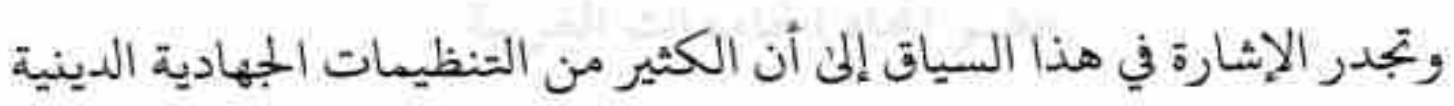

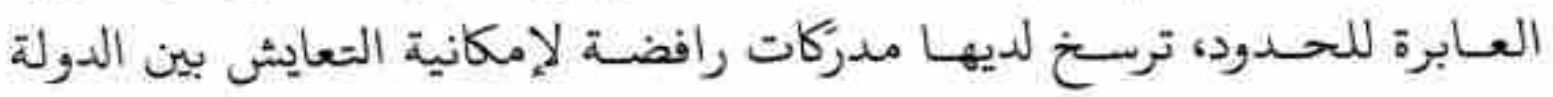

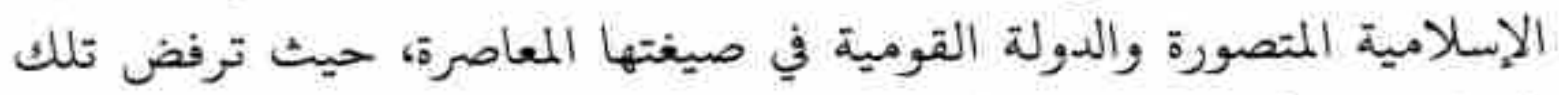

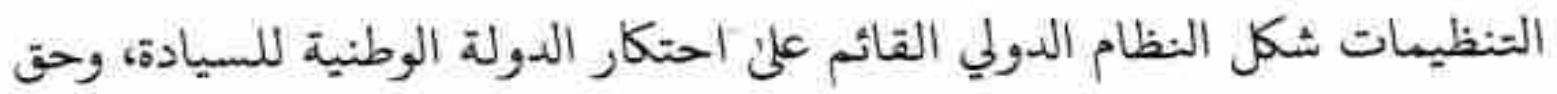

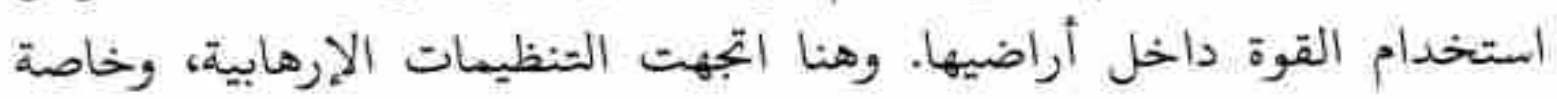


داعش إلم مساومة الدولة على الشراكة في وظائفها، في ما يطلق عليه لالاختراق

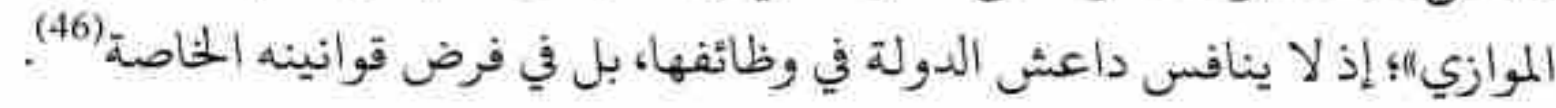
ورفقًا لاتجاه في الأدبيات، تحول تنظيم داعش من تنظيم إرهابي في العراق

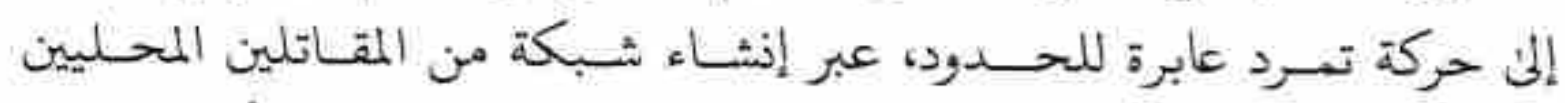
والأجانب(47). بحيث تم استغلال الأوضاع السيا السياسية والاقتصادية والأمنية المترديّية

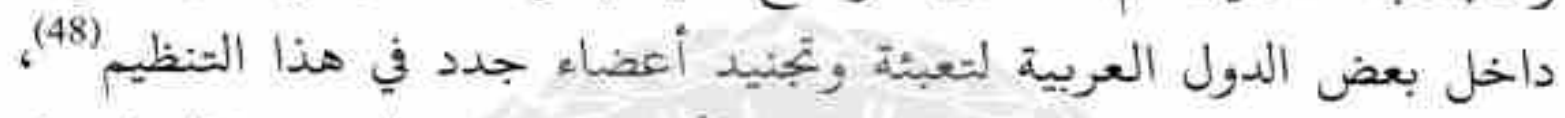

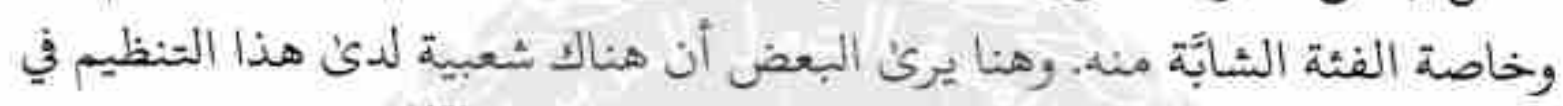

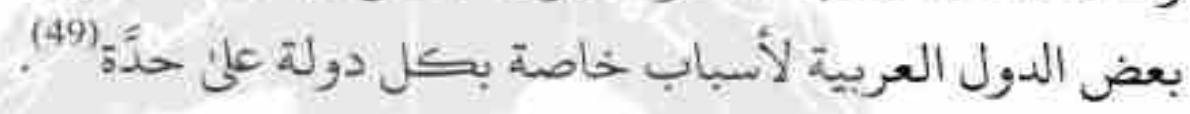
وعلى الرغم من سيطرة التنظيم علي أجزاء واسعة من دول رئيسة في المنطقة

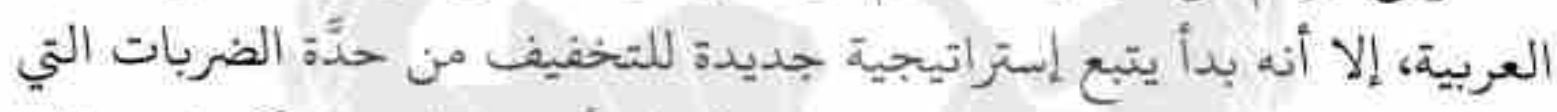

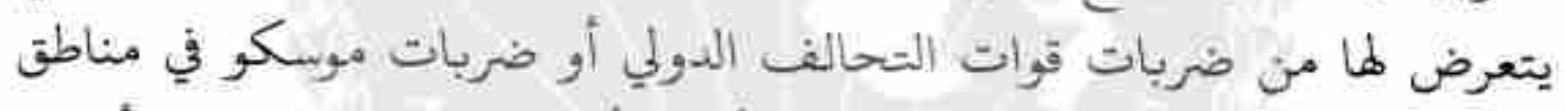

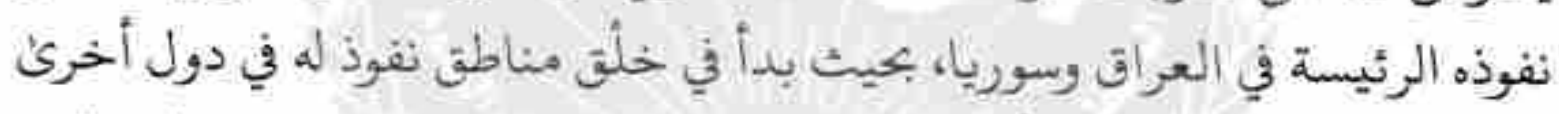

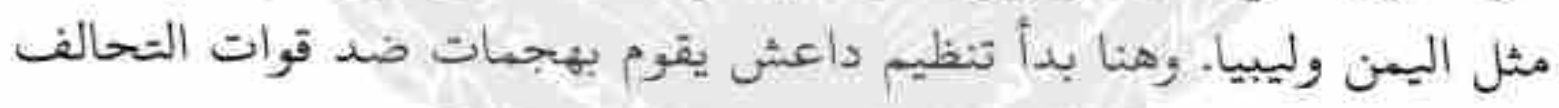

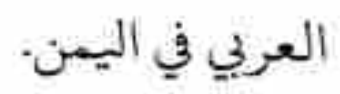

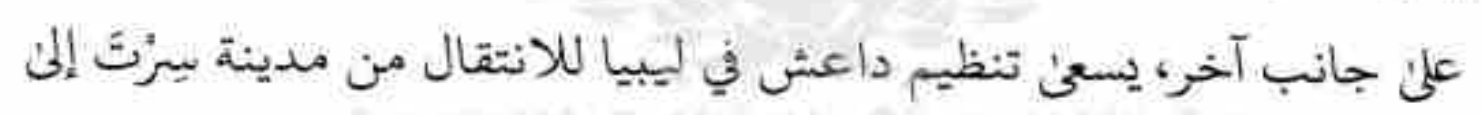

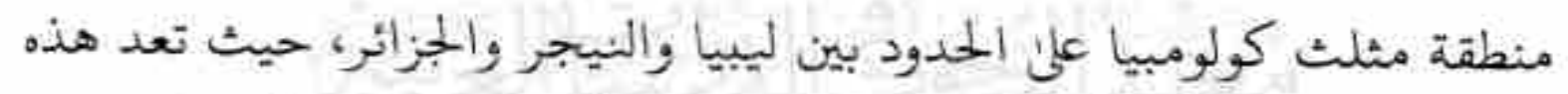

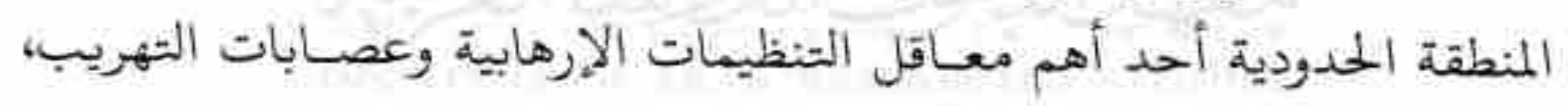

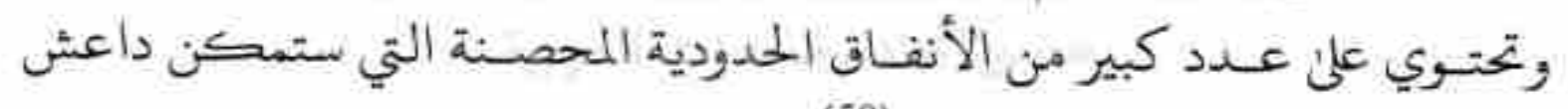
من القيـام بعمليات عابرة للحيدود (50).

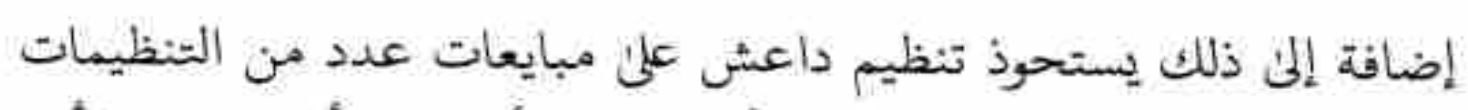

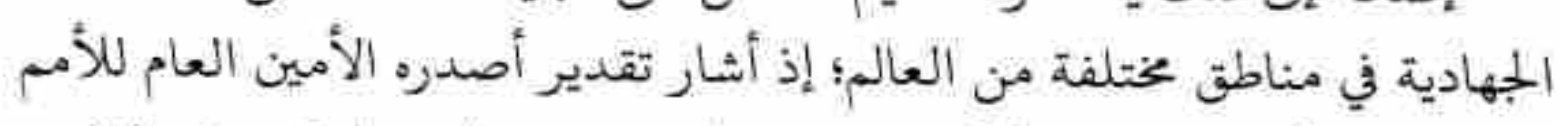

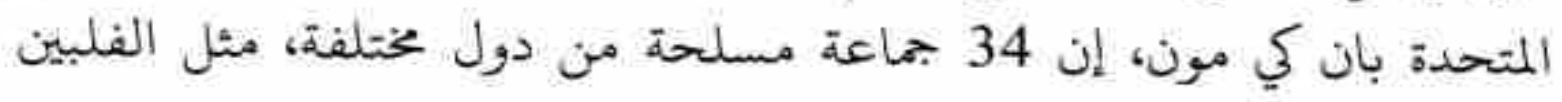


وأوزباكستان وباكستان وليبيا ونيجيريا، أعلنت ولاءها لتنظيم داعش خلال

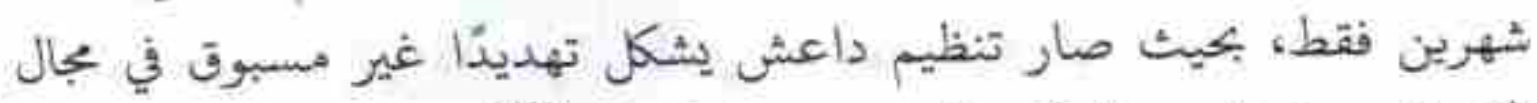

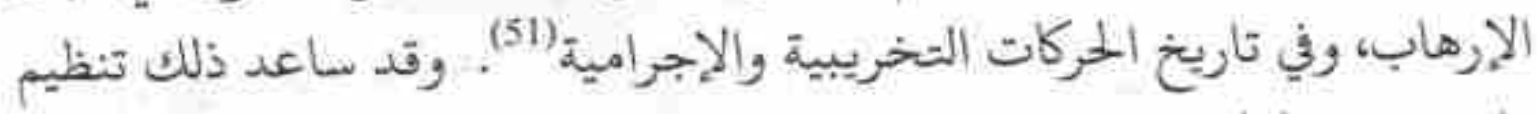

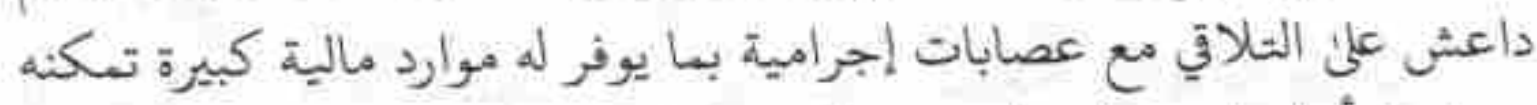
من شراء أسلحة ومعدات لتوبسيع نطاق عملياتث المسلحة.

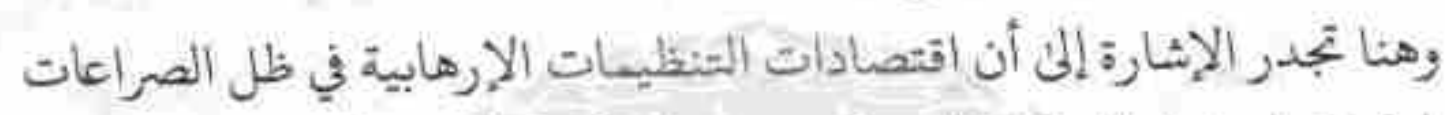

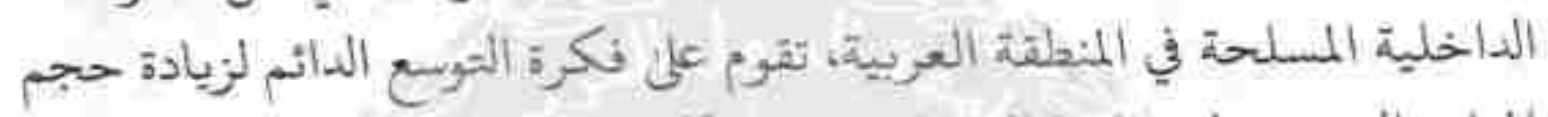

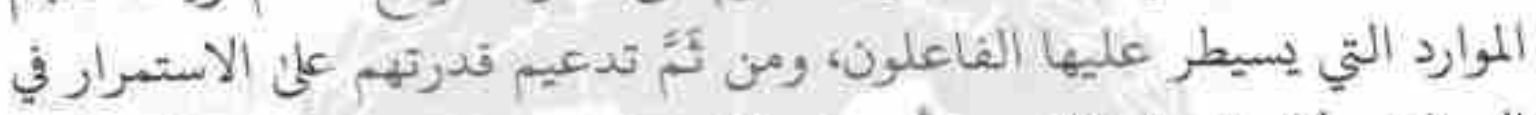

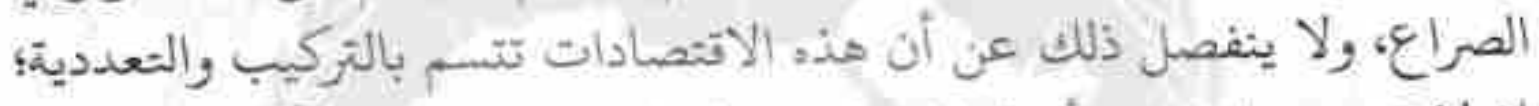

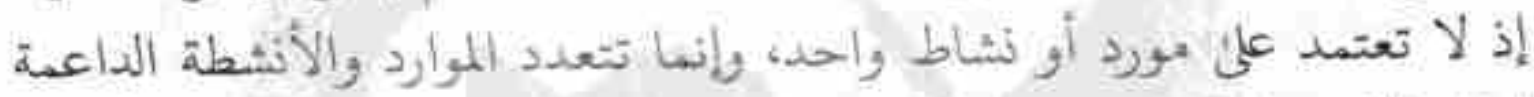

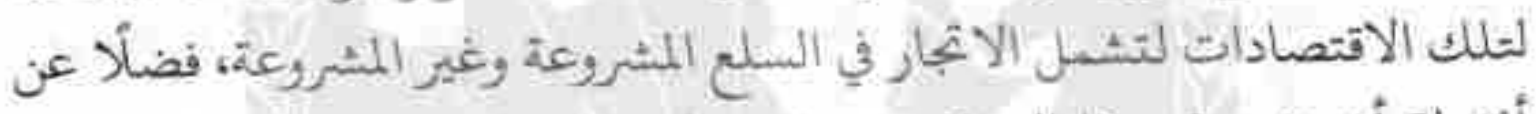

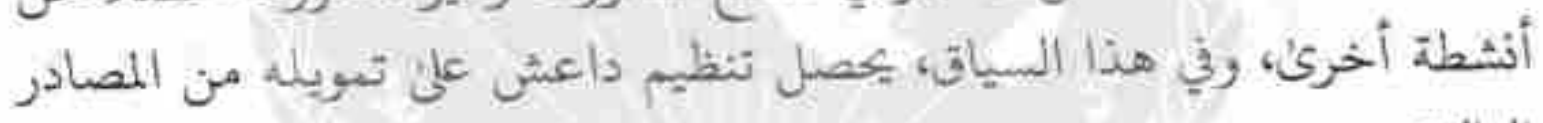
الكالية: ثب تبرعات غير رسمية من الأثرياء: حيث رصدت بعض التقارير الصادرة

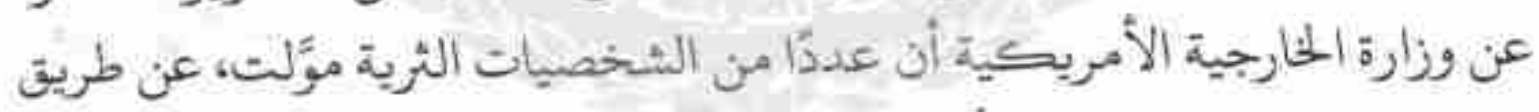

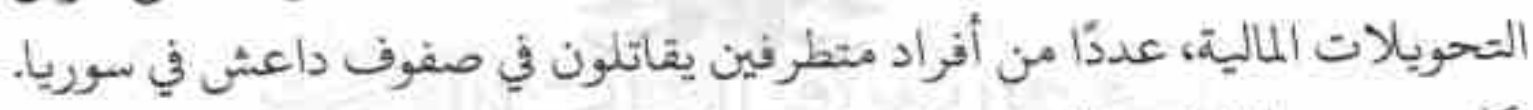

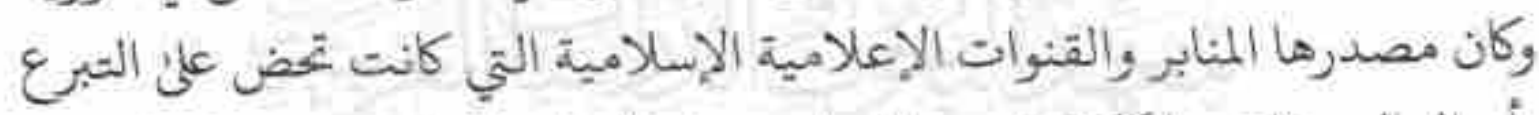

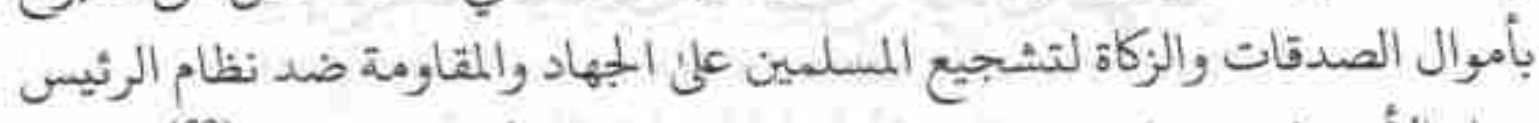

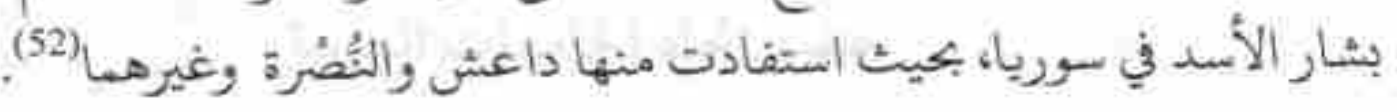

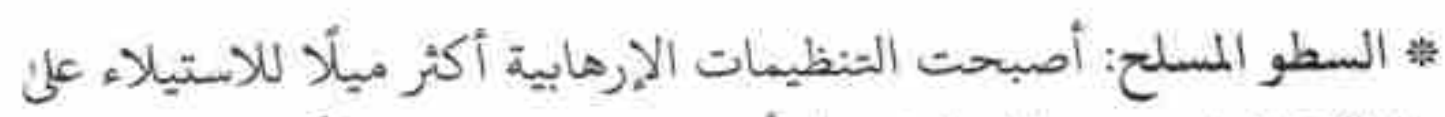

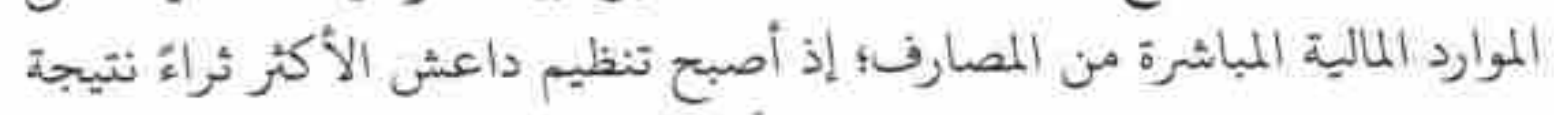

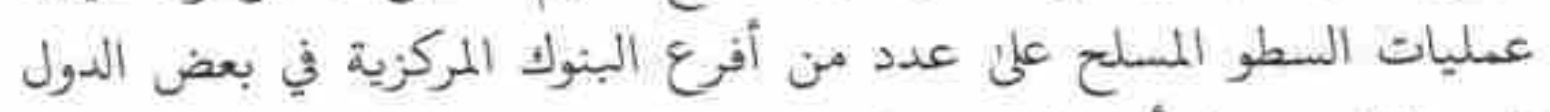

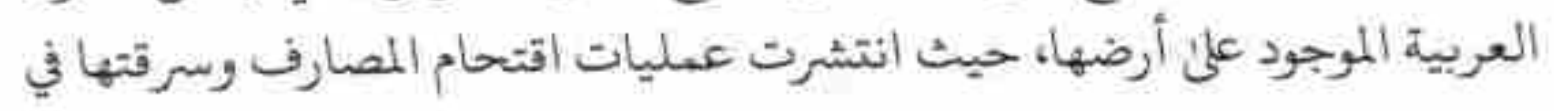


كل من العراق واليمن وليبيا. ففي العراق استطاع تنظيم داعش في يونيو

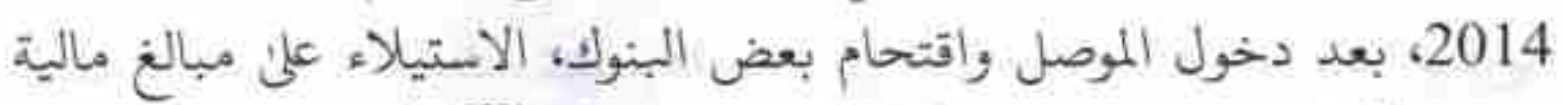

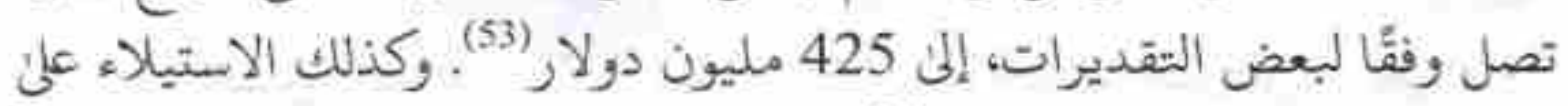
مناجم الذهب في الموصل بالعرات (54).

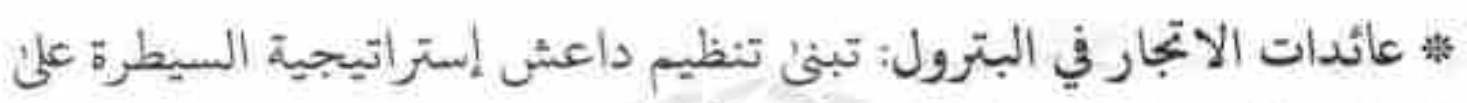

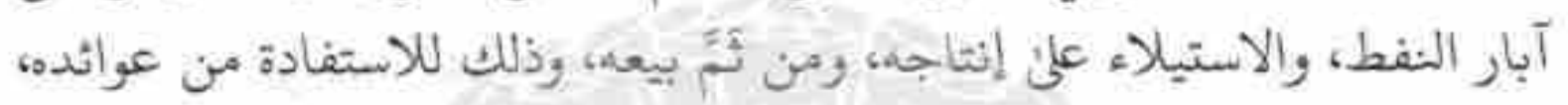

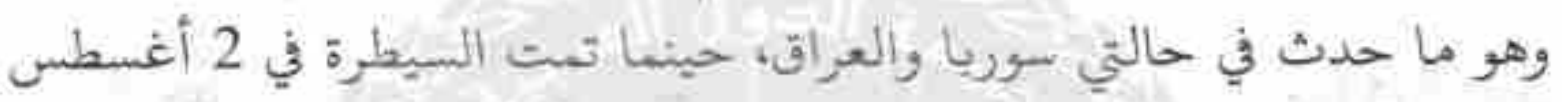

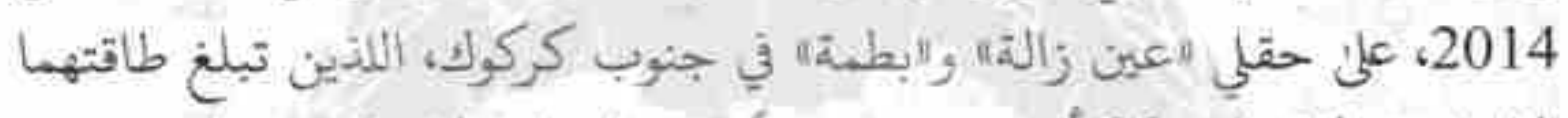

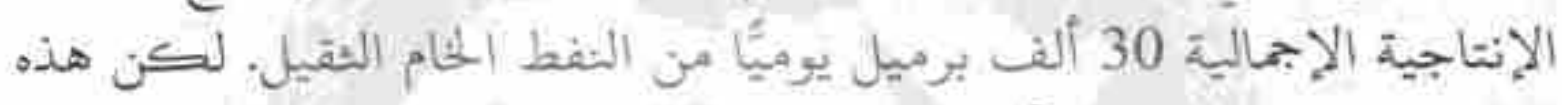

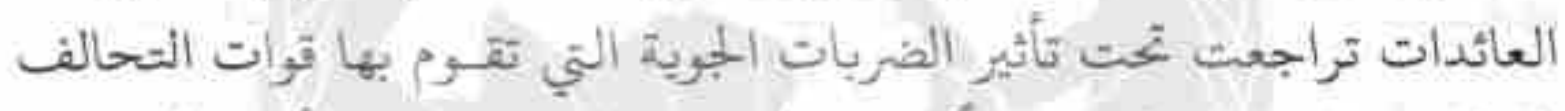

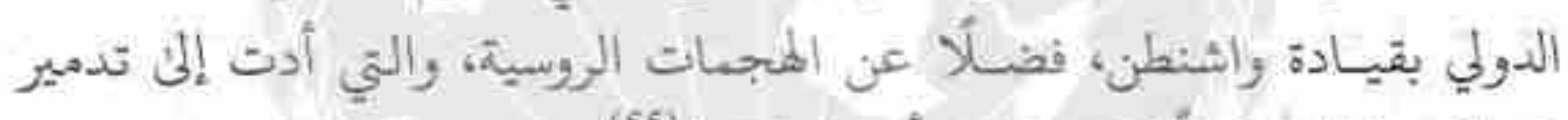

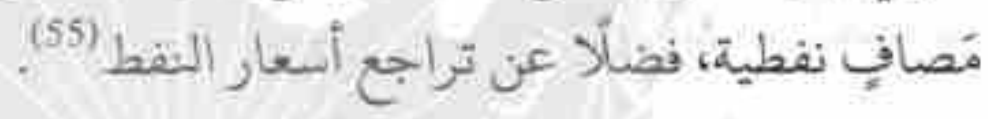

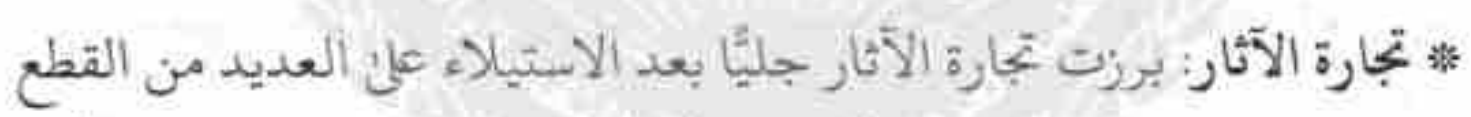

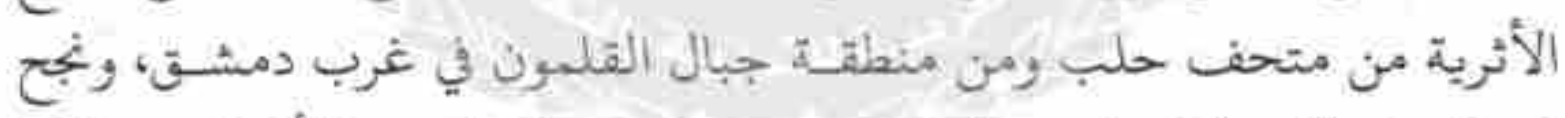

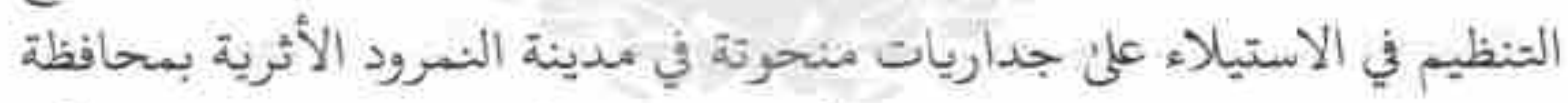

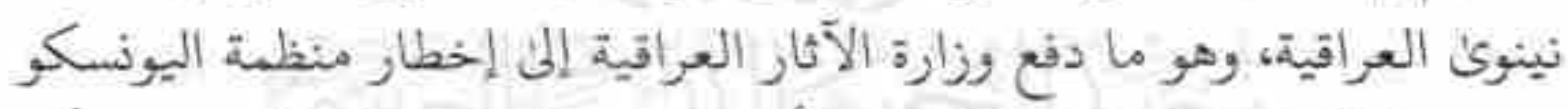

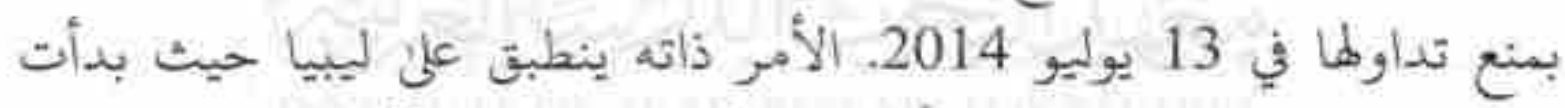
الجباعات الجهادية والقبائز في تأسيس شبكة للاتجار في الآثار في محيط منطقة سبراطة التاريخية.

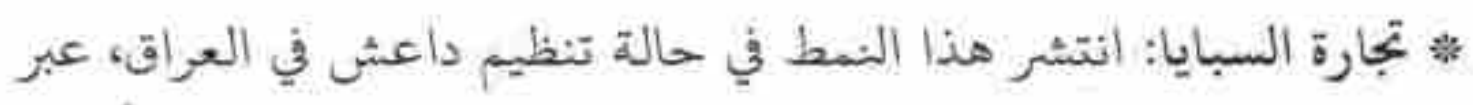

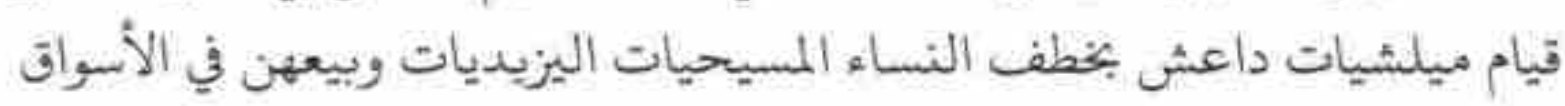

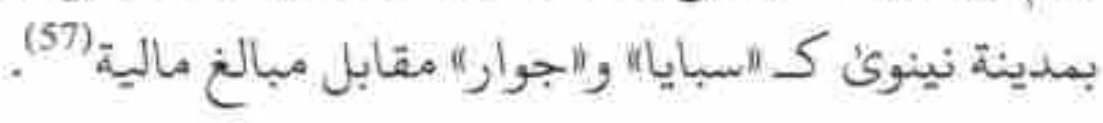


"إ فرض الجزية، والابتزاز المالي للمسيحيين: تمثل الحالة السورية نموذجًا

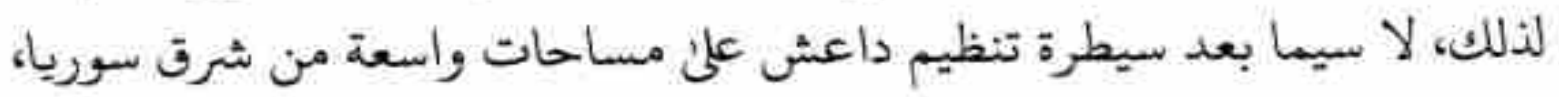

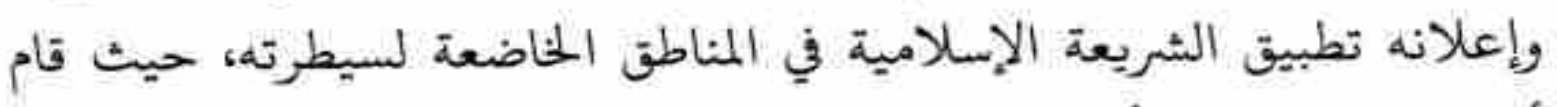

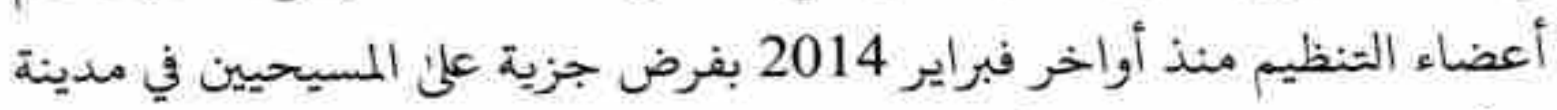

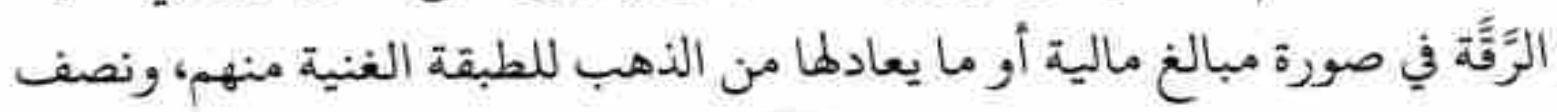
هذه القيمة لمتوسطي الحال. ثصيلة الضرائب على الأنشطة التجارية (البضائع والشاحنات) في المناطق

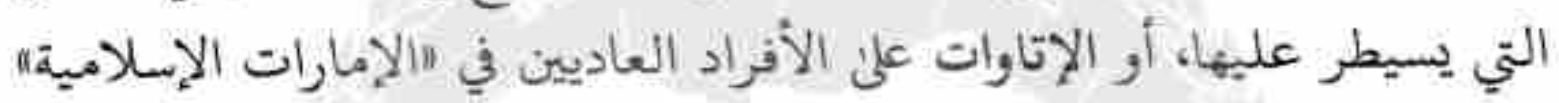

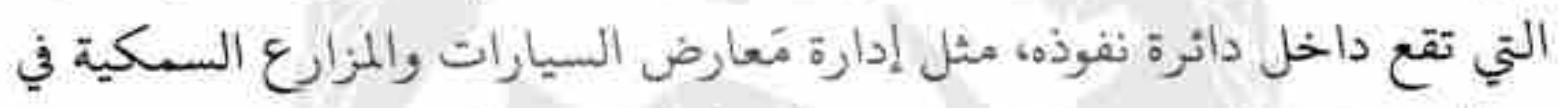

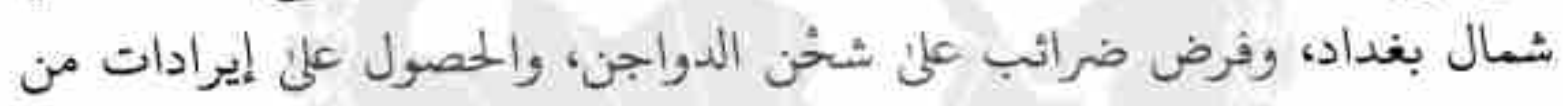

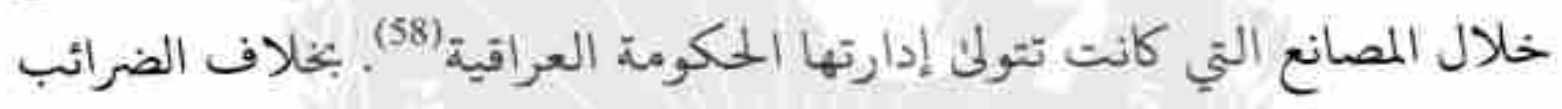

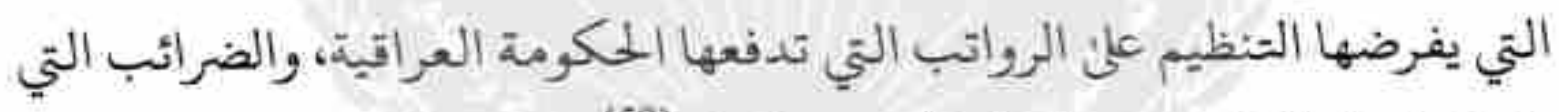
يفرضها علئ المزارعين وخاصة الحبوب والقطن (59) في المحصلة النهائية تدكنت التنظيسات اللإرهابية من ممارسة تكتيكات

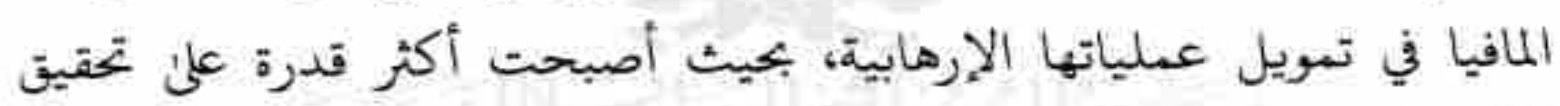

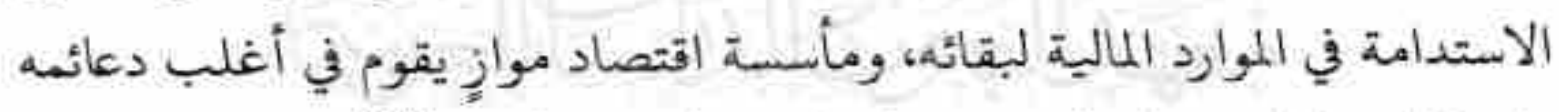

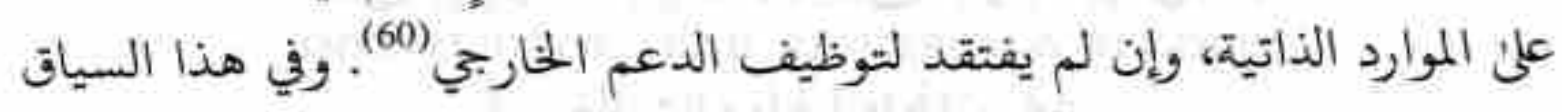
تكون هذه التنظيمات غير أيديولوجية ومدفوعة بتحقيق أرباح مالية، وتلجأ لأليدأ

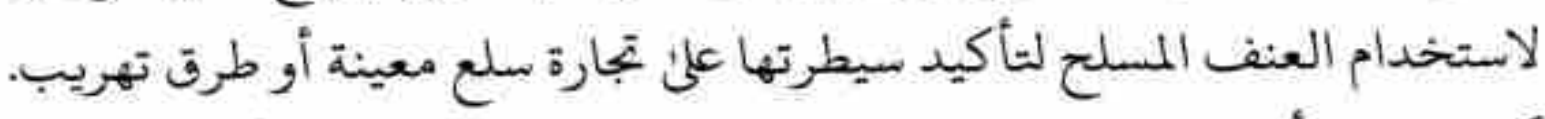

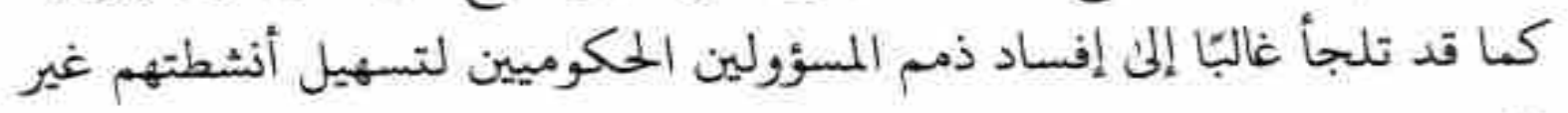
المشروعة. 
رابعًا - تأثيرات تمويل التتظيمات الإرهابيت على الأوضاع الداخليتً العربيت والتفاعلات الإقليميت:

تمثلت تأثيرات الصراعات الداخلية في المنطقة العربية، عسكريًّا وأمنيًا

واقتصاديًّا، في ما يلي:

* تزايد التهديدات الأمنية لدول الجبوار القلِق، لا سيما مع سيطرة فاعلين

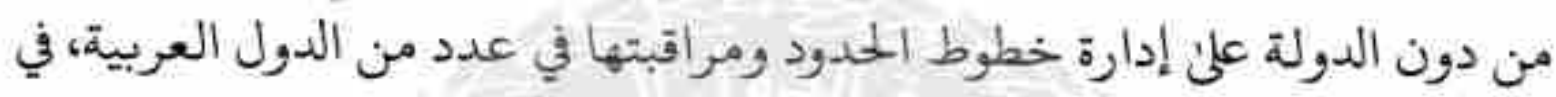

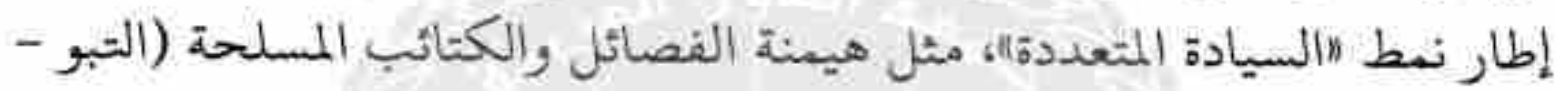

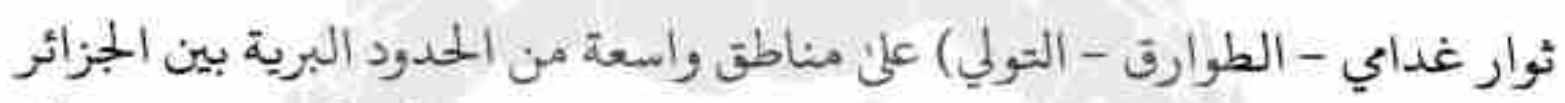

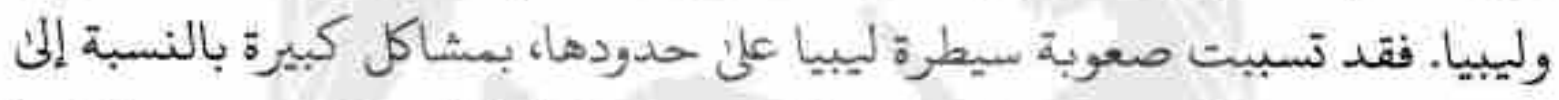

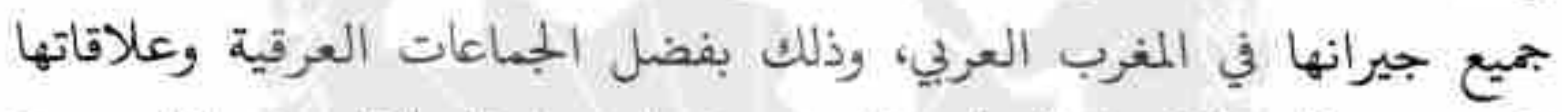

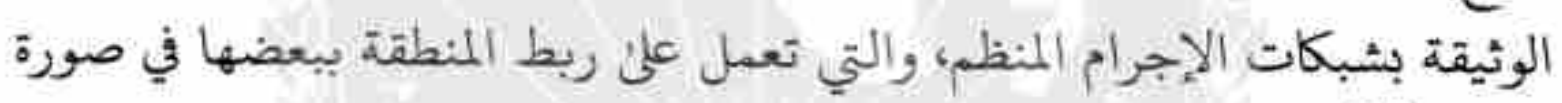
" احزام" (61)"

وقد تبلور هذا التأثير بشكل واضح من خلال عمليات تهريب المقاتلين

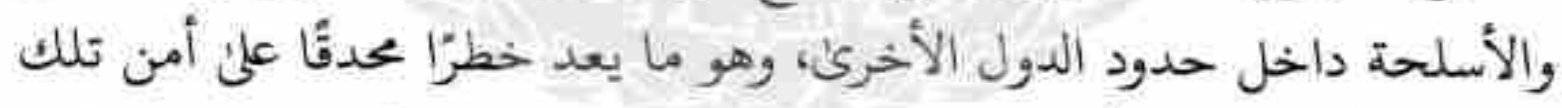

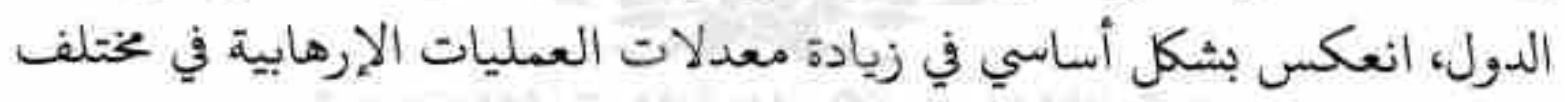

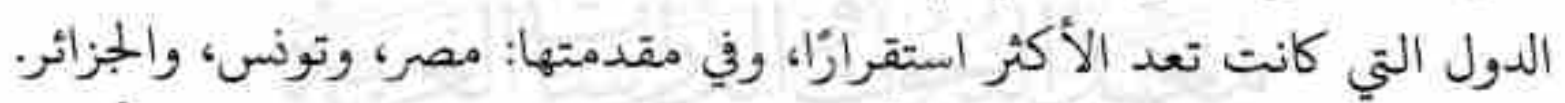

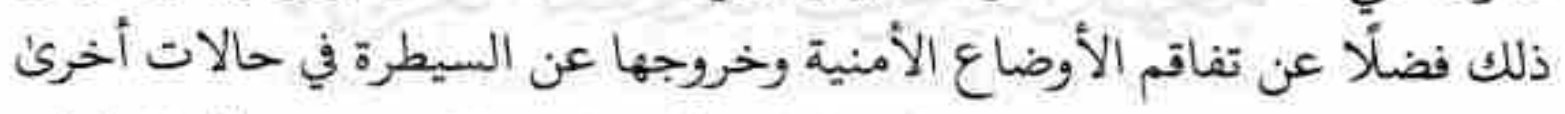

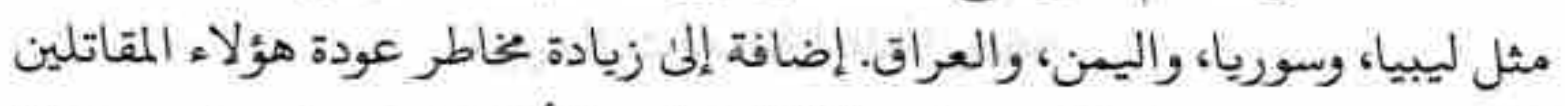

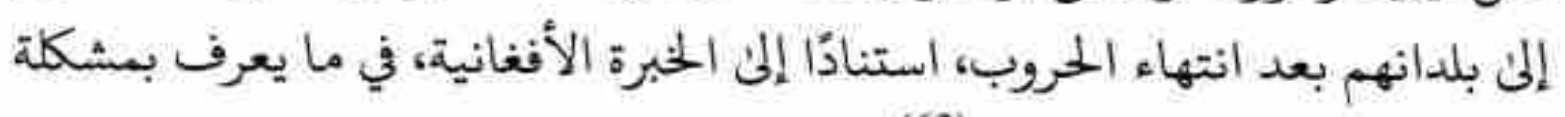
"العائدين من البؤر الصراعية|"(62).

" توسيع شبكات التجنيد للجماعات الراديكالية، أو توحش ظاهرة المقاتلين

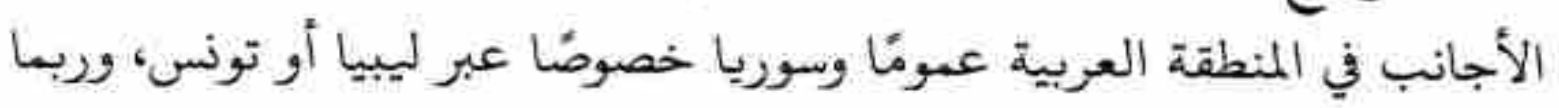


السعودية والعراق والأردن ومصر. فنظرًا لسهولة التنقل بين أرجاء منطقة

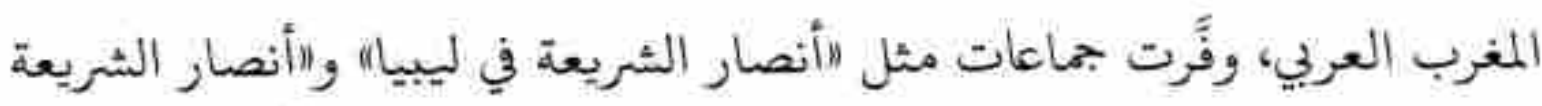

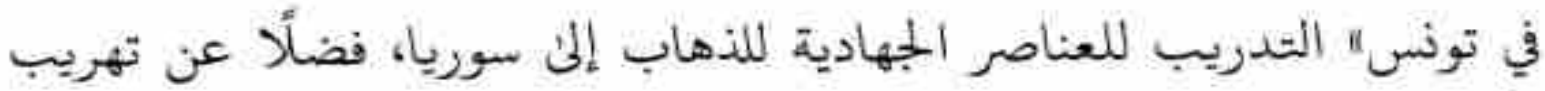

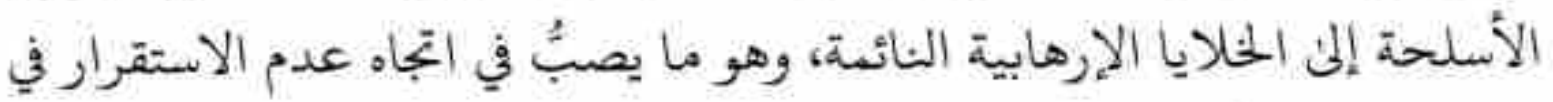

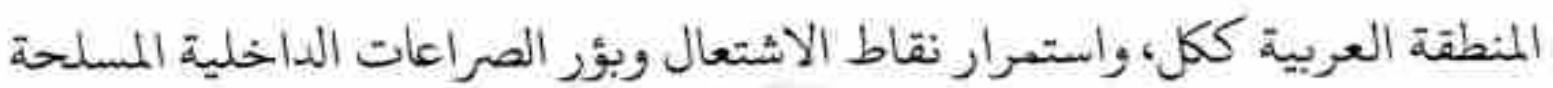

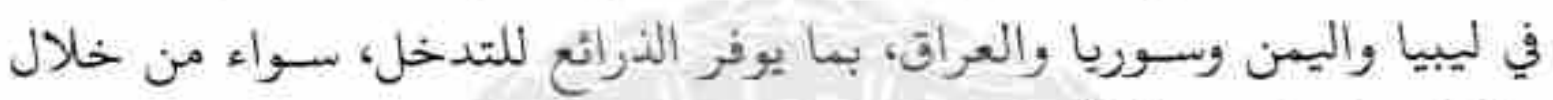

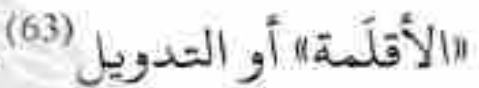

" تنامي تدفقات اللاجئين عبر الحمدود الرخوة، بسبب موجة الصراعات

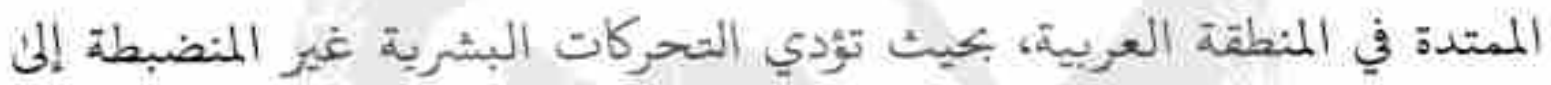

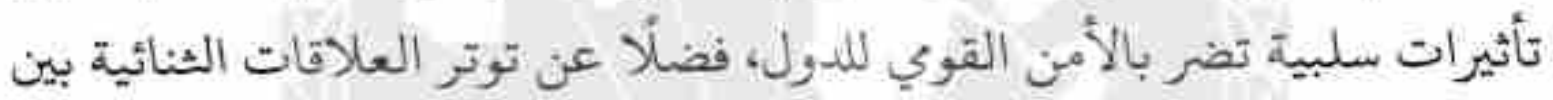

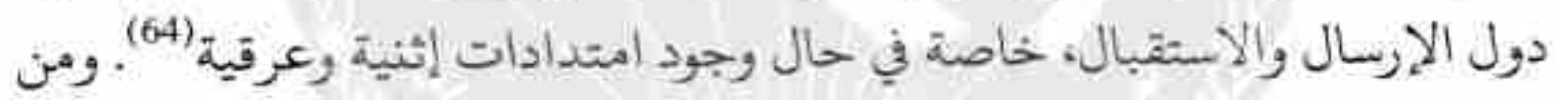

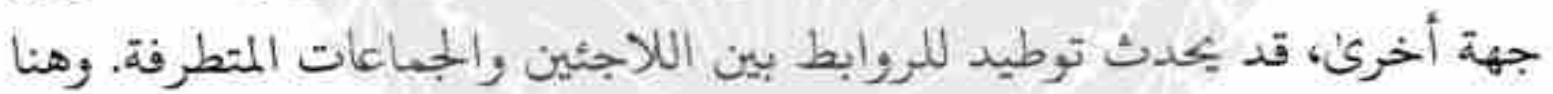

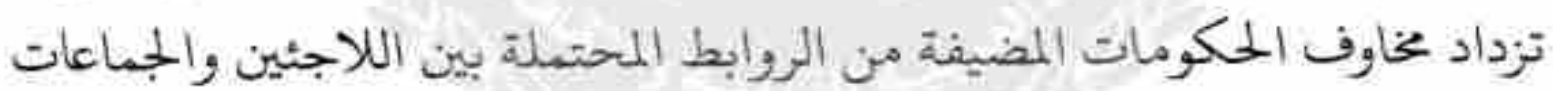

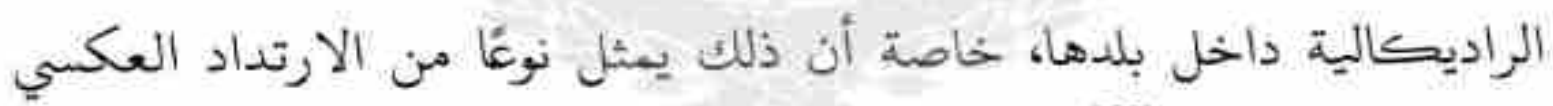
للصراعات الإقليمية (65).

فا ثأجيج مشاعر الأقليات المذهبية: تزداد حذَّة الأثر لاقتصادات الصراعات

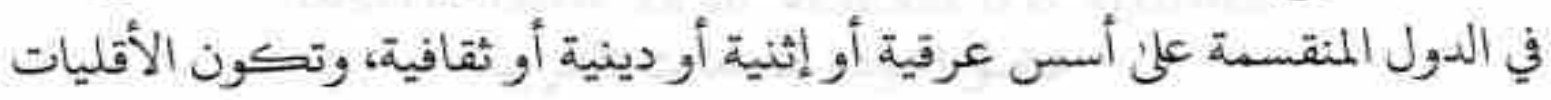

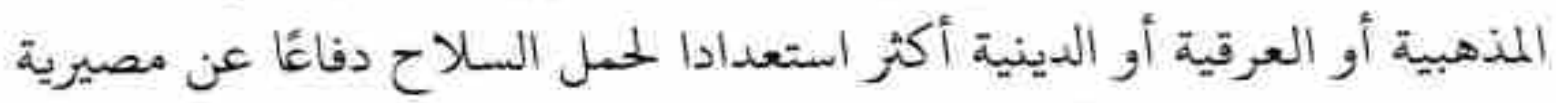

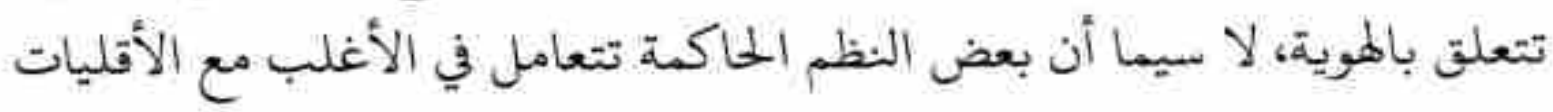

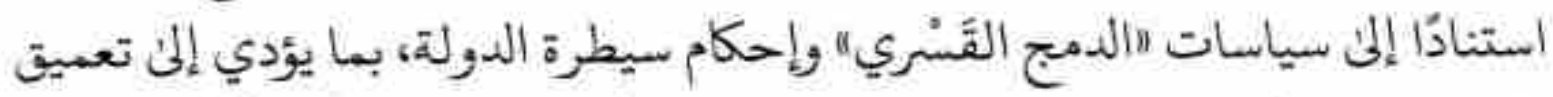

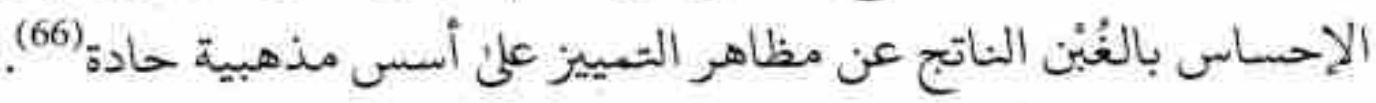


"* إعادة تشكيل عصابات التجارة غير الشرعية، من خلال ظهور فاعلين

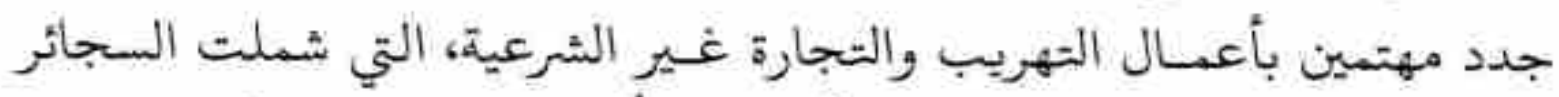

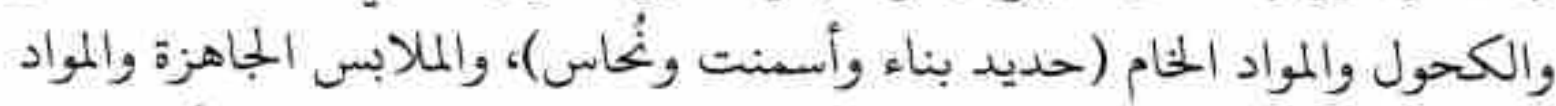

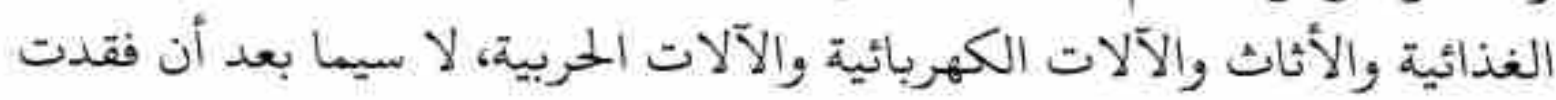

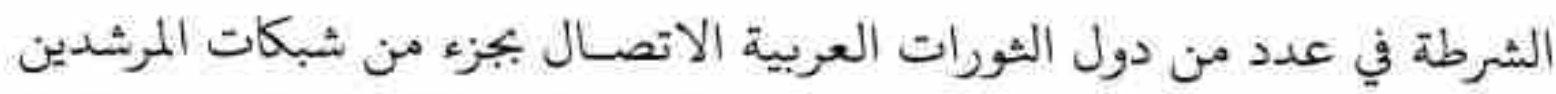

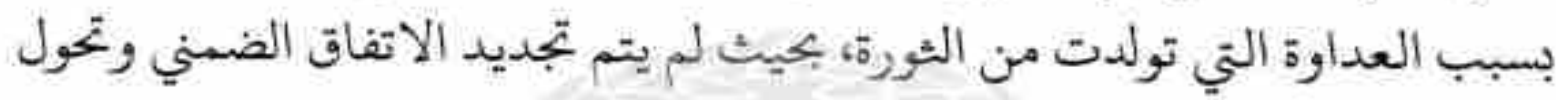

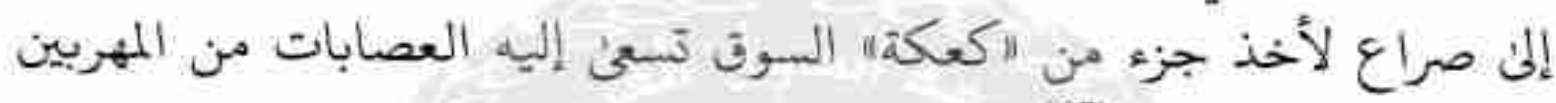
والمجاهدين علي السواء (67)

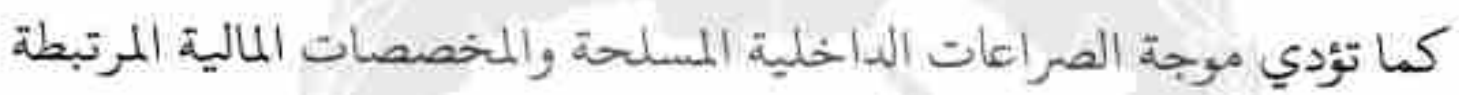

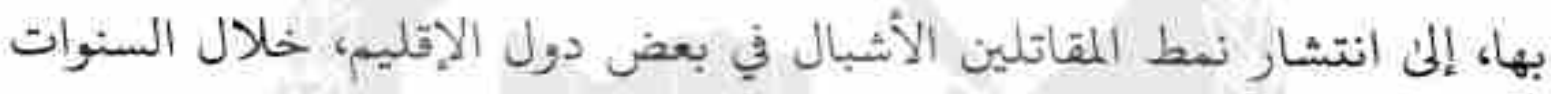

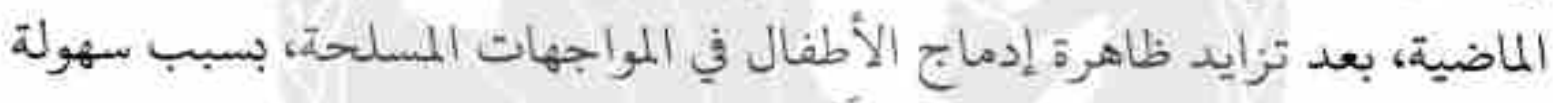

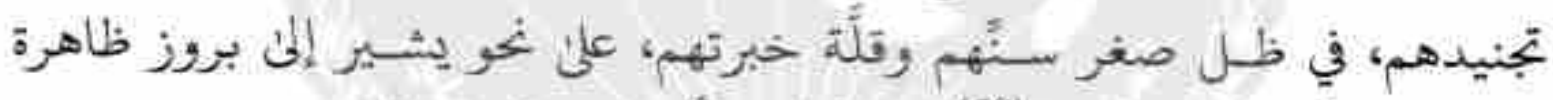

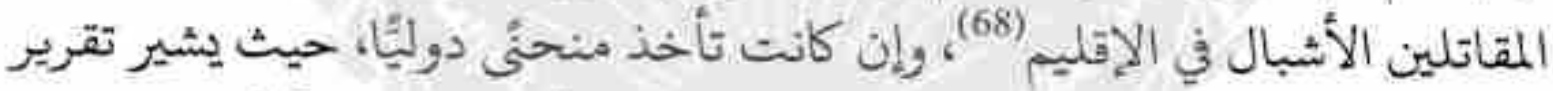

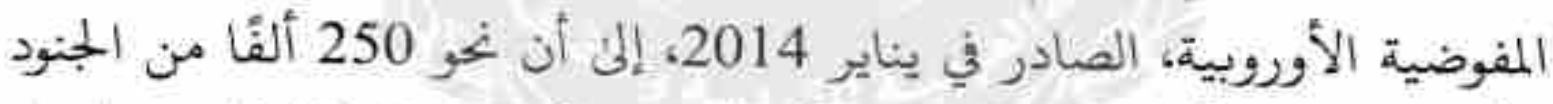

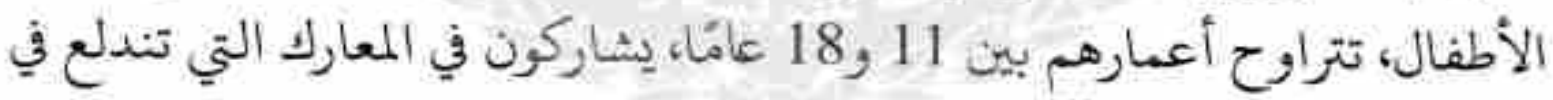

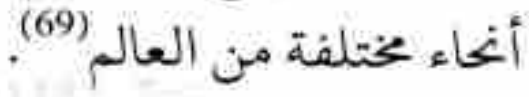

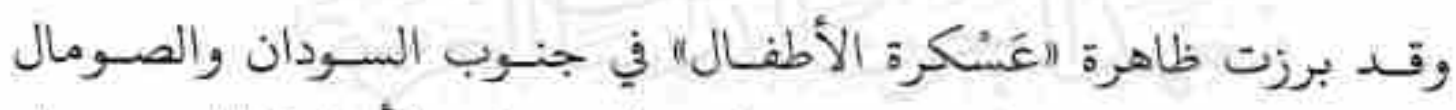

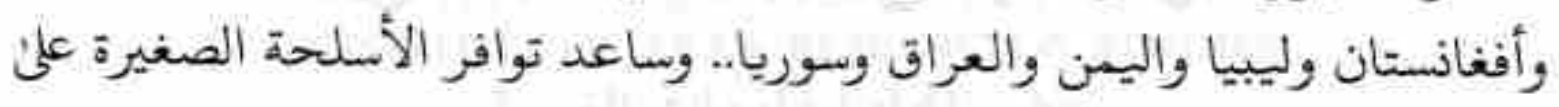

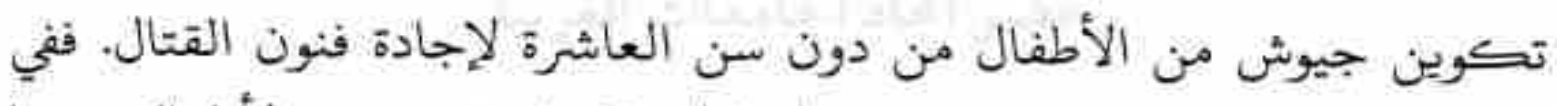

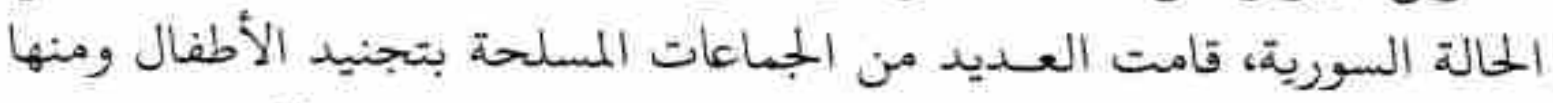

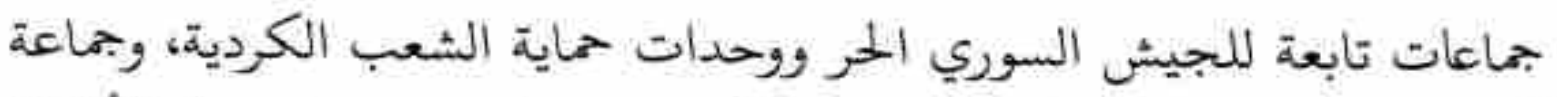

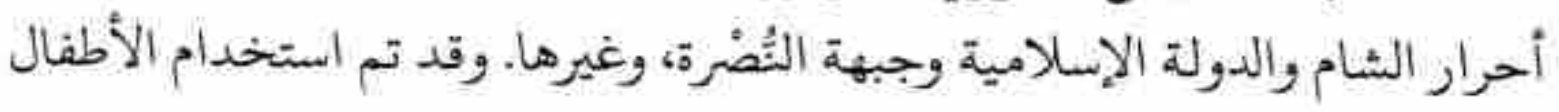

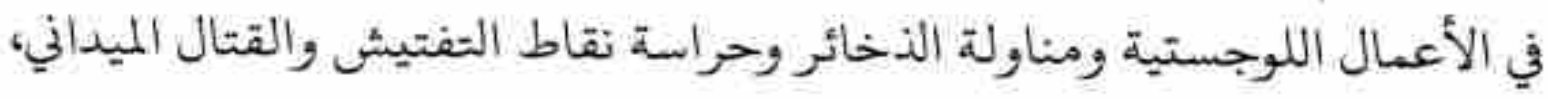




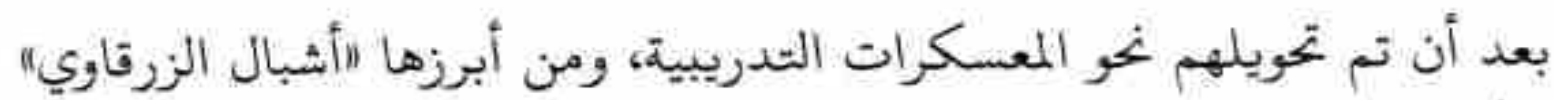

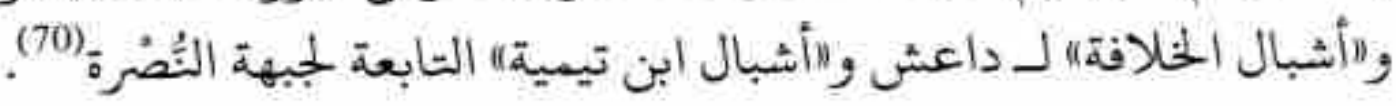

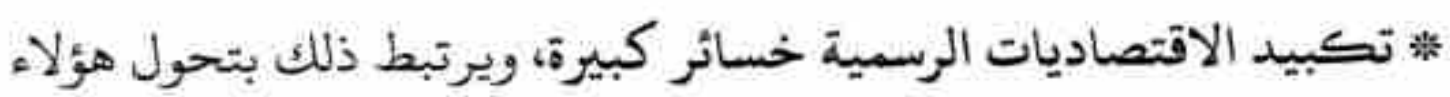

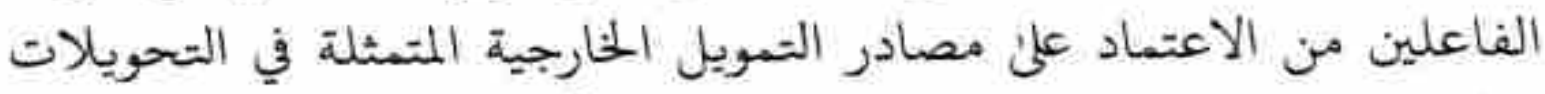

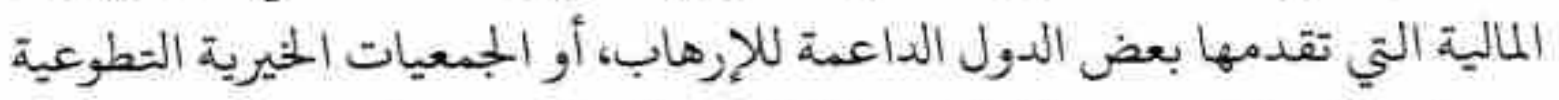

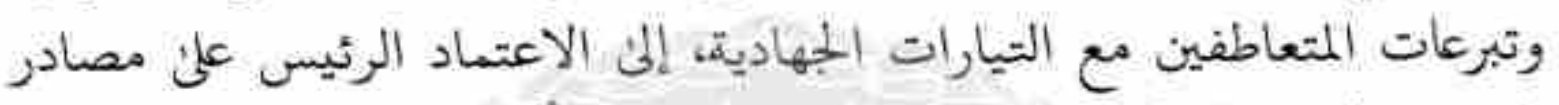

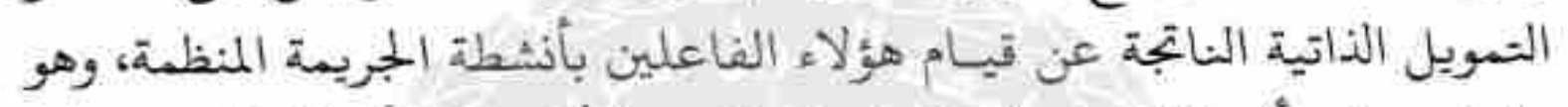

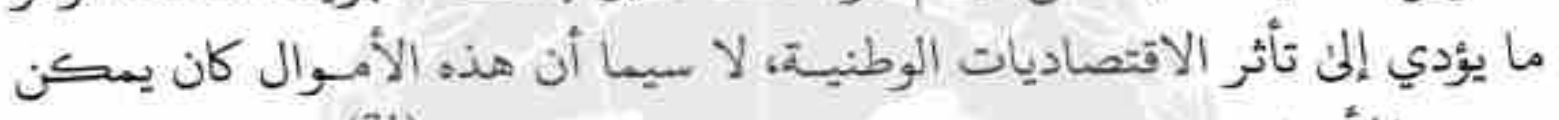

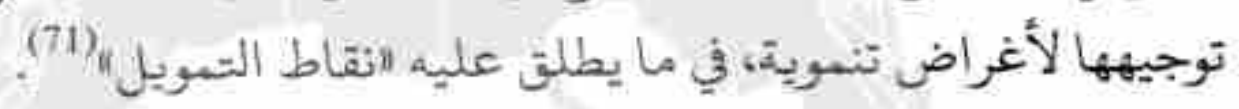

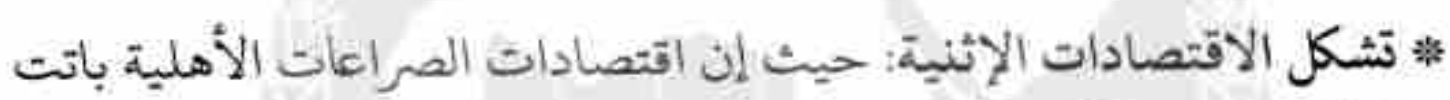

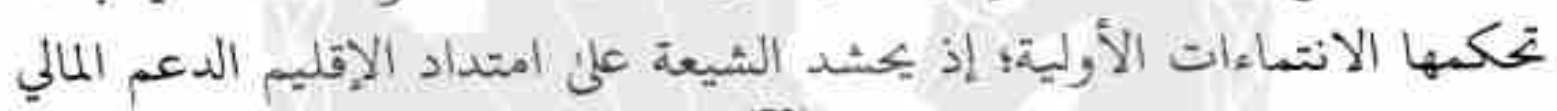

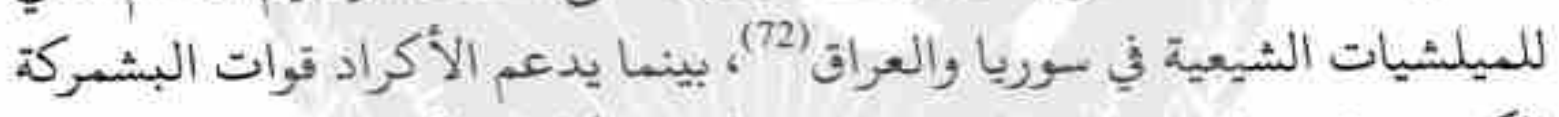

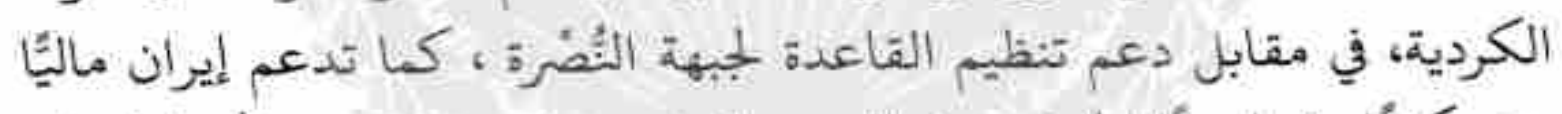

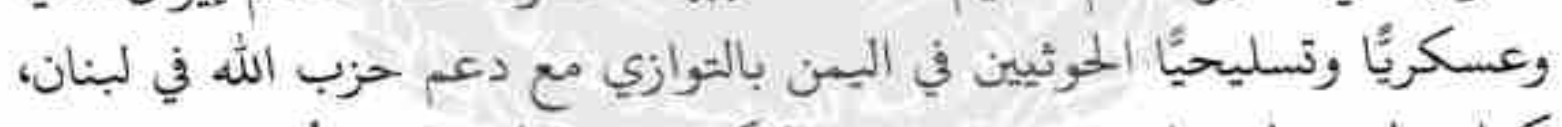

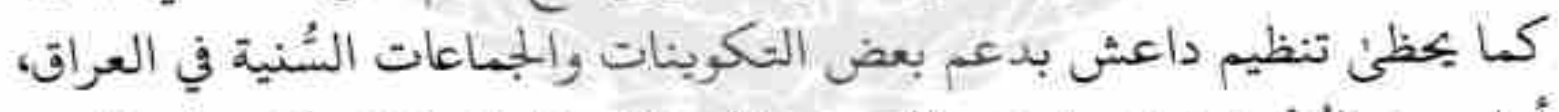

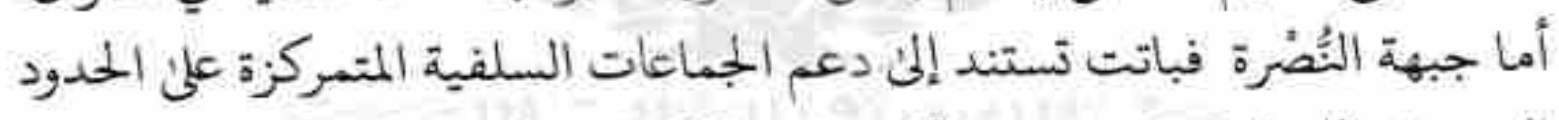

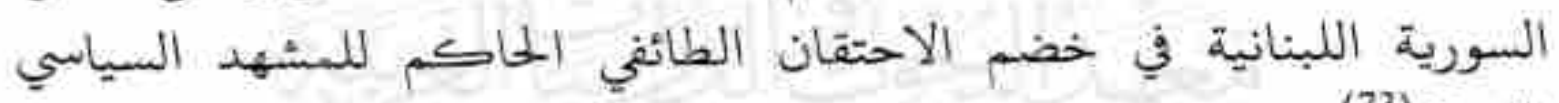
اللبناني (73).

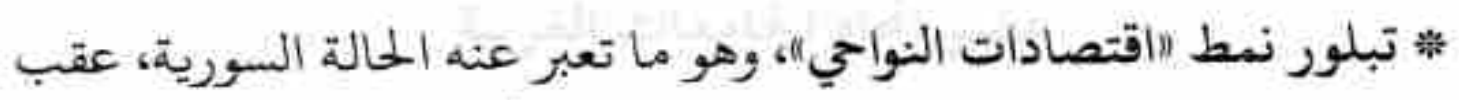

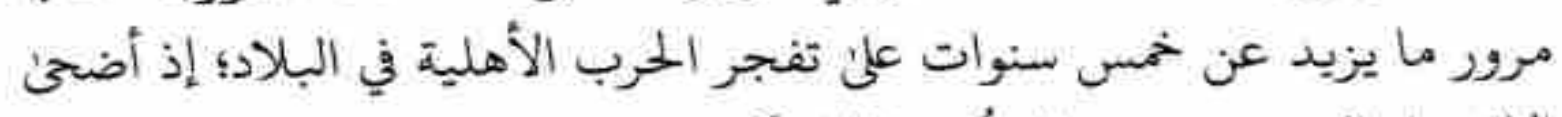

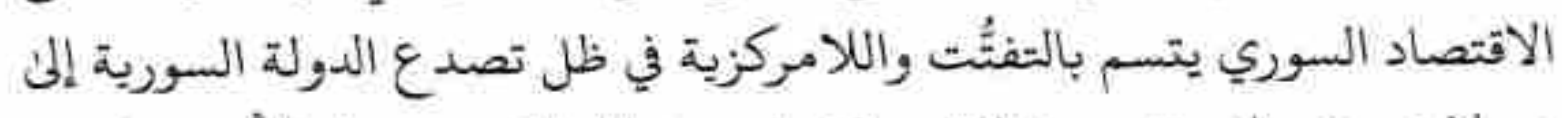

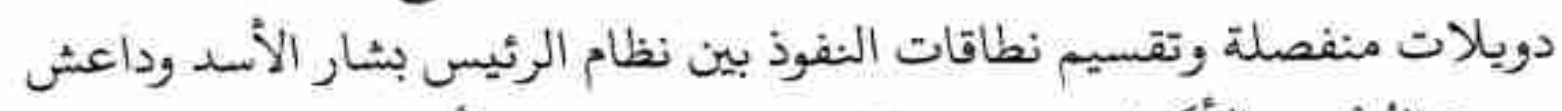

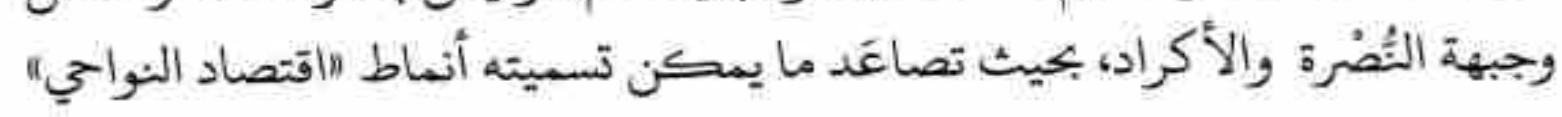


لإدارة التفاعلات الاقتصـادية وسـد احتياجات المواطنين في ظل اللامركزية

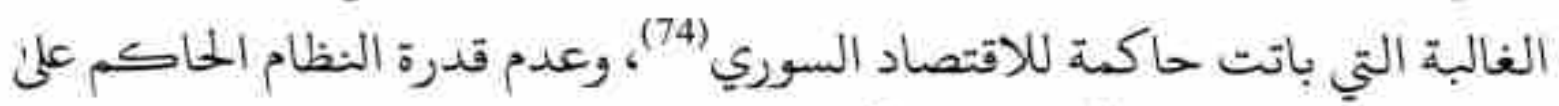

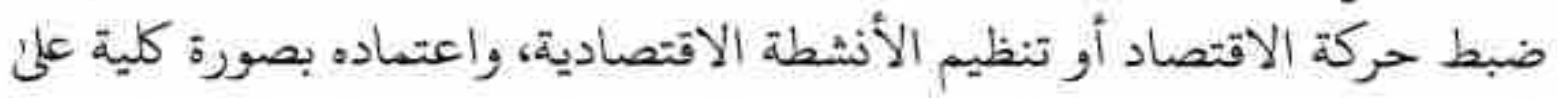

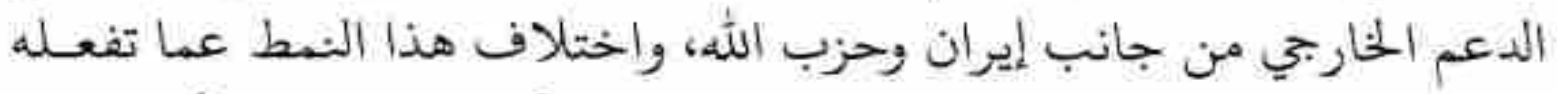

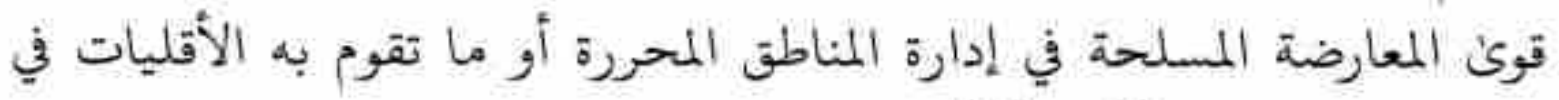

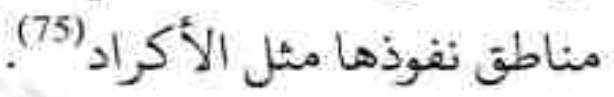

\section{خامستا - مداخل تقليص الصراعات الداخليت في الوطن العربي:}

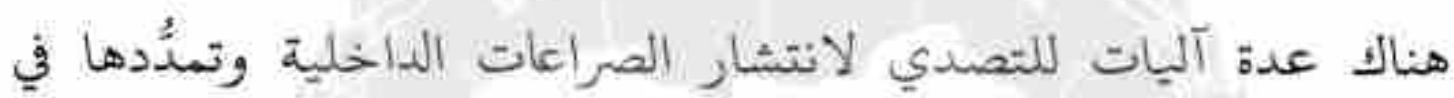

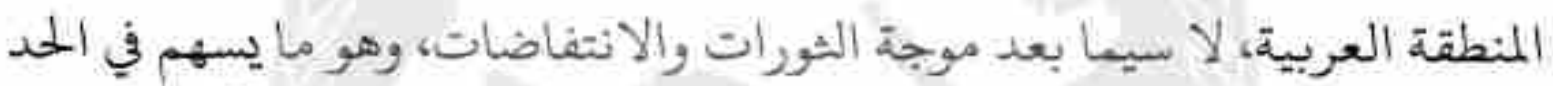

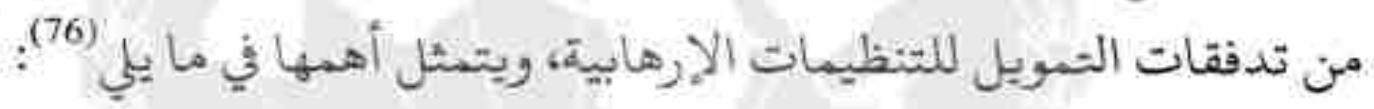
1- التوافق السياسي: يبدأ احتواء الصراعات الأهلية بتحقيق التوافق الجامع

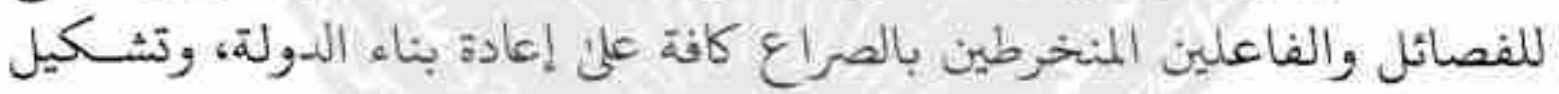

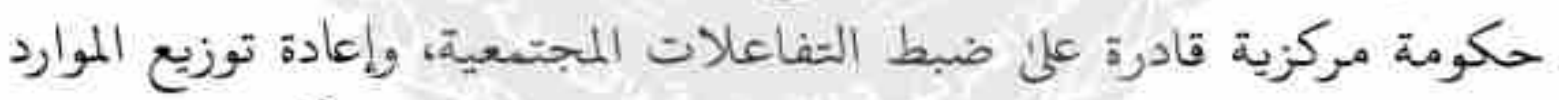

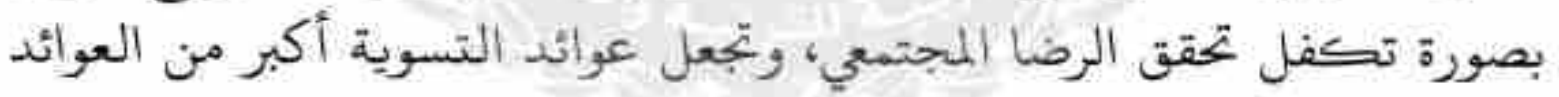

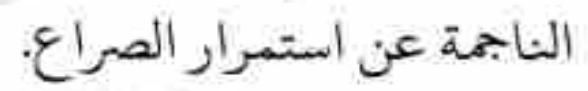

2- التنسيق الدولي: وينطوي على توافق الأطراف الإقليمية والدولية على الني

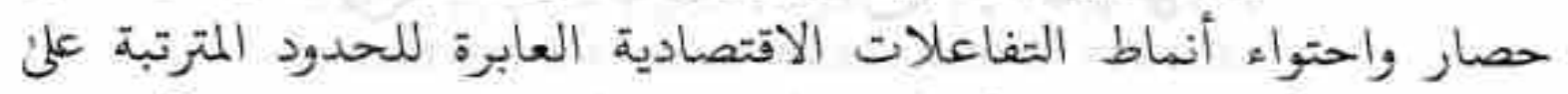

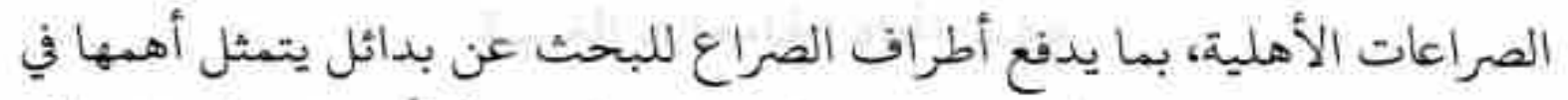

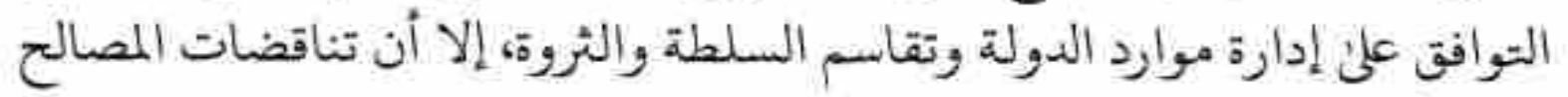

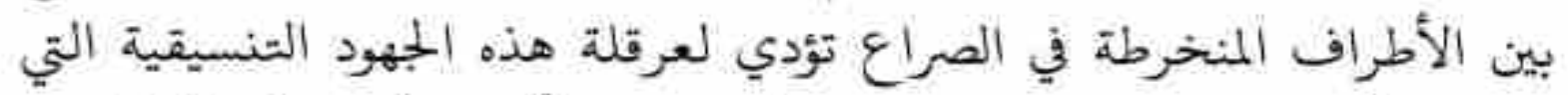

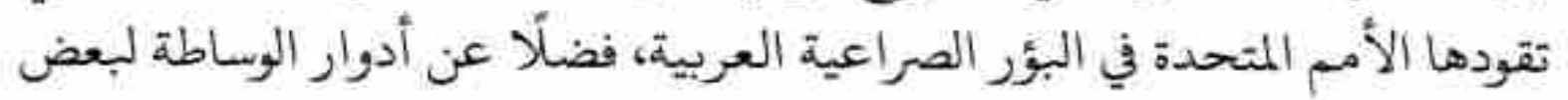

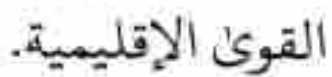


3- المدخل القانوني: يعزز افتقـاد مختلف الكيانات الصـاعدة للاعتراف

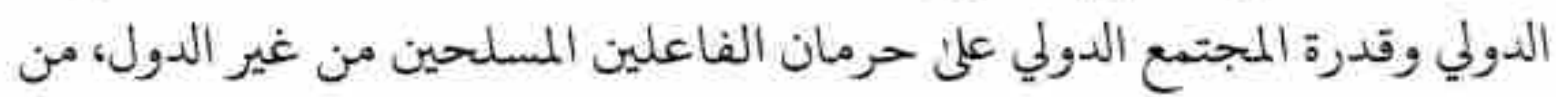

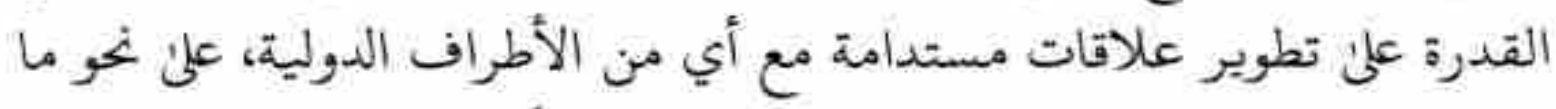
تشير إليه العقوبات الدولية التي تفرضها المنظمات الأمية على المرئ الحوثيين في اليهن.

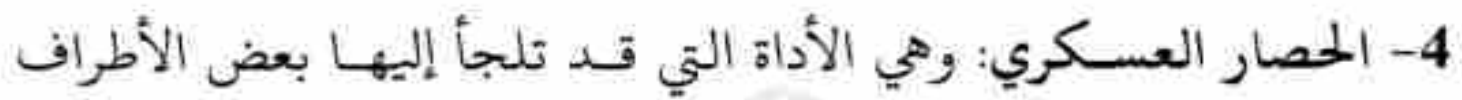

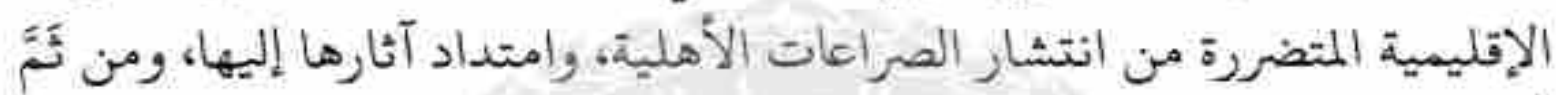

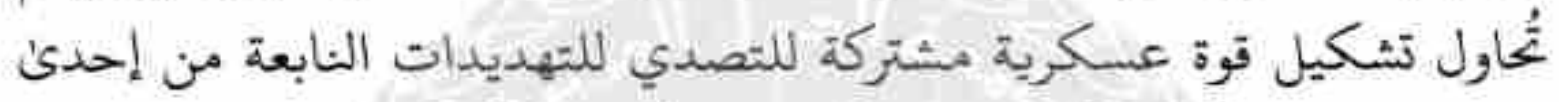

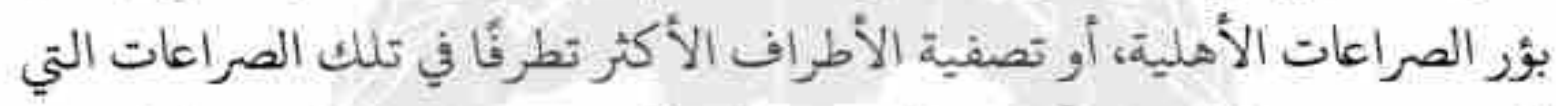

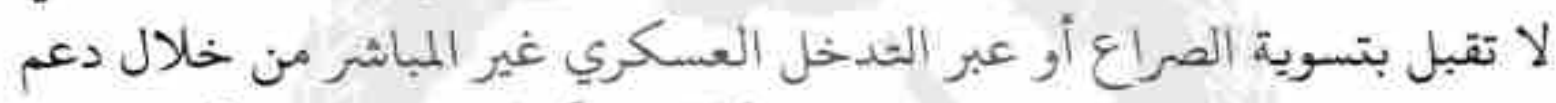

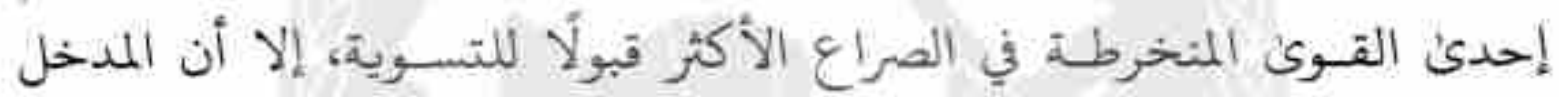

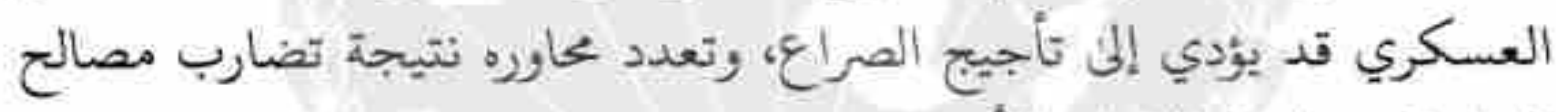

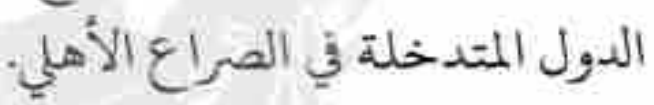

سادستا - مسـارات مستقبل الصراعات الداخليت وتمــدد التتظيمات

\section{الإرهابيت في الوطن العربي:}

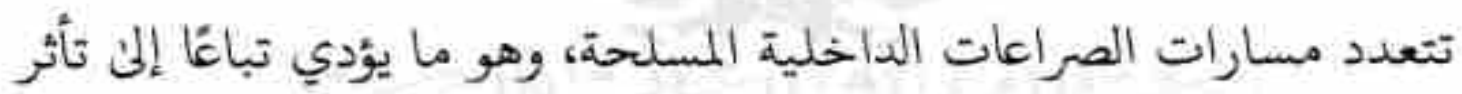

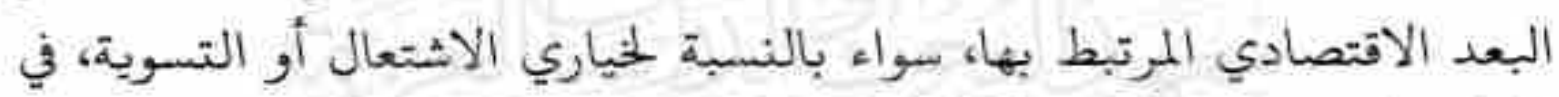

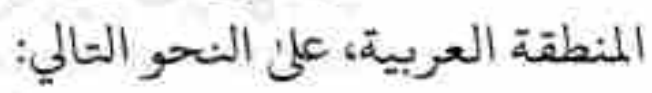

"مسار الفوضي: يرئ هذا المسار استمرار تصاعد وتيرة الصراعات

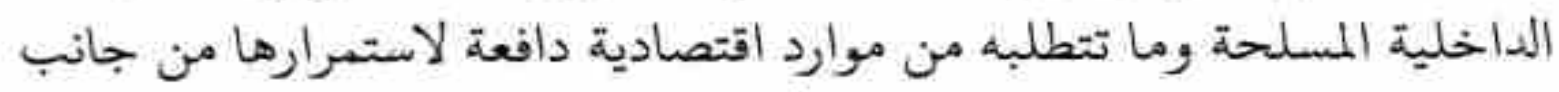

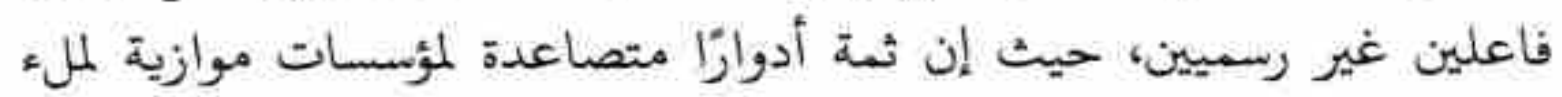

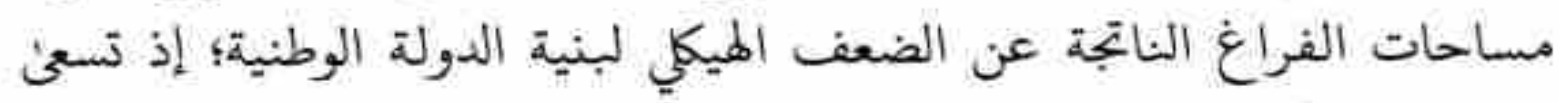

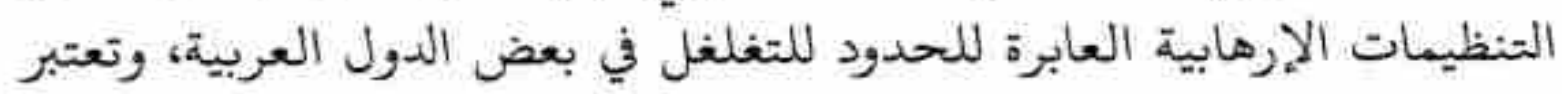


نفسها خيارات بديلة لغياب السلطة المركزية الموحدة، وتفرض قوانينها الخاصة

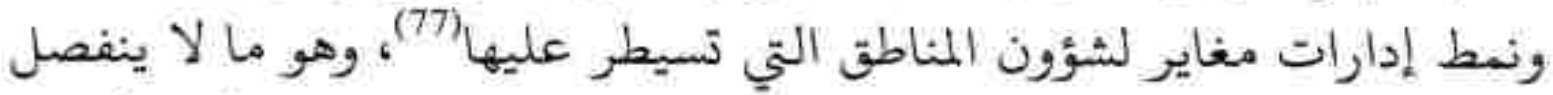

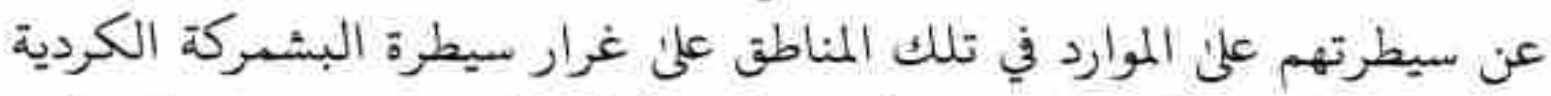

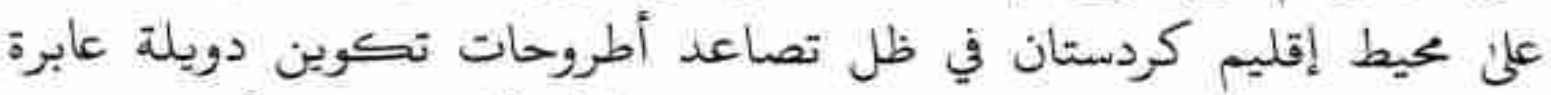

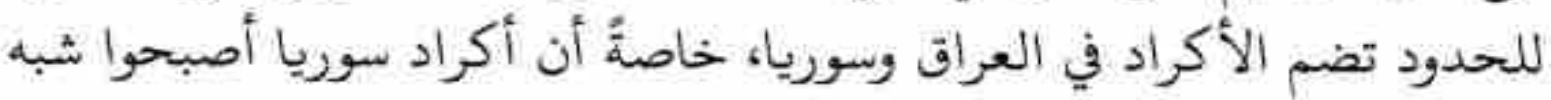

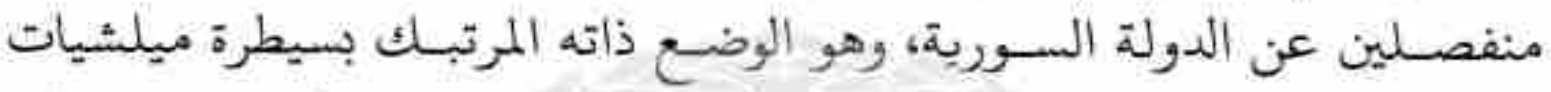

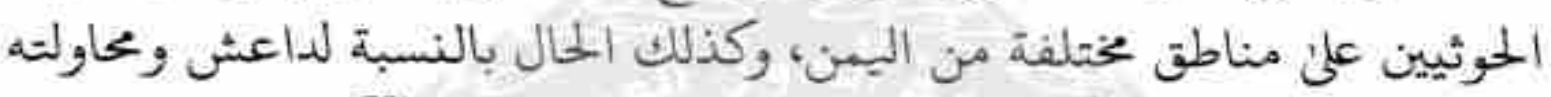
تأسيس دويلة ممتدة الأطراف عبر الحئ مندود السورية العراقية (78).

فقد برزت نسخ كل من تثظيمي داعش والقاعدة بما هدف إلى إسقاط

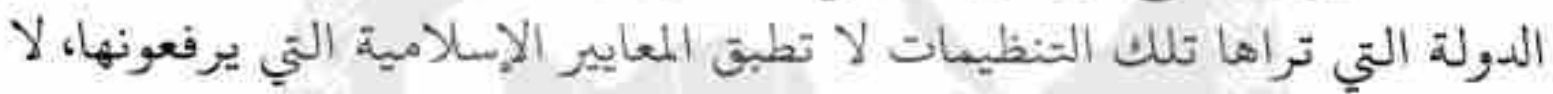

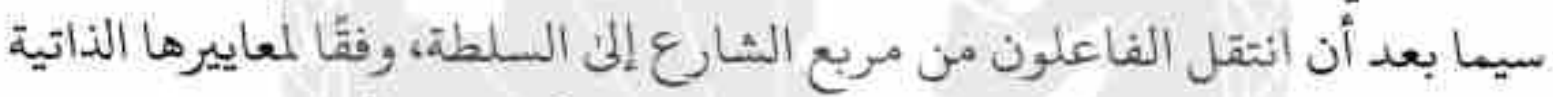

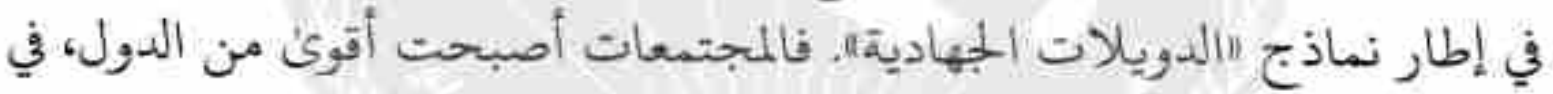

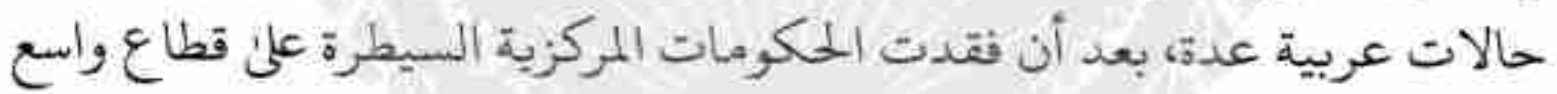

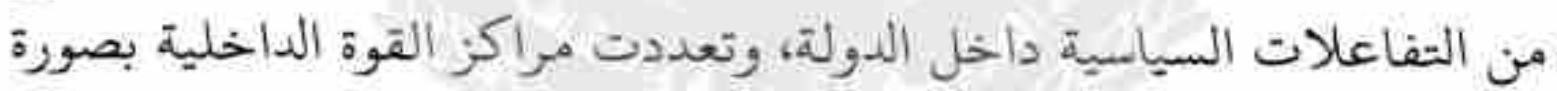

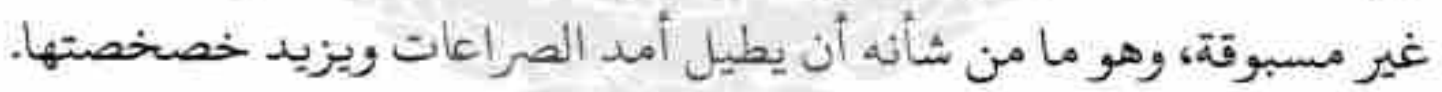
ويرتبط ذلك بتضخم ميزانيات الفاعلين المنخرطين في هذه الأنماط

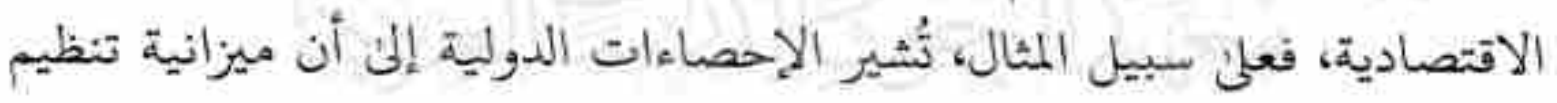

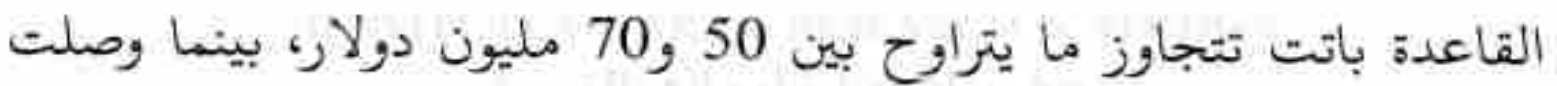

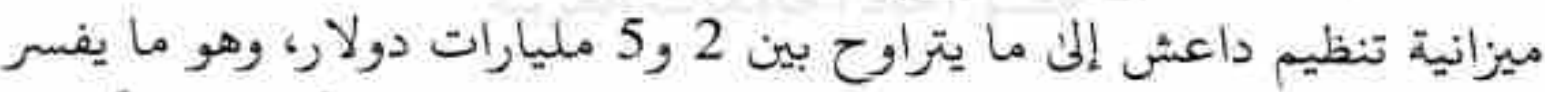

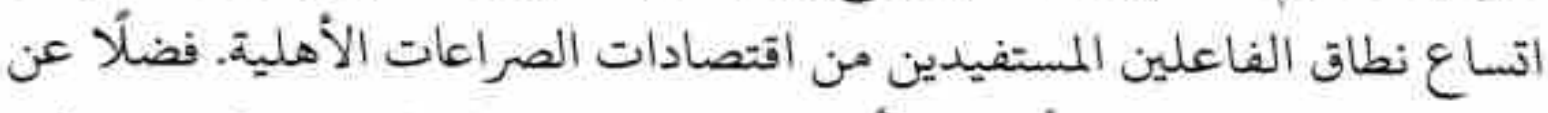

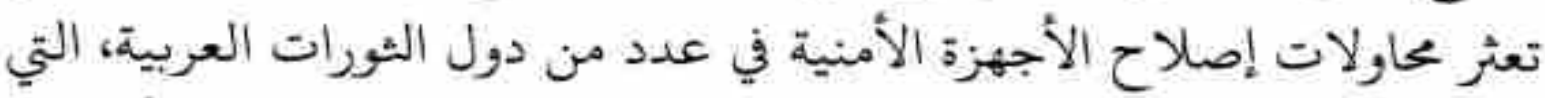

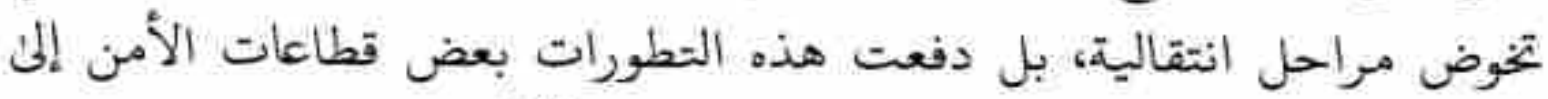
التورط في الفساد والتواطؤ مع الشبكات الإجرامية (79). 
* مسار الهشاشة: ينطلق هذا المسار من تحول الصراعات في العديد من

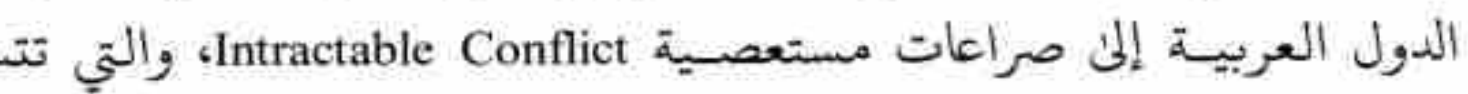

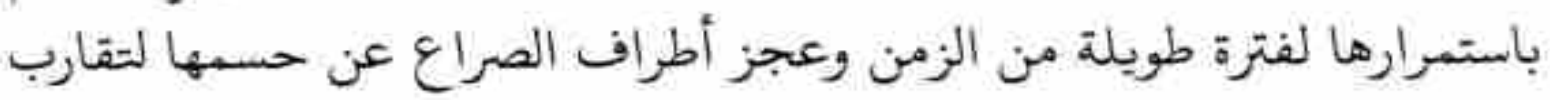

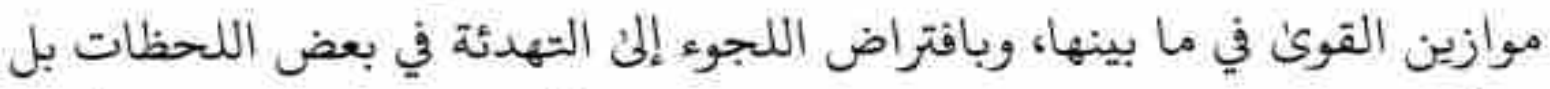

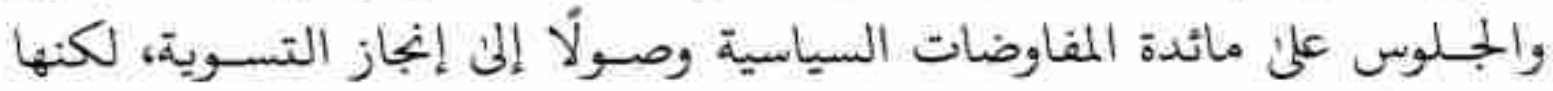

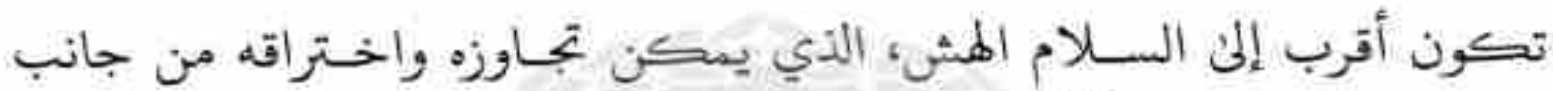

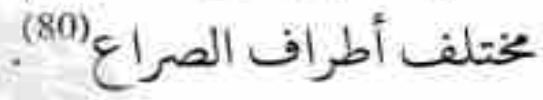

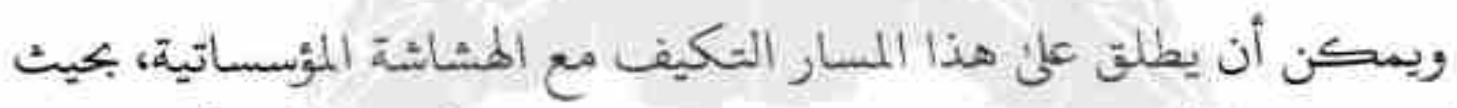

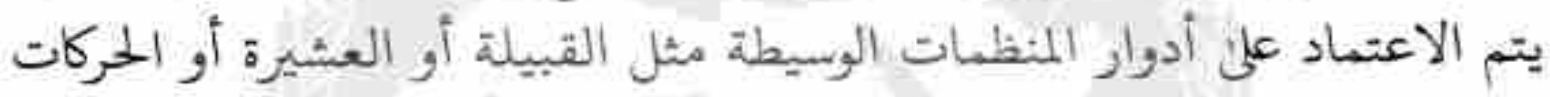

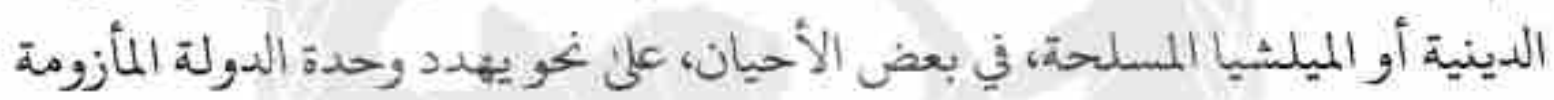

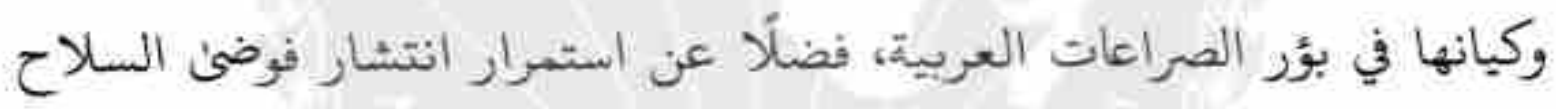

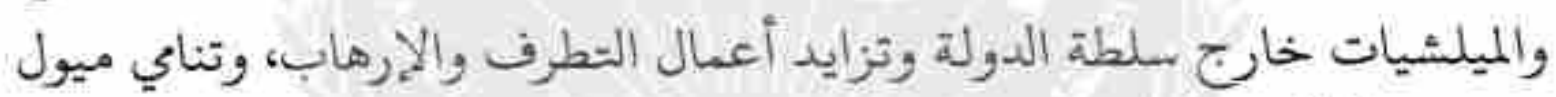
الانفصال (81).

* مسار الاستقرار: يحدث عندما يدرث أطراف الصراع عدم القدرة علئ

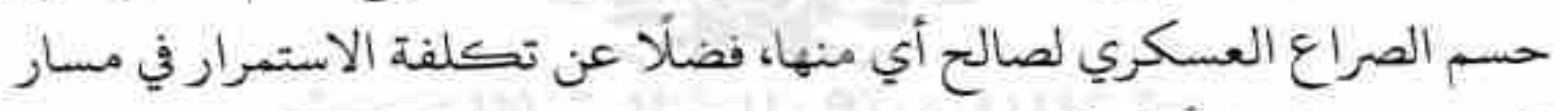

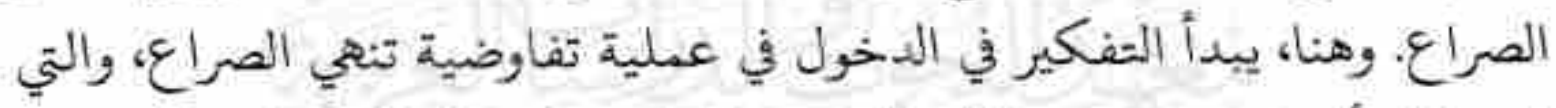

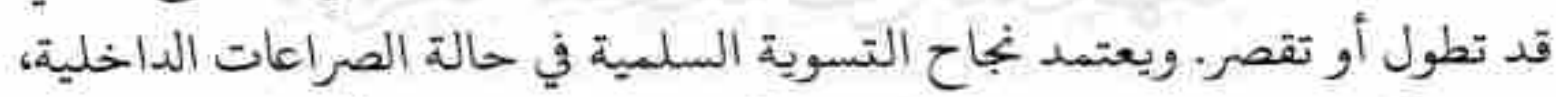

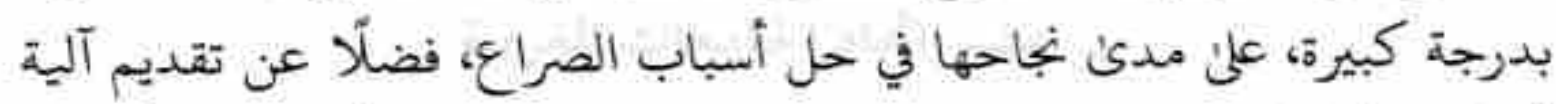

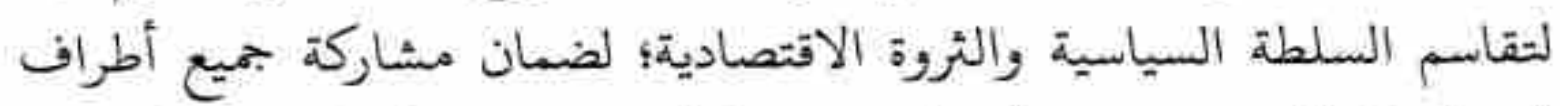

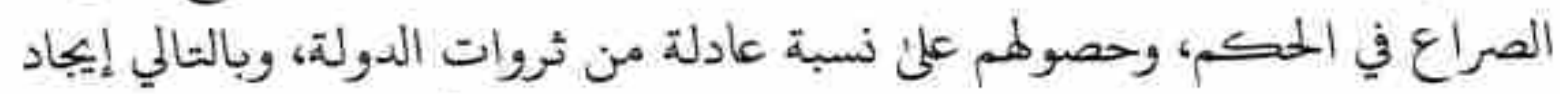

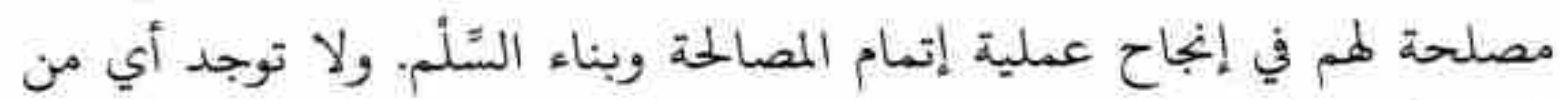

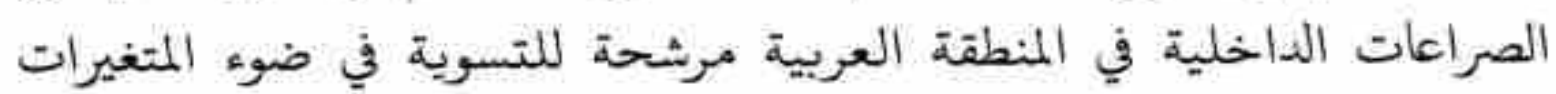


الراهنة، بل أصبح انعدام الأمن هو الملمج الحاكم في غالبية الدول العربية التي مرت بحرالـ عنيف (82).

ويفترض هذا المسار أن النظم اللهاكمة في بعض الدول العربية تسعنى

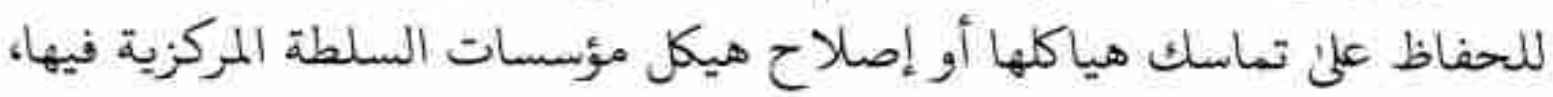

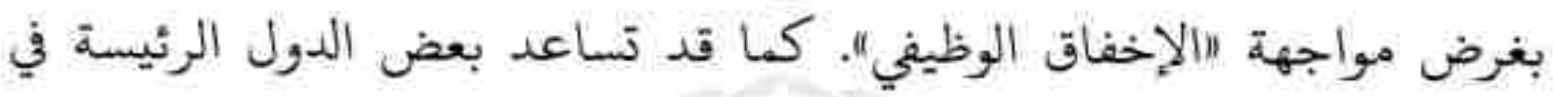

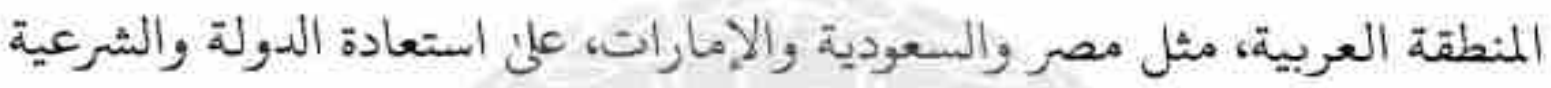

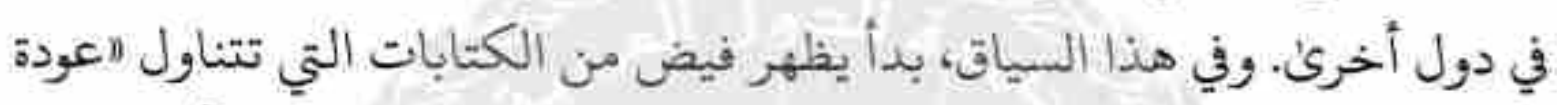

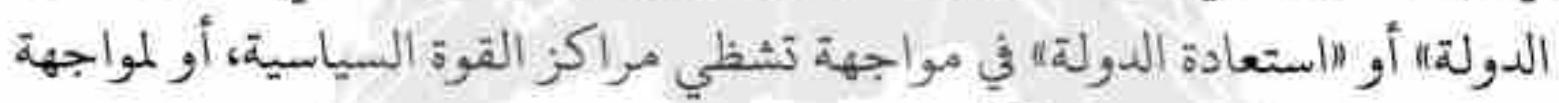

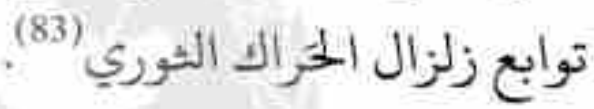
خلاصة القول: إن المسار المرجح لواقع الصراعات الذاخلية المسلحة العربية،

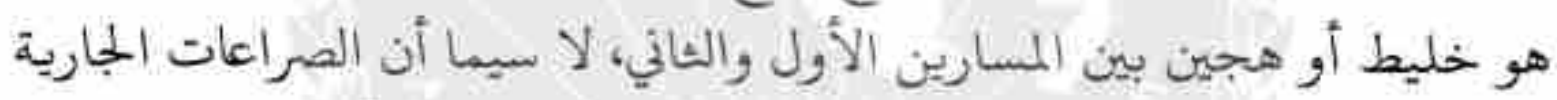

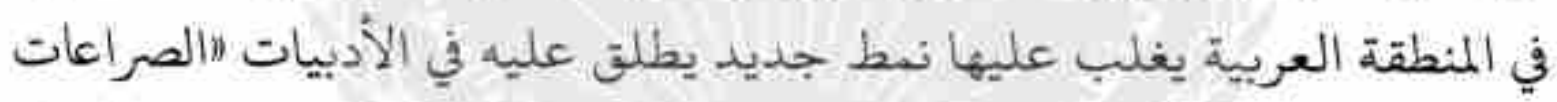

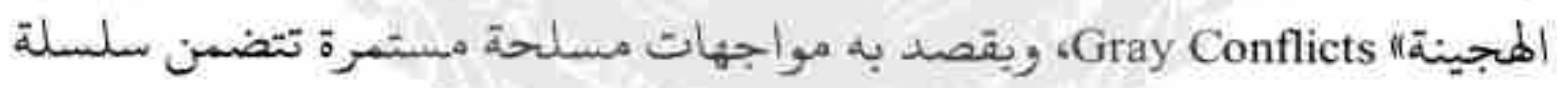

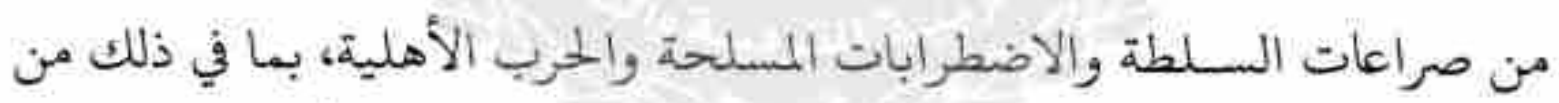

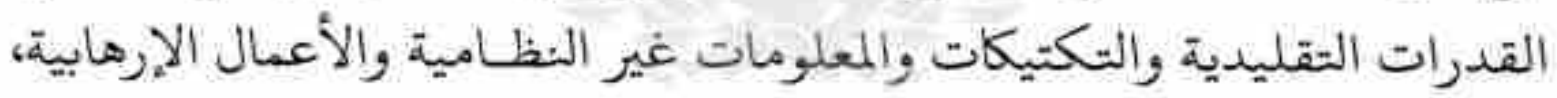

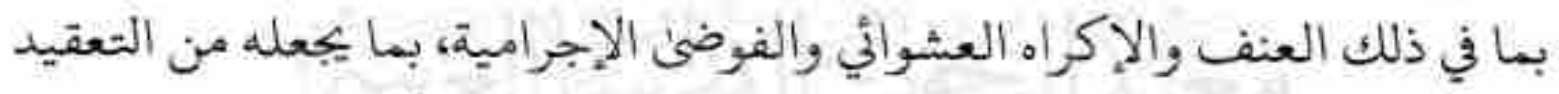

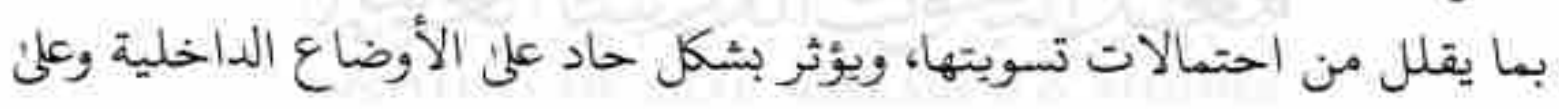

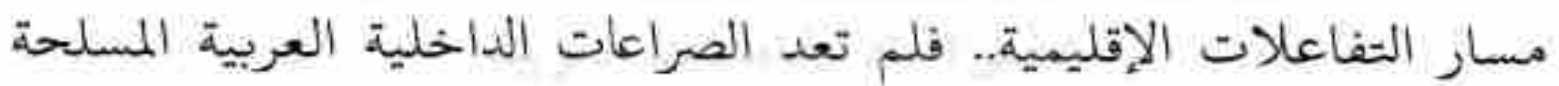

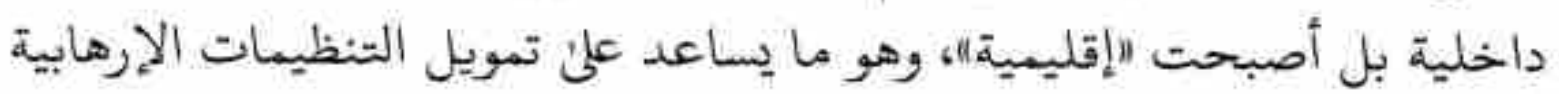

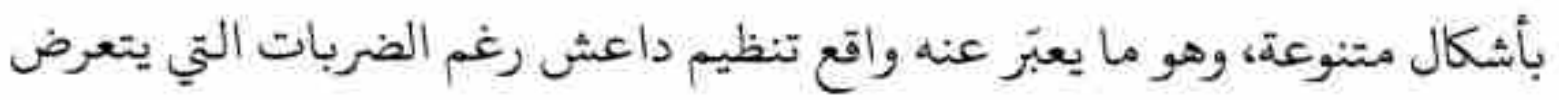
لها في مناطق نفوذه الرئيسة.

* 


\section{الهـوامش - اث}

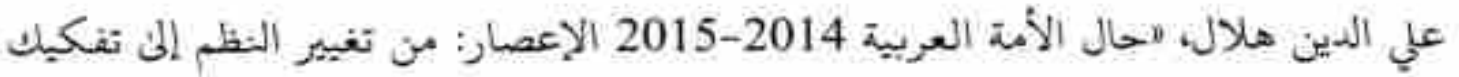

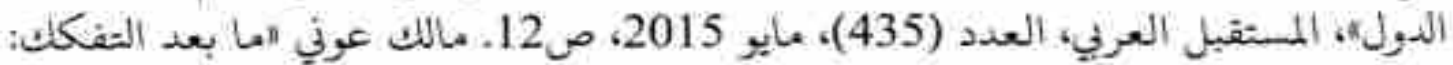

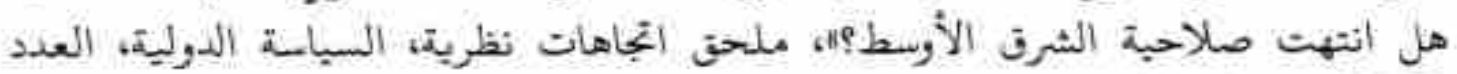

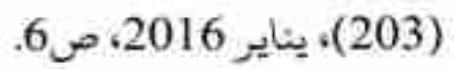

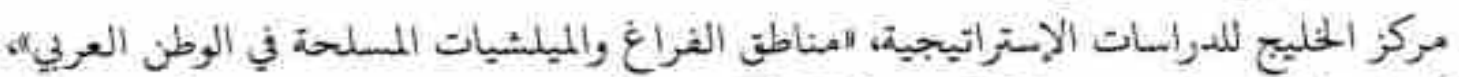

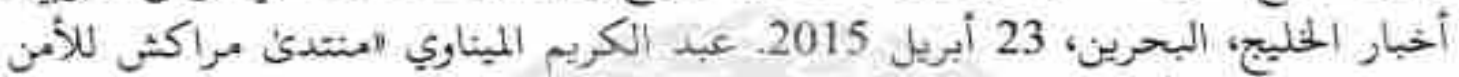

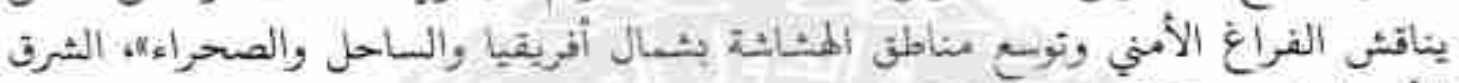
Micheal Hudson, The crisis of the Arab States, الأوسط، لندن، 25 يناير 2014 (Washington: Belfer Center for Studies and International Affairs. February 2015).

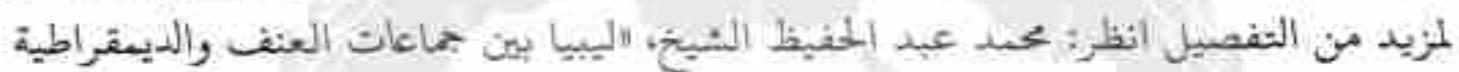

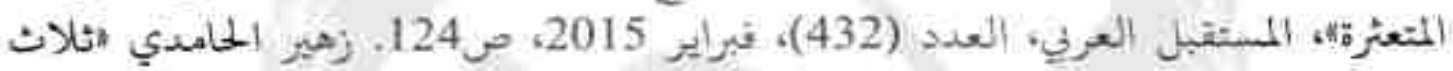

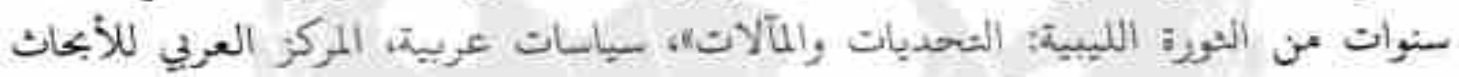

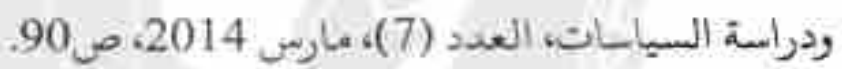

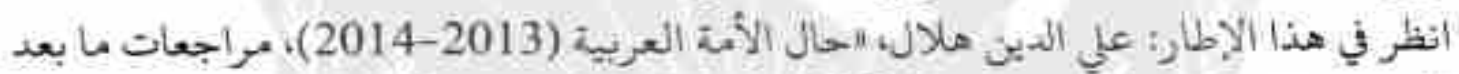

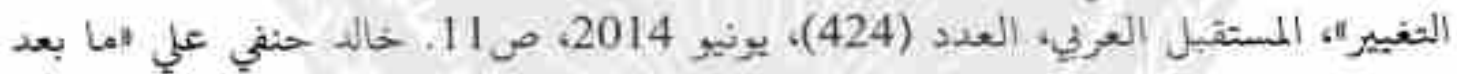

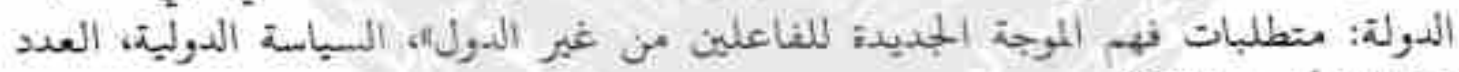
توارن

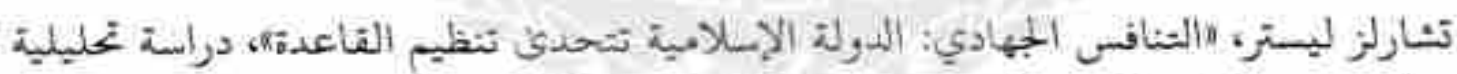

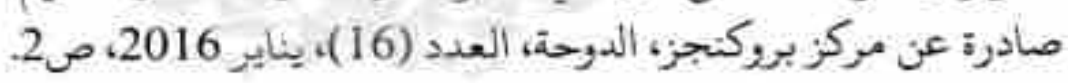

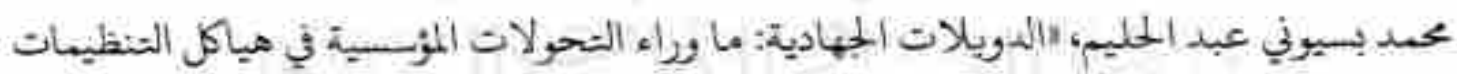

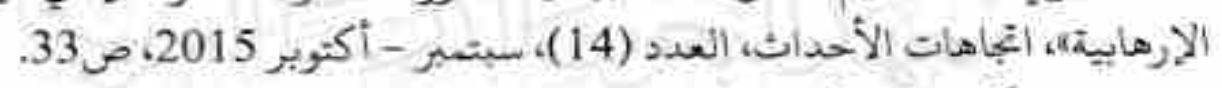

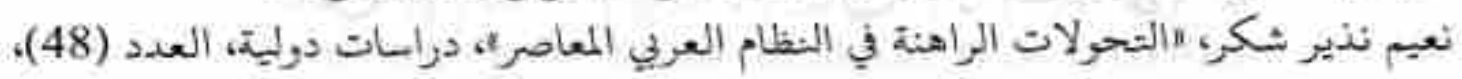

$$
\text { 39.2011 }
$$

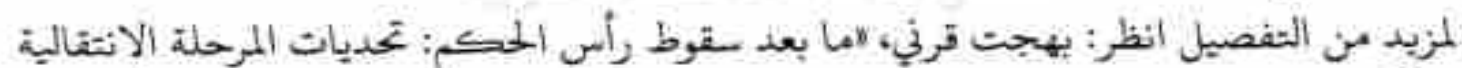

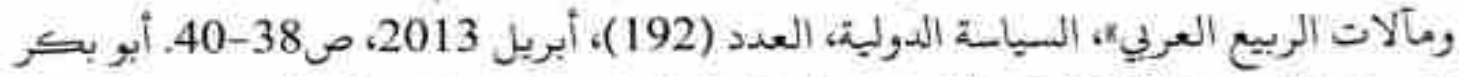

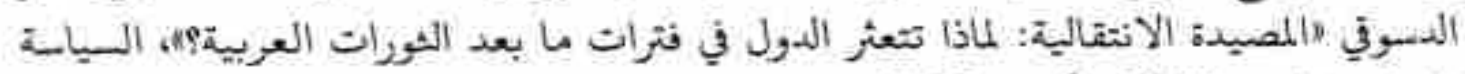

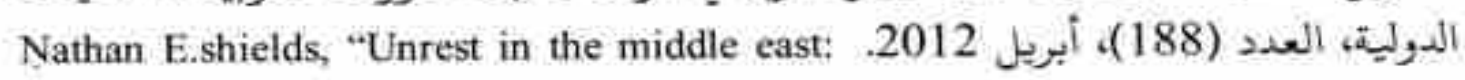
potential implication for international terrorism and counterterrorism policy",

Global Security Studies, volume 3, issue 2, Spring 2012. 


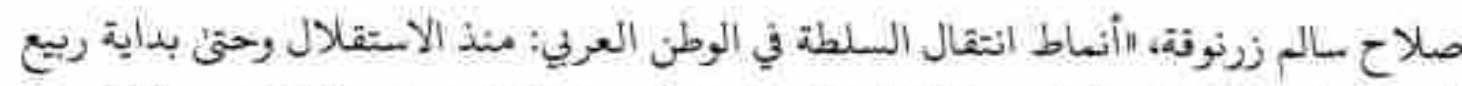

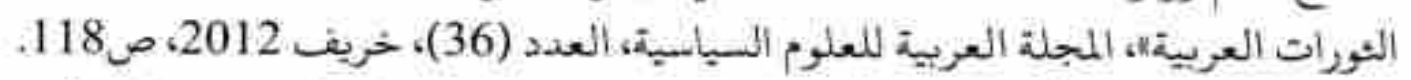

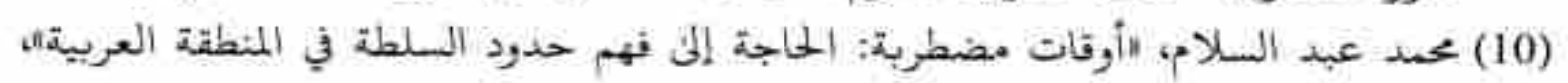

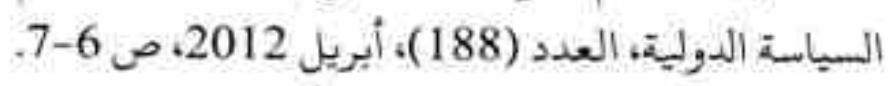

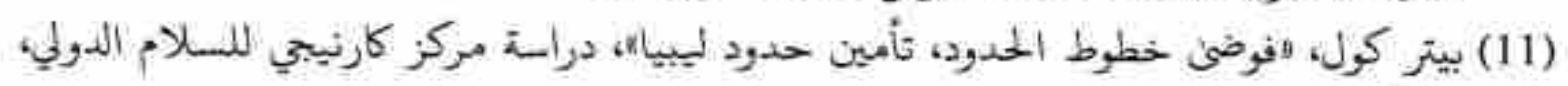
12

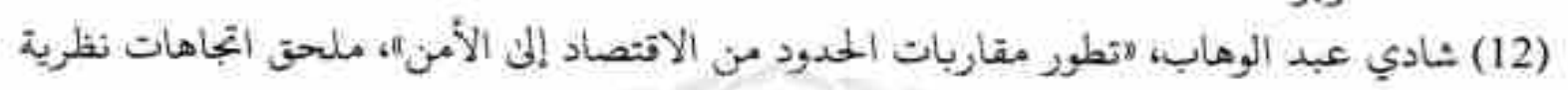

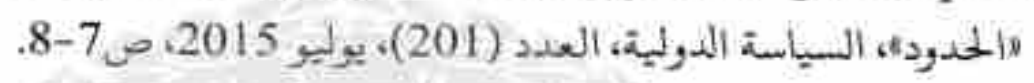

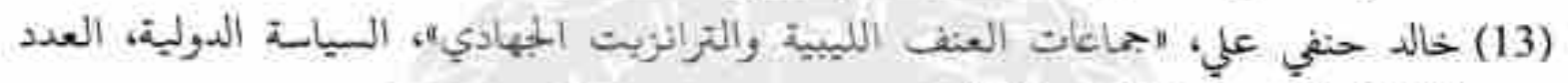

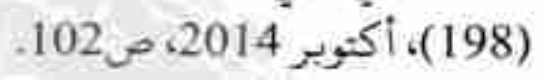

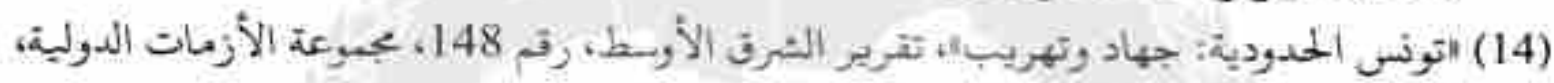

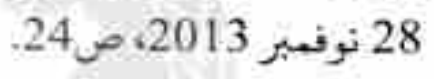

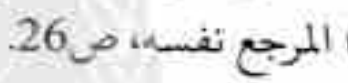

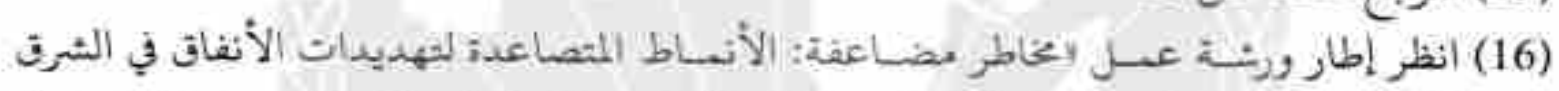

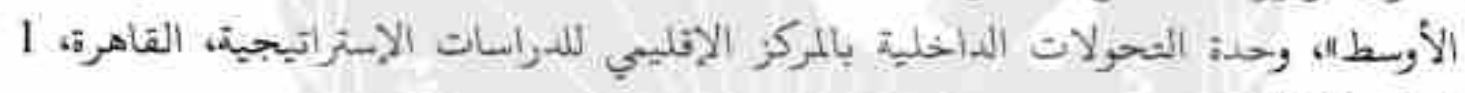

$$
\text { فبرابر } 2016 .
$$

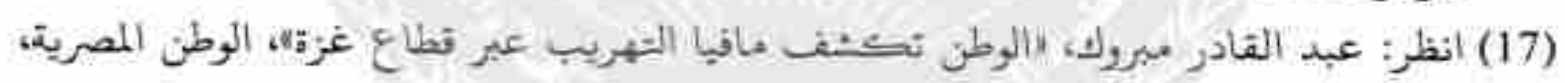

$$
11 \text { يوليو } 2015 .
$$

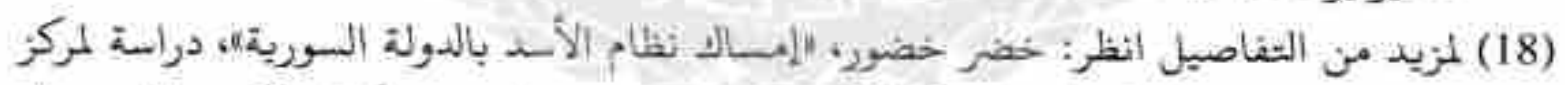

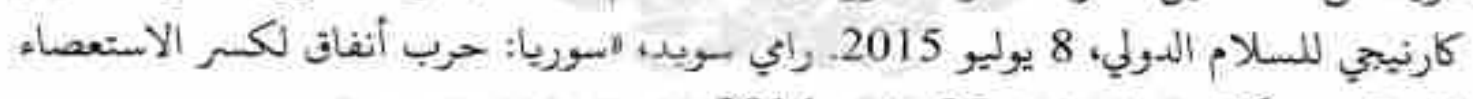

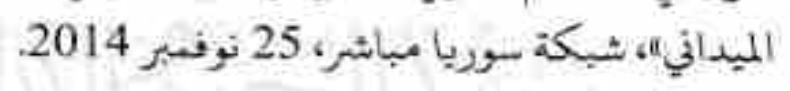

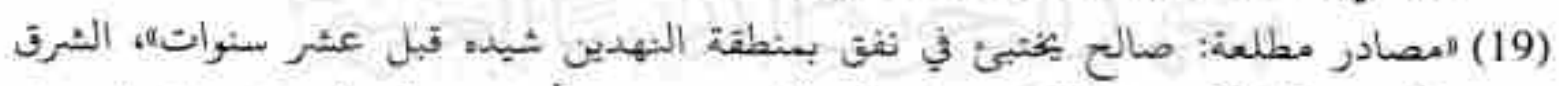

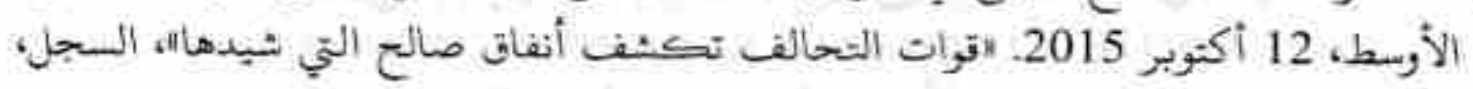
12 أكتوبر 2015

(20) "ابالصور.. اللحوثيون يكفرون نفقًا تحت مبتئ السفارة السعودية بصنعاءة، يمن 24، 17 مارس .2015

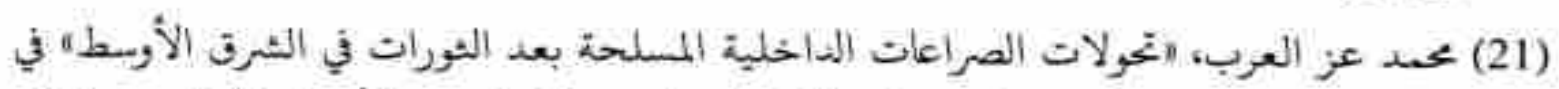

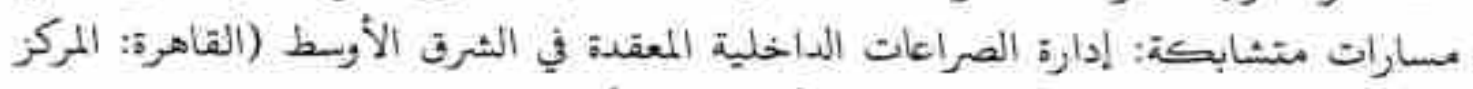

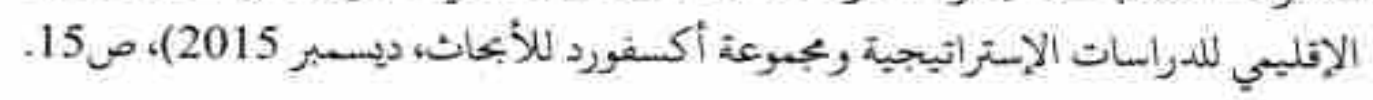




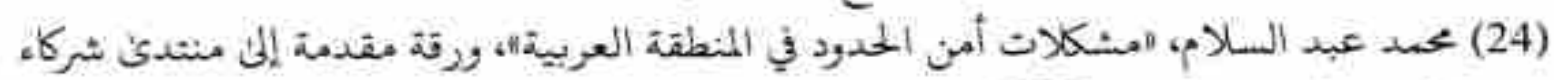

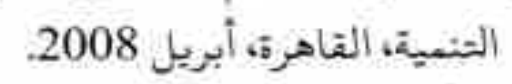

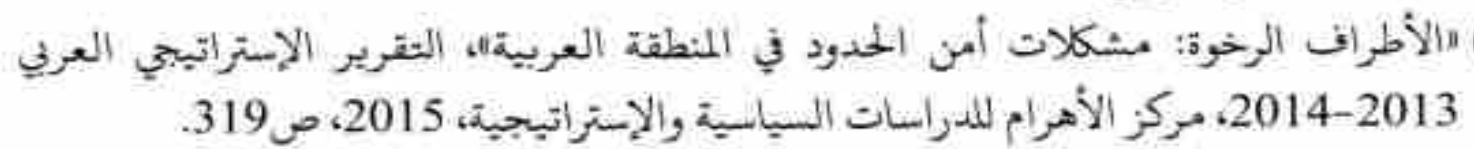

(26) Patrick M. Regan, «Interventions with civil war: A retrospective survey with prospective ideasm, Civil Wars, Vol.12, No.4, December 2010, p.458.

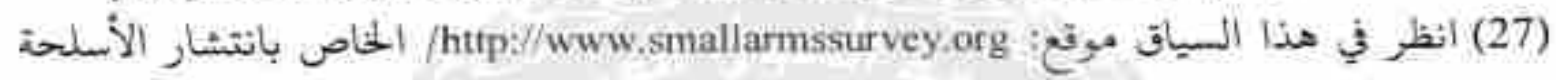

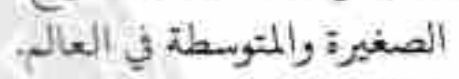

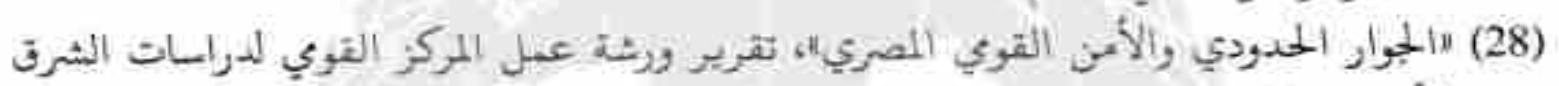

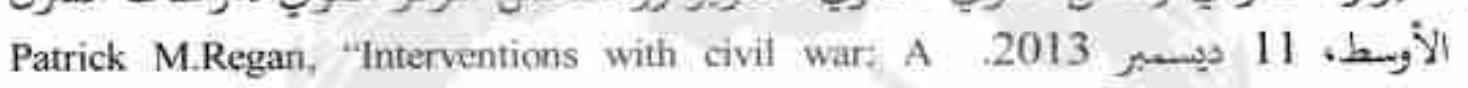
retrospective survey with prospective ideas". Civil Wars, Vol.12, No.4, December 2010.

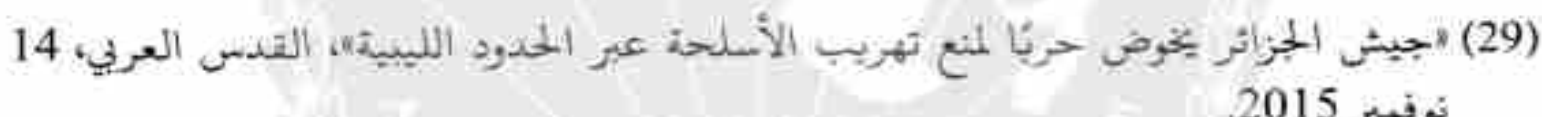
توفنبر 2015.

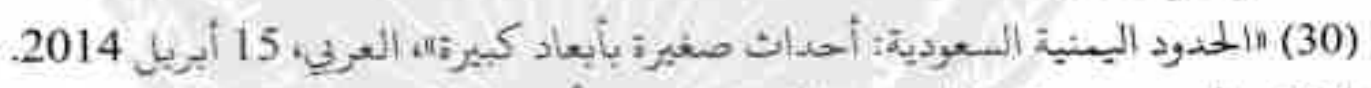

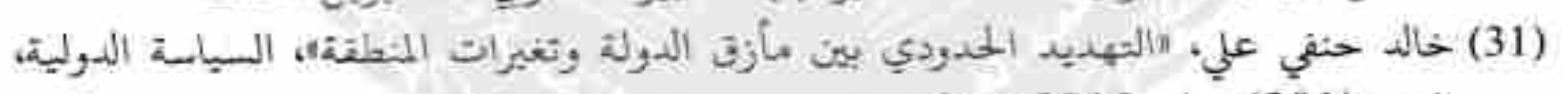

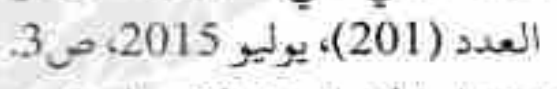

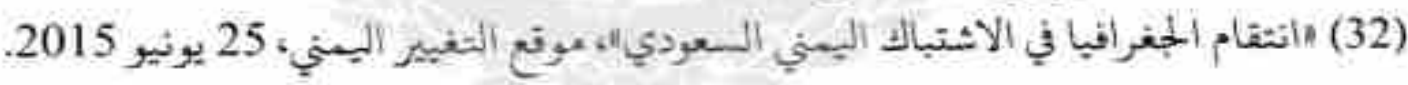
http://www.al-tagheer.com/art32321 html

(33) انظر في هذا المسياق تقرير عكتب الأمين العام للأفم المتحدة عن خدر انسفادة الإرهابيين من

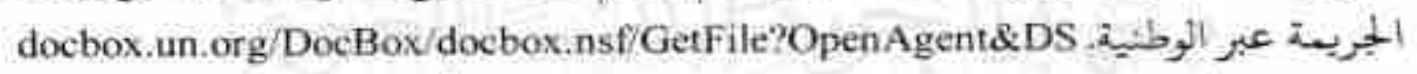

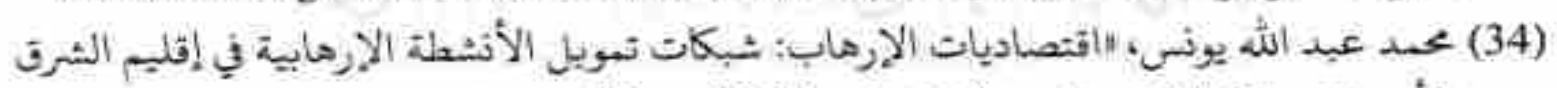

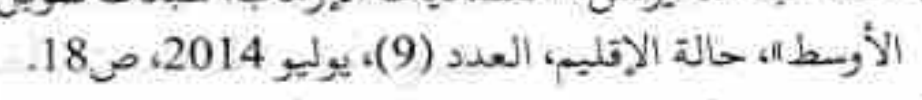

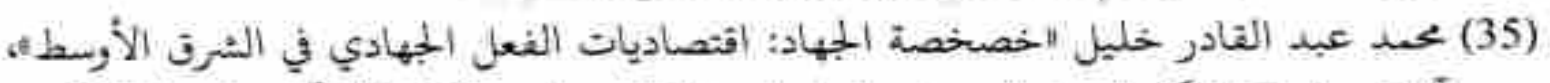

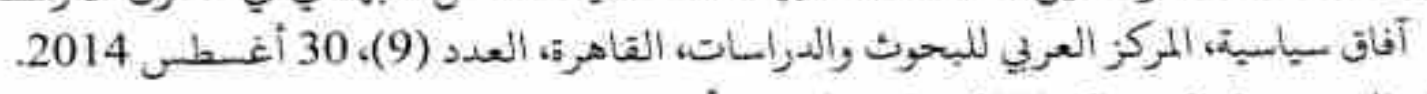

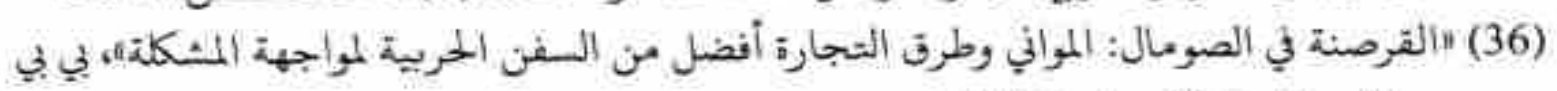

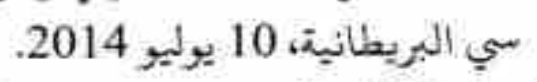

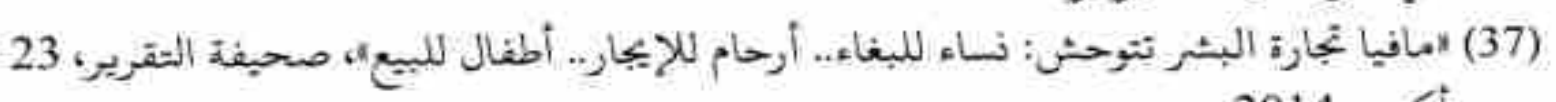

$$
\text { أكتوبر } 2014 .
$$




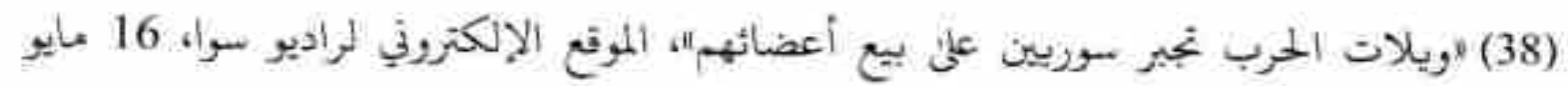
2016

(39) الاداعش عن النفط إلى الرأس وبينها الحبل السبريه، رويترز، 18 فبراير 2015، علاء حلبي

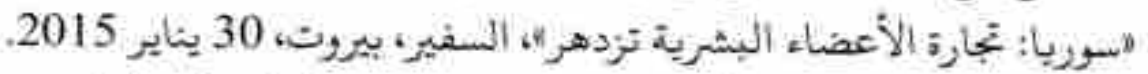

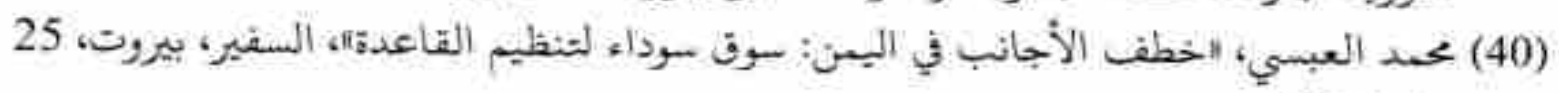

(41) توم كيتنج أقتصاد الجهاد: كيف تجني الجهاعات المتطرفة الأموالهبه، راقب، 11 ديسمبر 2014

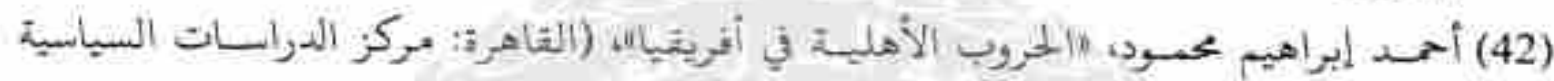

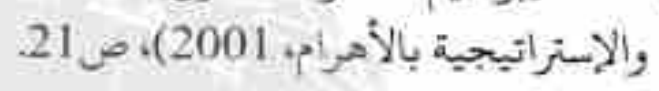

(43) Marc R. Roseblum, Jerome P. Bjelopera \& Kristin M. Finkleg,» Border secutity: understanding threats at US borders, Congressional Research Service, 21

February, 2013, p8-9.

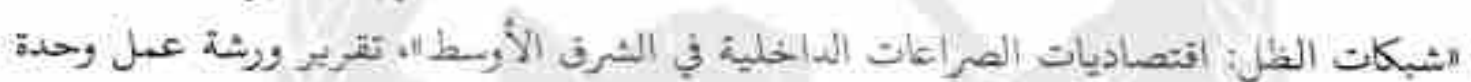

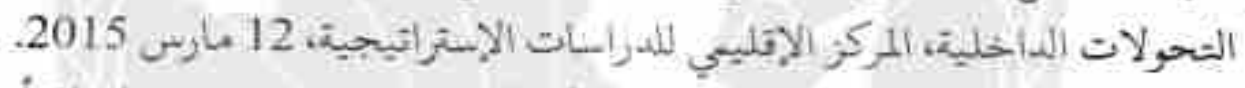

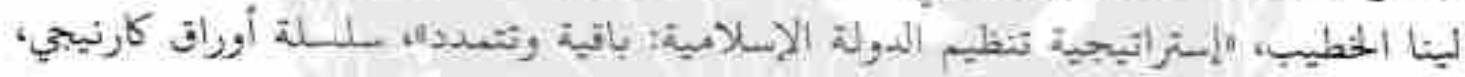

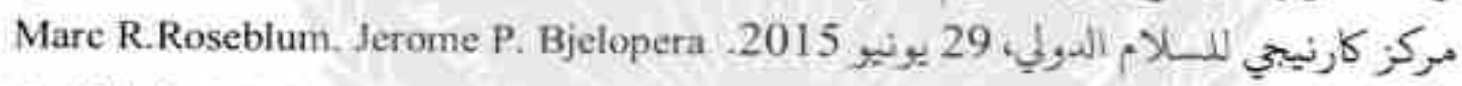

\& Kristin M.Finkleg," Border security: understanding threats at US borders",

Congressional Research Service 21 February, 2013.

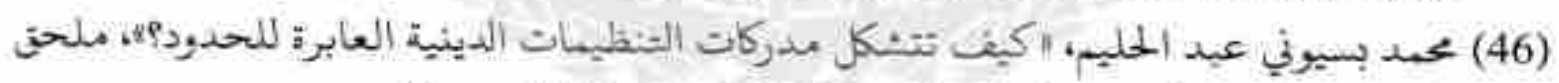

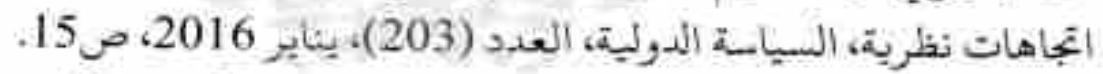

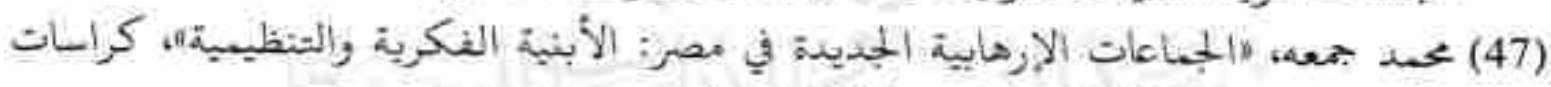

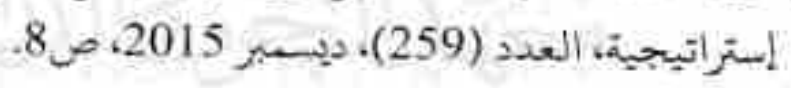

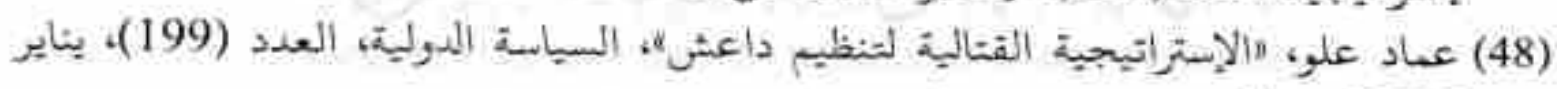

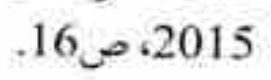

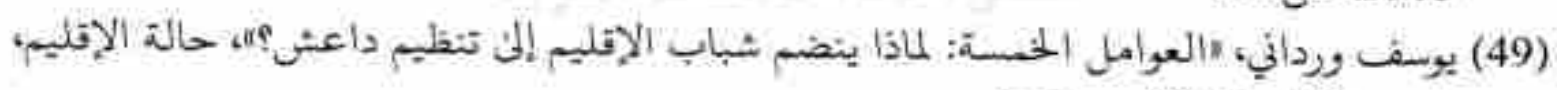

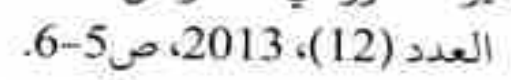

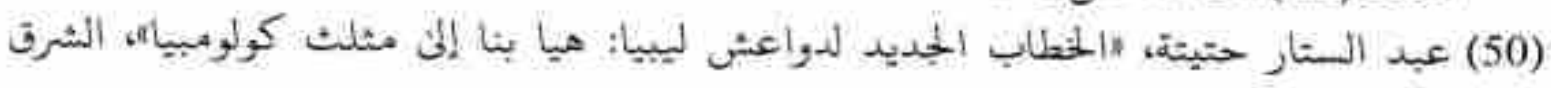

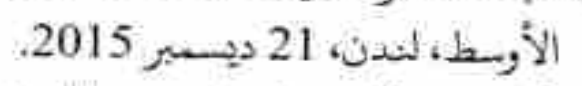

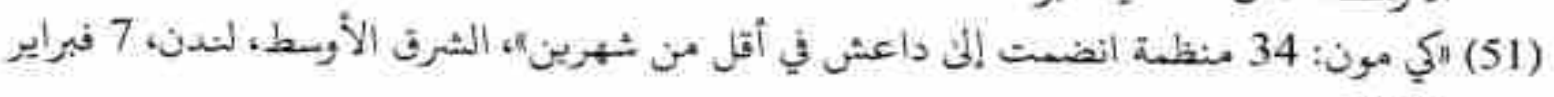




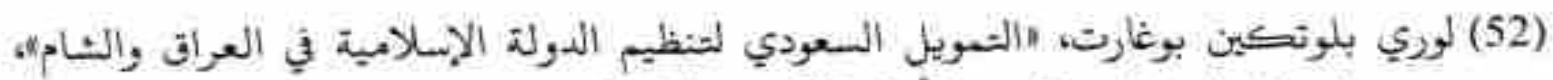

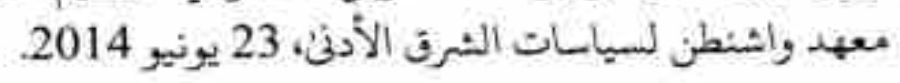

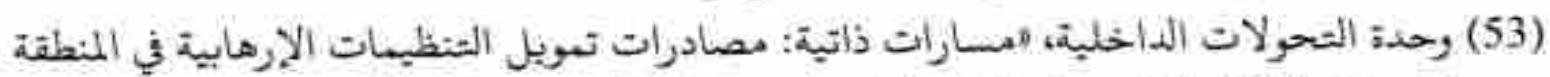

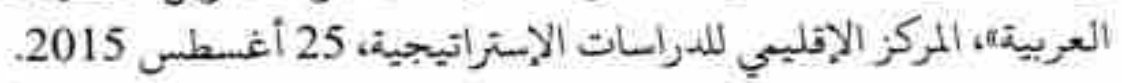

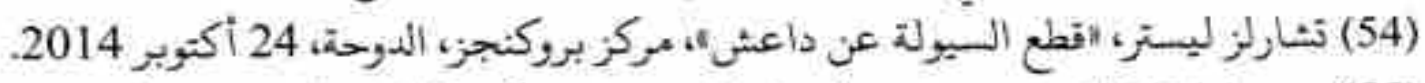

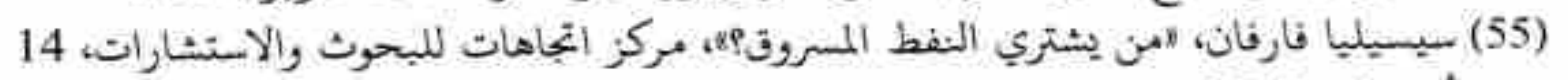
أغسطس 2015.

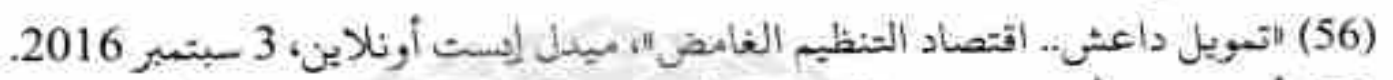

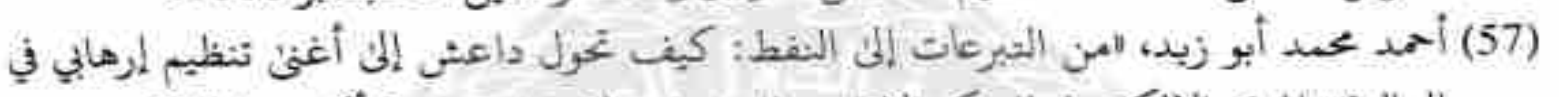

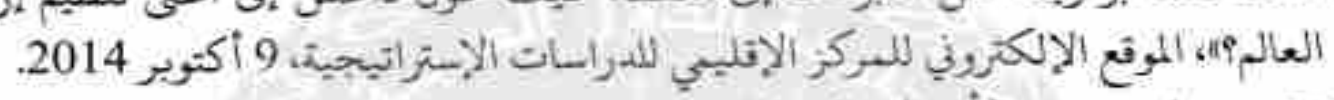

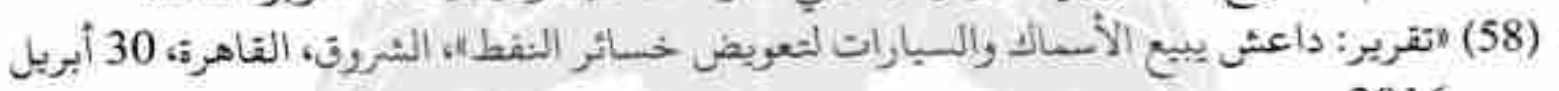
2016

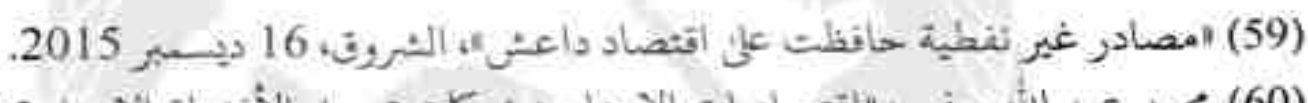

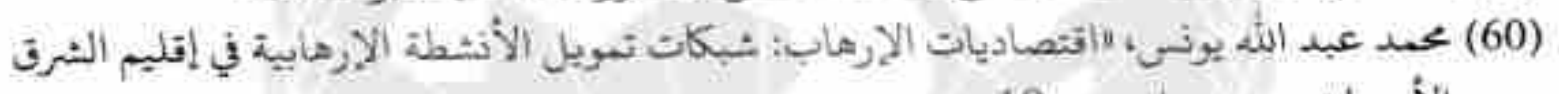

$$
\begin{aligned}
& \text { الأوبسط ال، مرجع سابن، ص } 19 .
\end{aligned}
$$

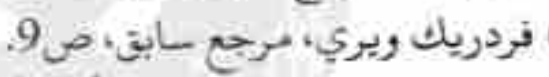

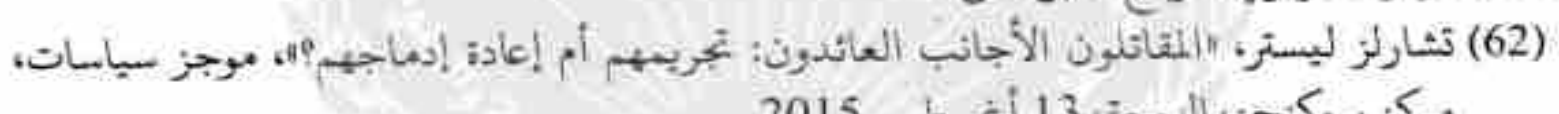

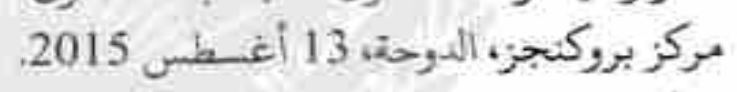

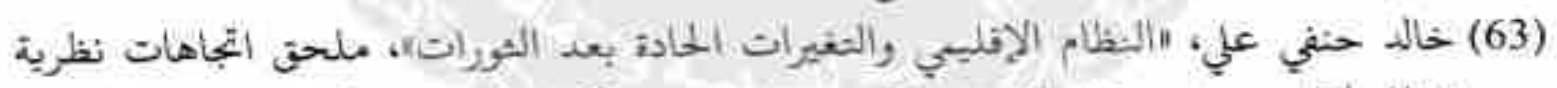

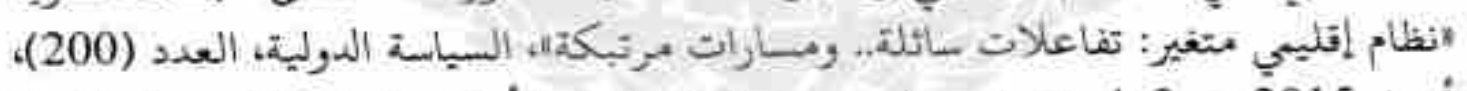

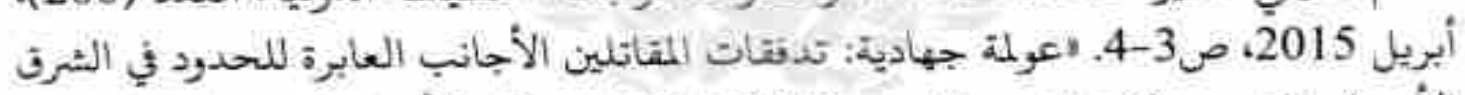

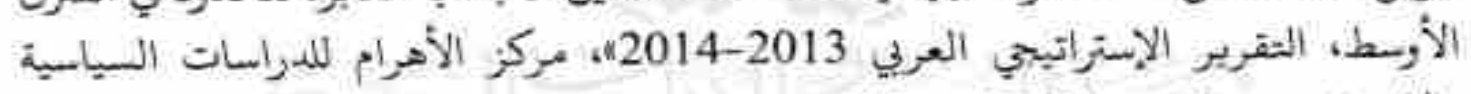

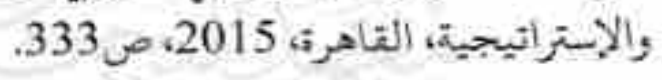

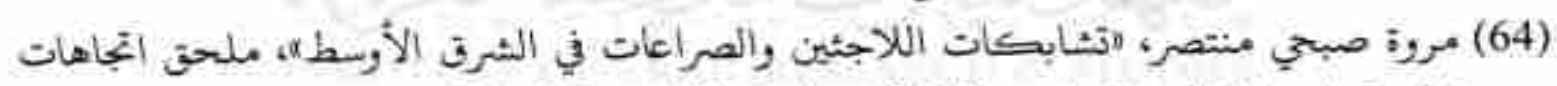

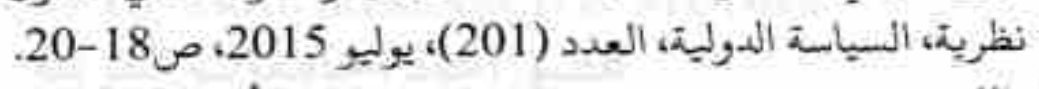

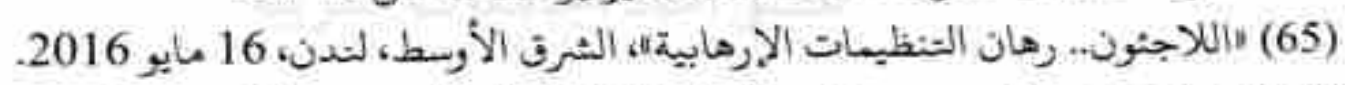

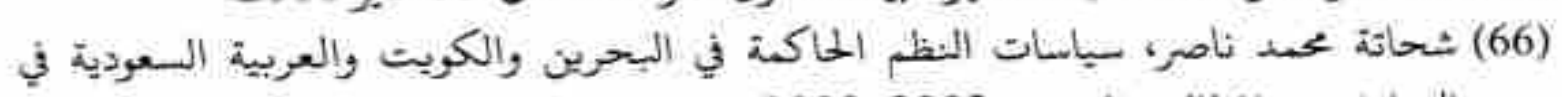

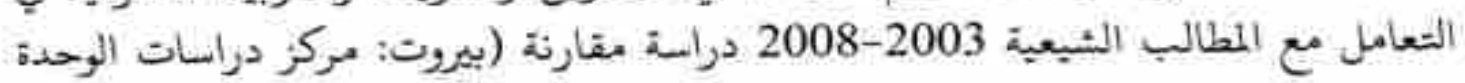

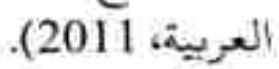

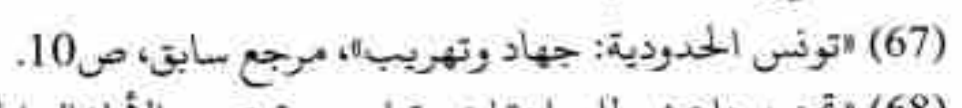

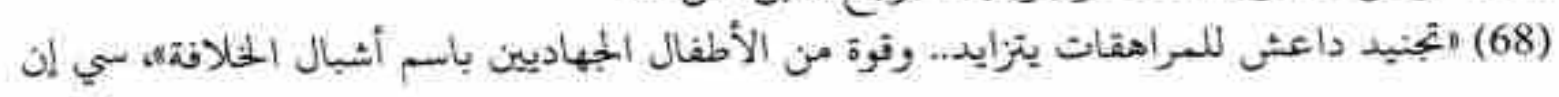


إن عري، 25 فبراير 2015. صفاء عزب بأشبال الخلافة. جيل جديد من الإرهابيين في مدرسة داعشى، مجلة المليج، 24 يوليو 2015. (69) مصطفئ الطرهوني، اططيور الظلام تنغذئ على أكباد الأطفال في الحروبا، المديثة، 6 مايو 2014 (70) أممد زكريا الباسوسي، لالمقاتلون الأشبال: تحديات انتشار نمط الجنود الأطفال في دول

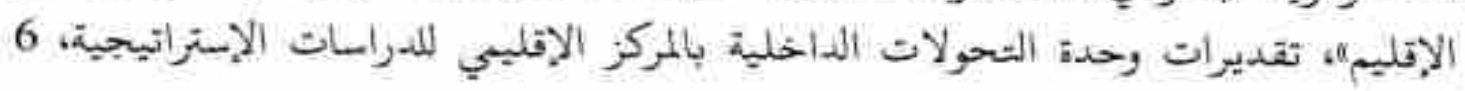

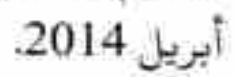
(71) لوري بلونكين بوغارت، رألانقطاع عع قطر والكويت بثأن تموبل الإرهاب، معهد واشنطن

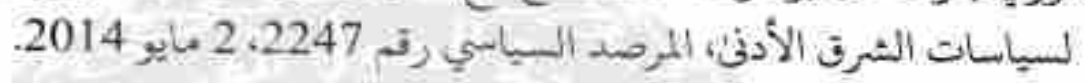

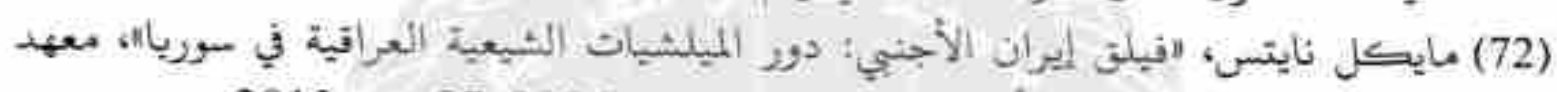

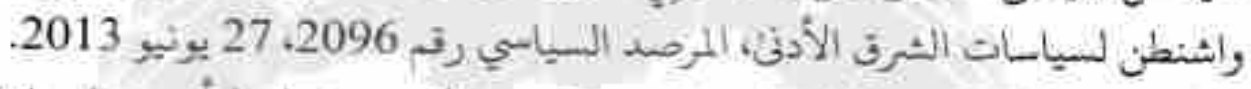

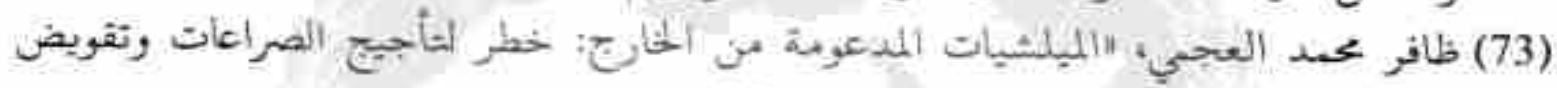

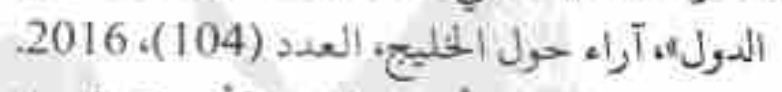

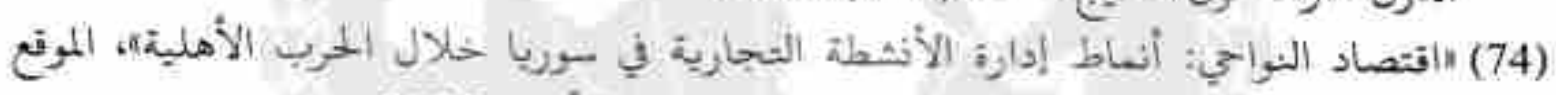

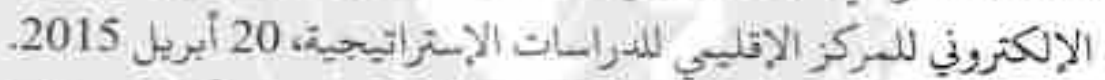

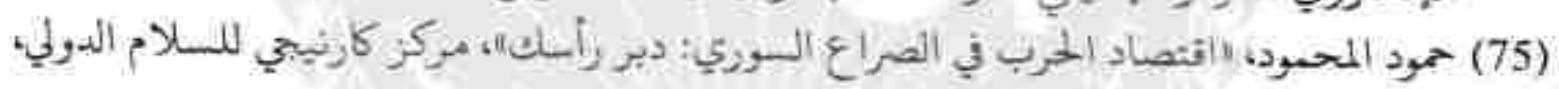
23 يوليو 2015.

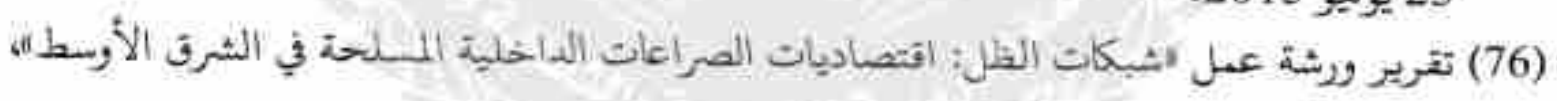
مرجع سابق.

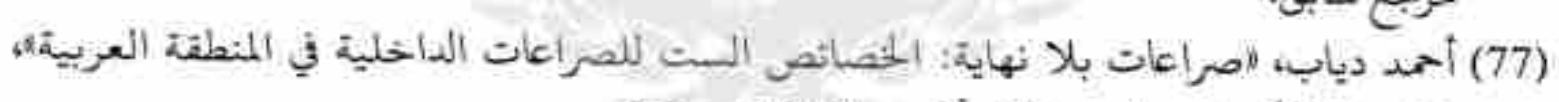

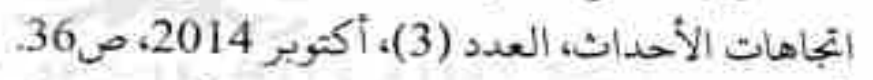

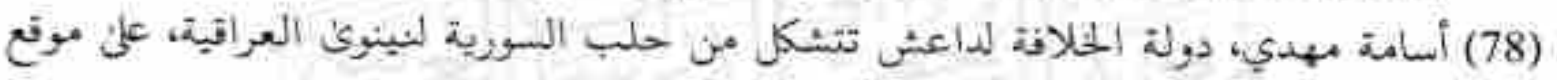
http://elaph.com/Web/News/2014/6/912556.html

$$
\text { إيلاف الإخباري، على الرابط الإلكتروني الثالي: }
$$

(79) يزيد صابغ، امعضلات الإصلاح: ضبط الأمن في المراحل الانقالية في الدول العربيةلا، دراسة

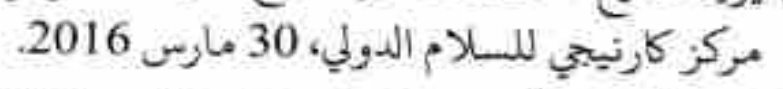

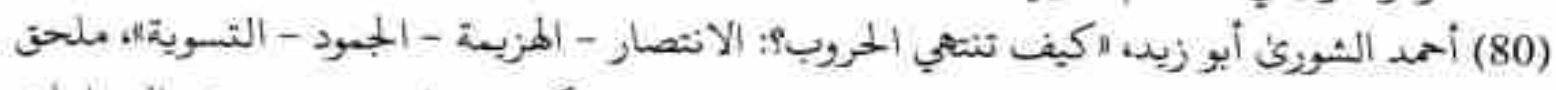

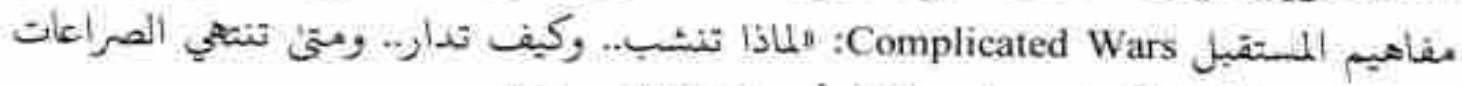

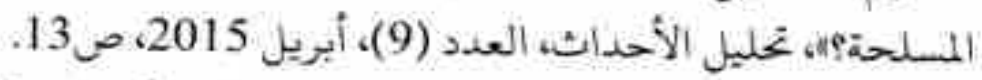
(81) "المجتمع المدني والصومال: تحديات الفراغأ، الاتحاد، أبو طبي، 21 يونيو 2013. 


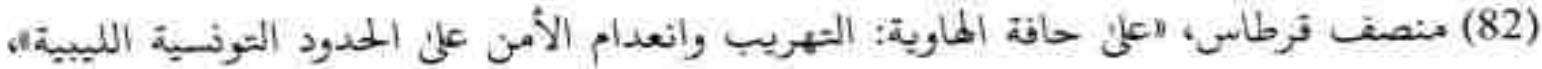

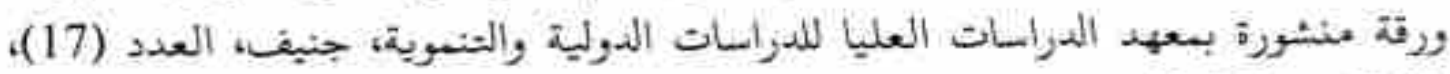

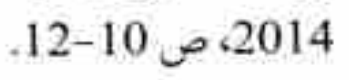
(83) محهد عبد الله يونس، "أستعادة الدولة: التجاه استرداد المسيادة في بعض الدول العربيةل، تحليل الأحداث، أبو ظبي، العدد (1)، أغسطي يون 2014. 


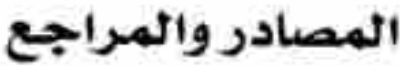

أولاً - باللفت العربيتةن

1' 1

1- أحمـ إبراهبم محسبود، مالحروب الأهلية في أفريقيال، (القاهرة: مركز الدراسـات السياسية

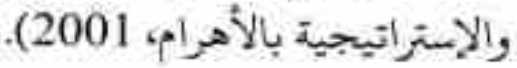

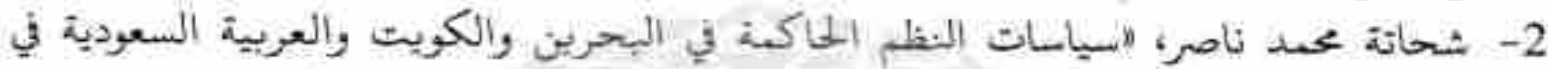

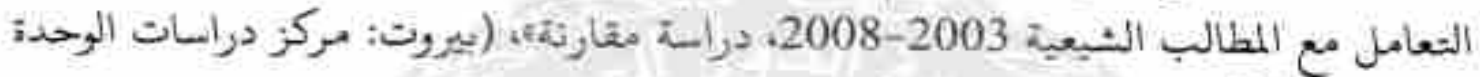

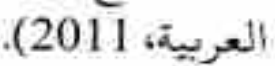

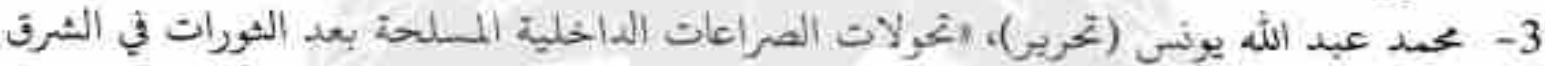

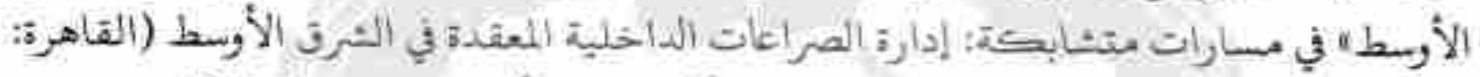

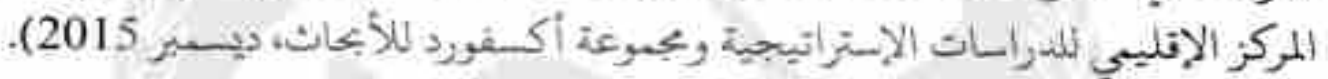

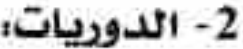

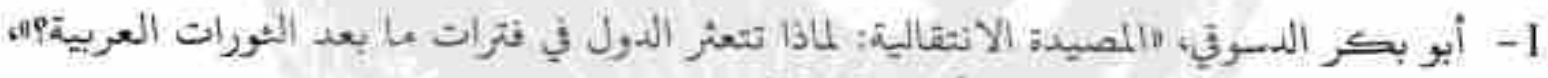

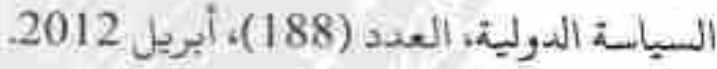

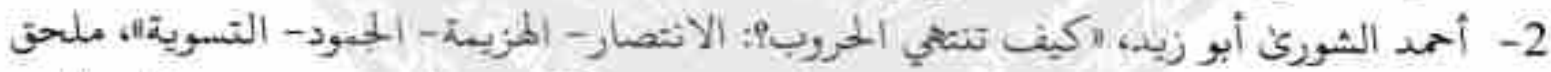

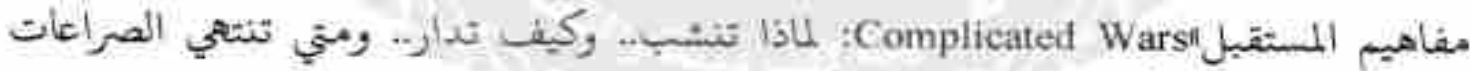

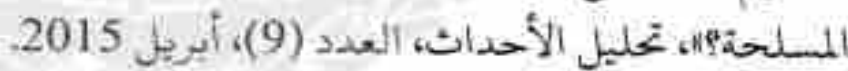

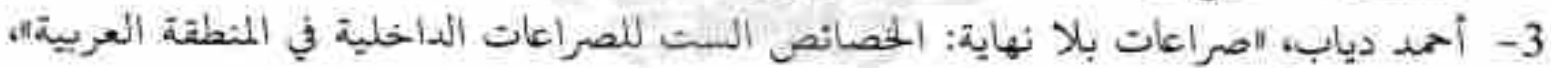
التجاهات الأحداث، العبد أعداب (3) ، أكتوبر 2014.

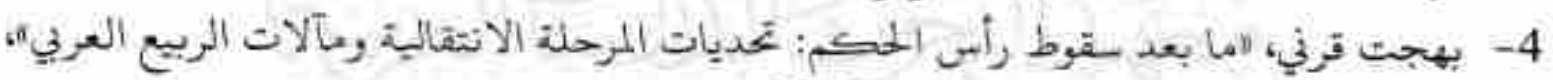

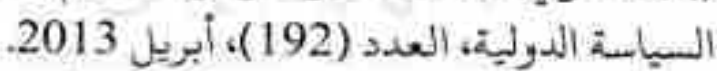

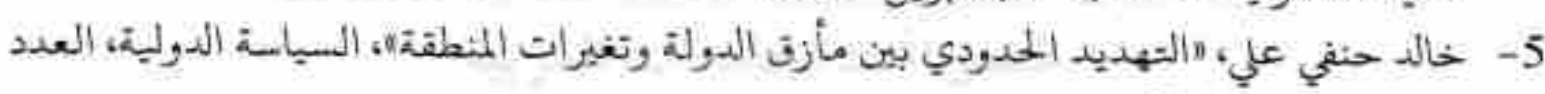
201)

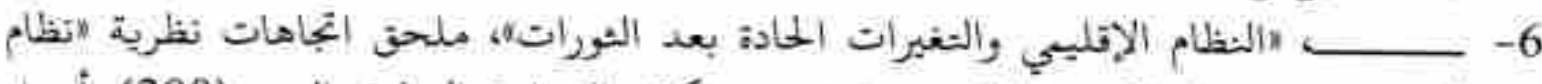
إقليبي متغير: تفاعلات سائلة. ومسارات مرتبكة، السياسة الدولية، العدد (200)، أبريل .2015 ، اجاعات العنف الليبية رالثراتزيت المهادية، البيابة الدولية، العدد (198)، $-7$ أكتوبر 2014. 


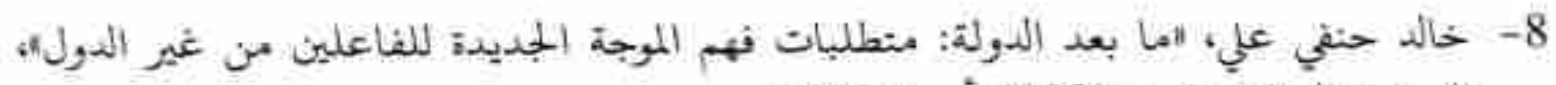

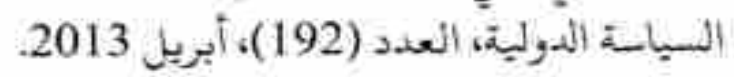

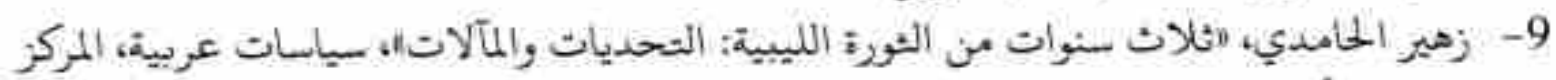

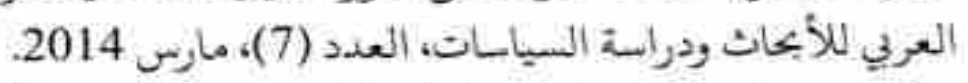

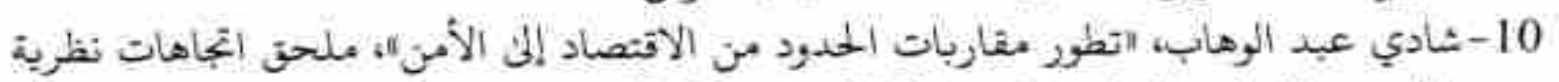

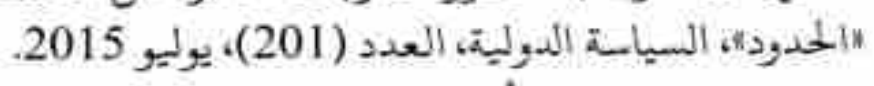

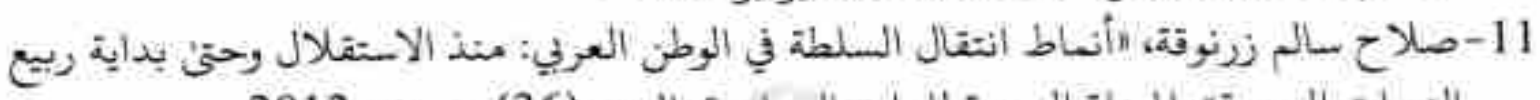

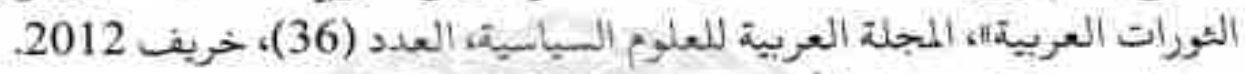

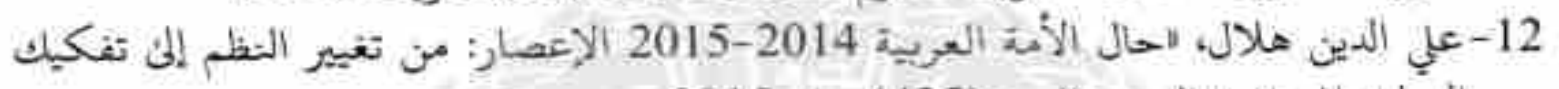

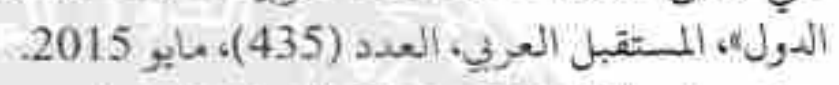

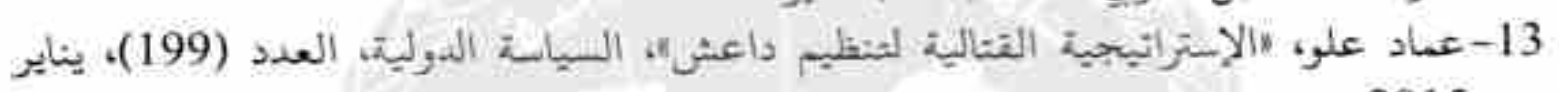
2015

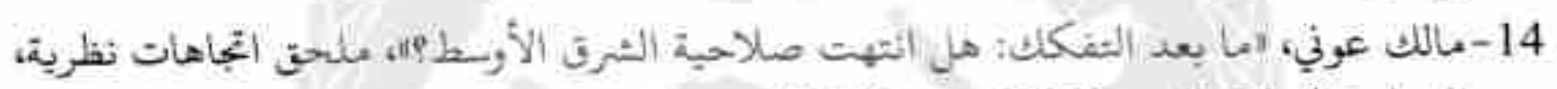

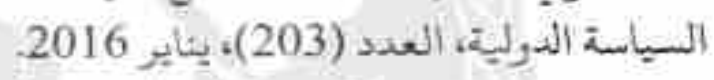

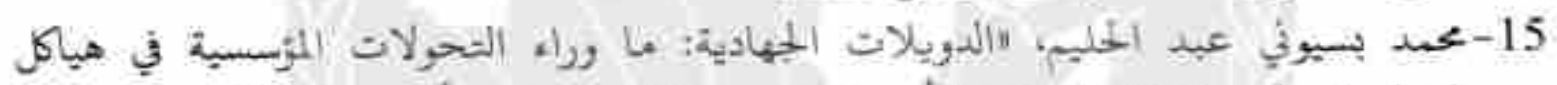

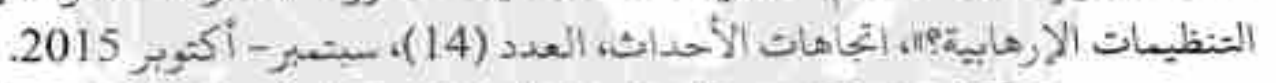

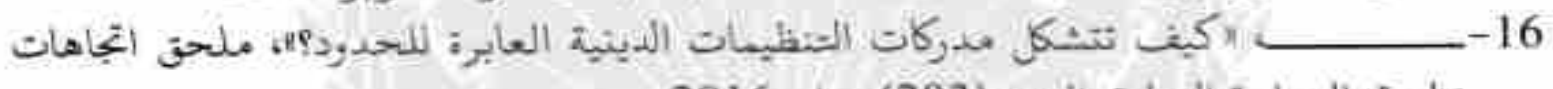

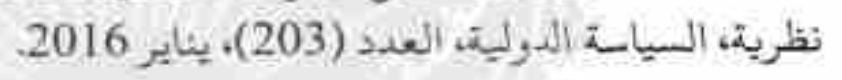

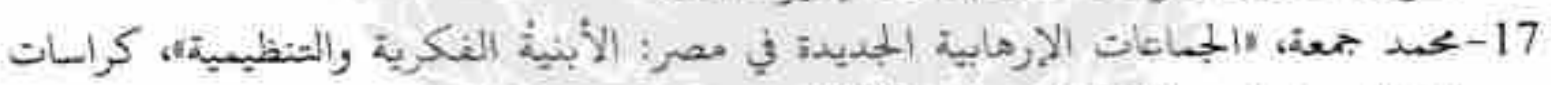

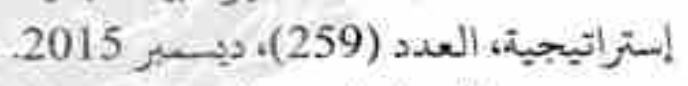

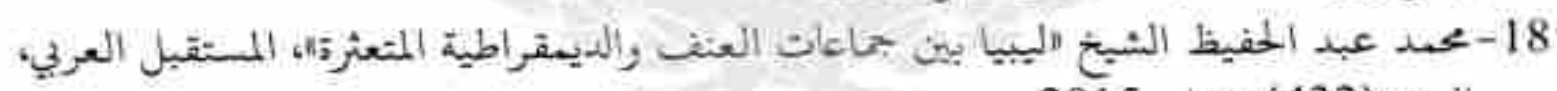
العدد (432)، فبراير 2015.

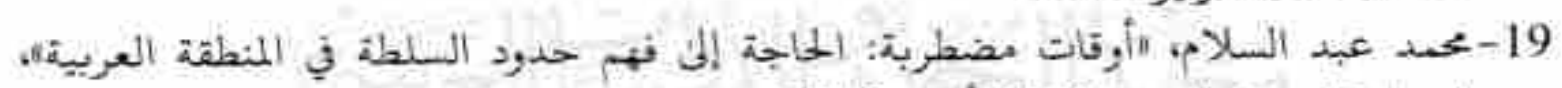

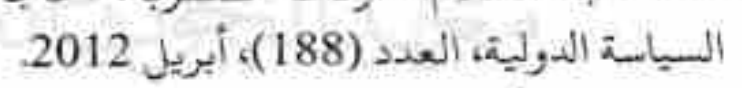

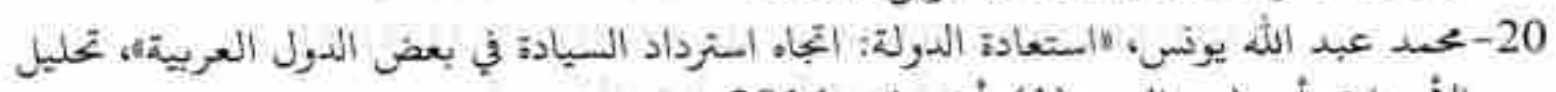

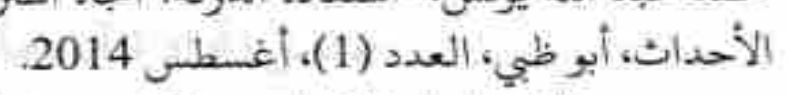
"اقتصاديات الإرهاب: شبكات تهويل الأنيطة الإرهابية في إقليم الشرق الأوسطباء. $-21$

$$
\text { حالة الإقليم، العدد (9)، يوليو } 2014 .
$$

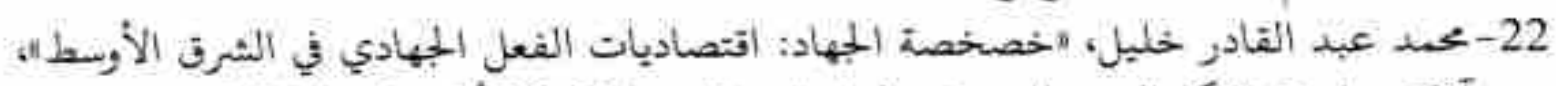

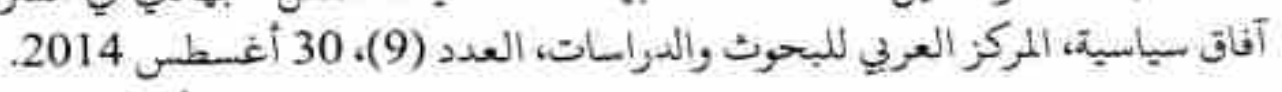

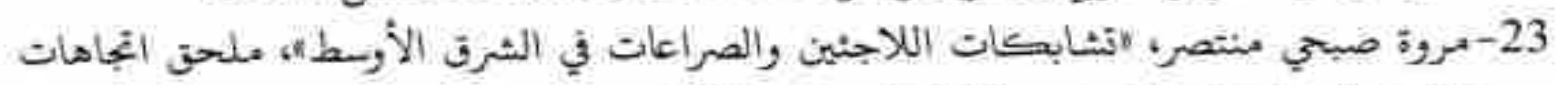

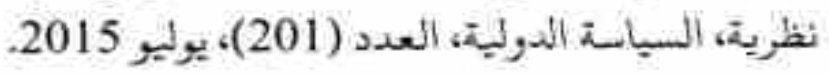




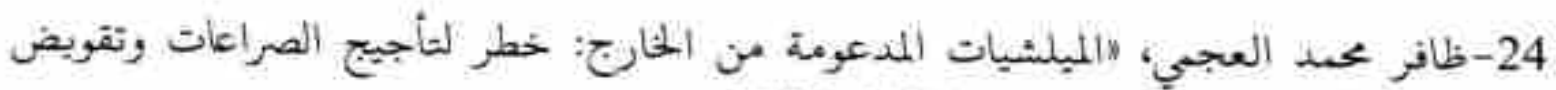

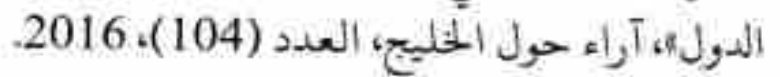

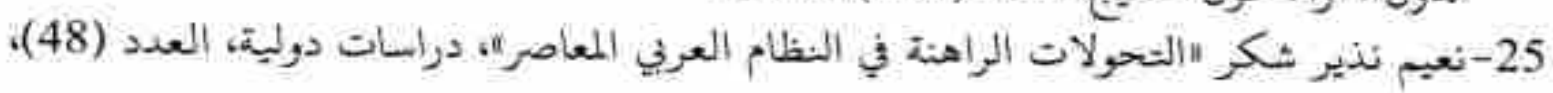
2011

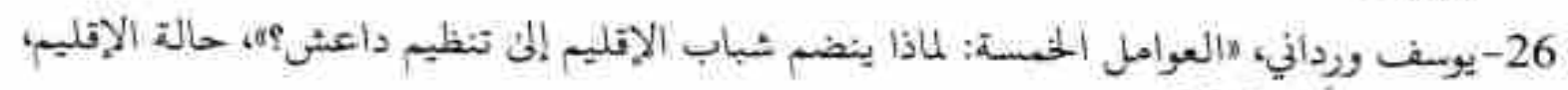
العدد (12)، 2013.

\section{3- الأوراق:}

1- أحمد زكريا الباسوسي، بيئات حاضية: المنظيفات الإرهابية في المنطقة العربية.بئز الانتشار

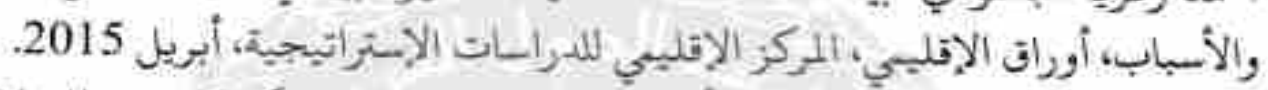

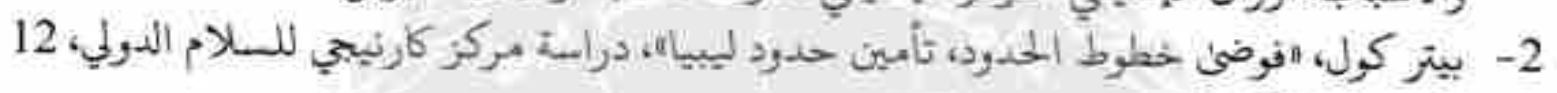
أكتبربر 2012.

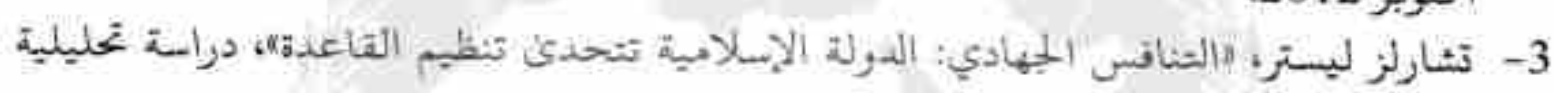

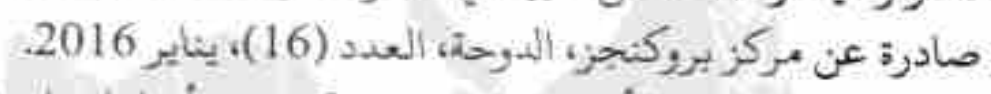

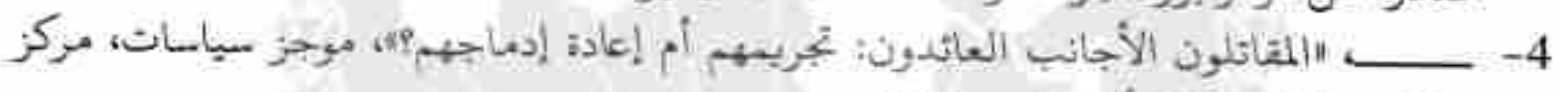
بروكنجز الدوحت، 13 أغسطس الغون 2015.

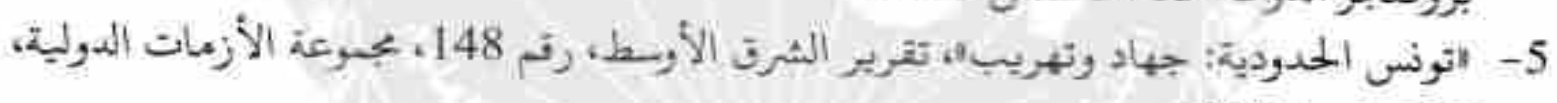
28 نوفنبر 2013.

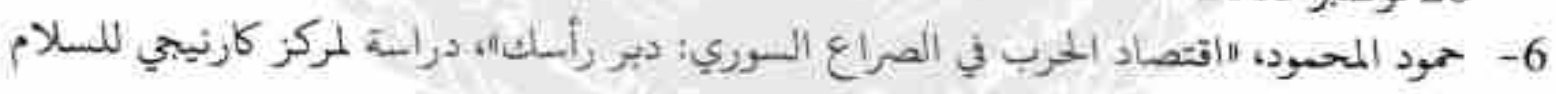
الدولي، بيروت، 23 يولير المبرد، 2015.

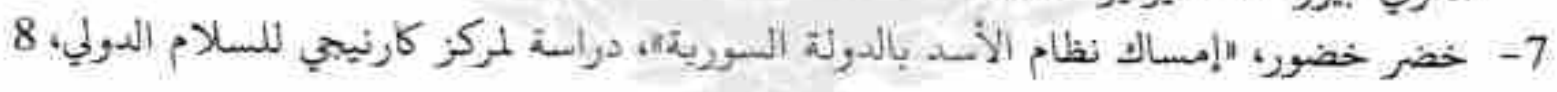
يولير 2015.

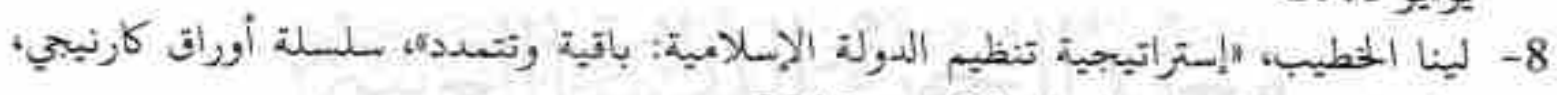
مركز كارنيجي للسفلام الدولي، 29 يونيو 2015.

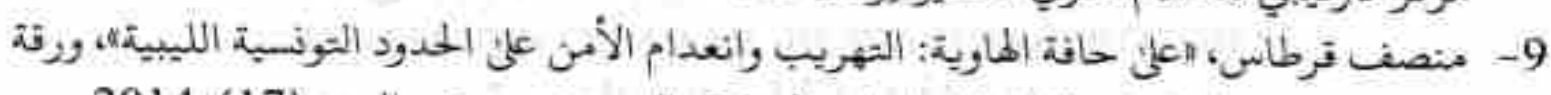

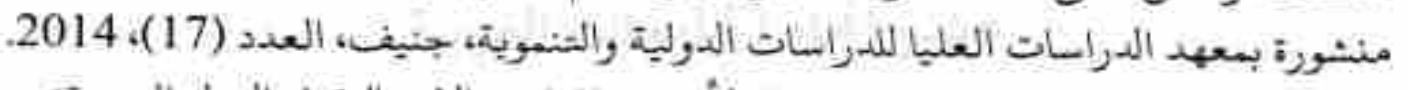

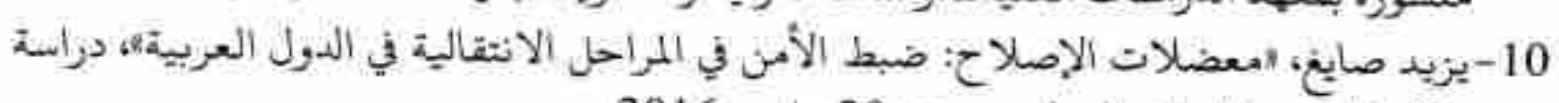

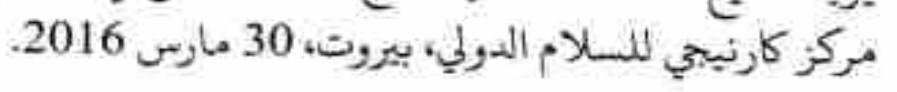

4- المؤتمرات والندوات1

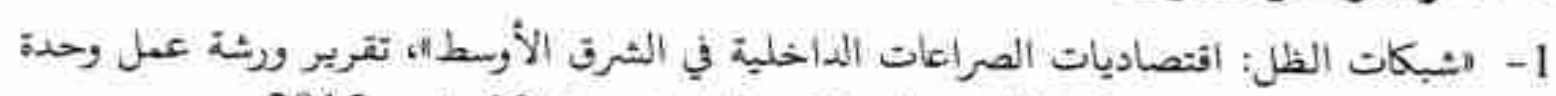

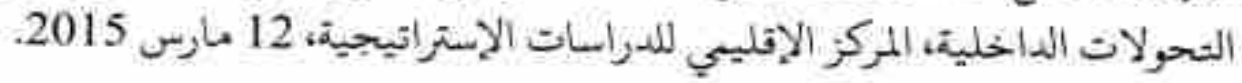




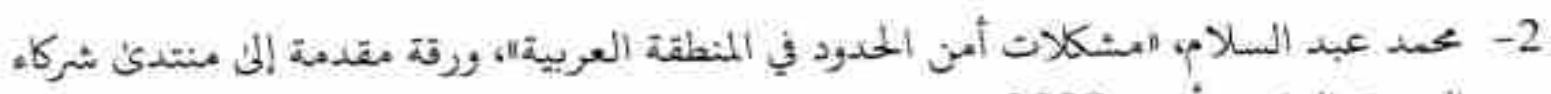

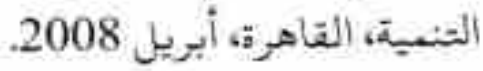

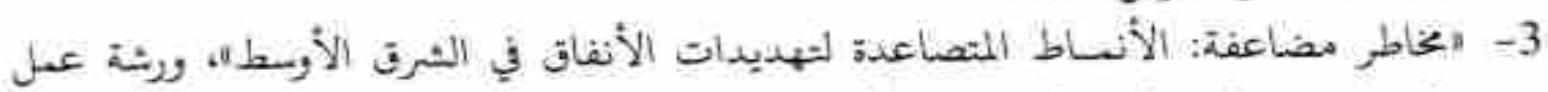

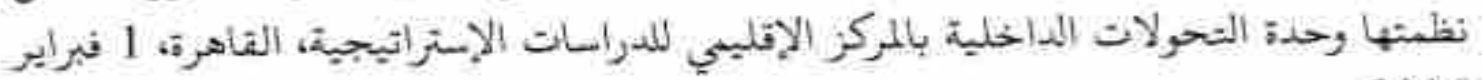

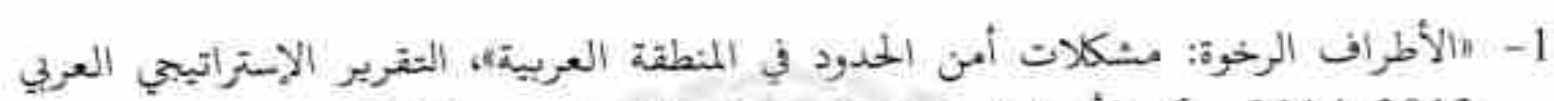

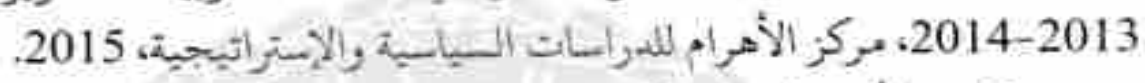

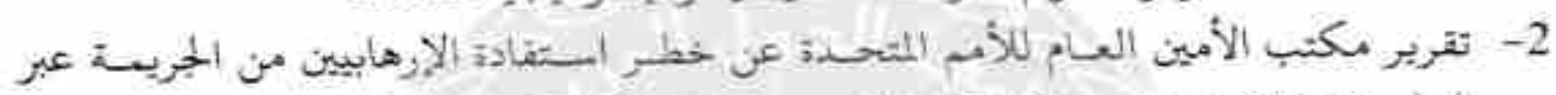

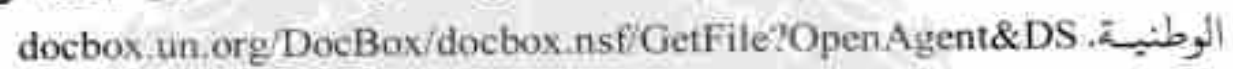

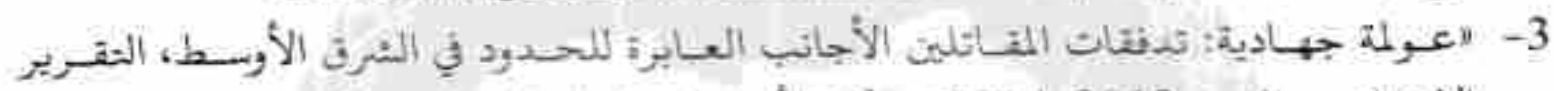

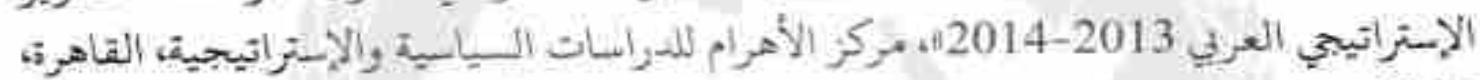

\section{6- المقالات:}

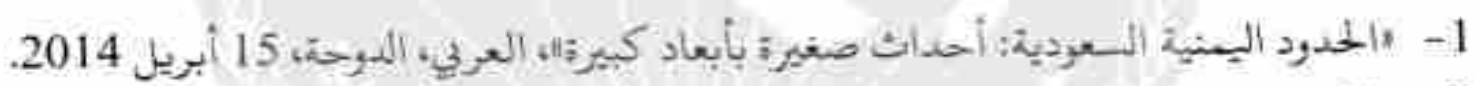

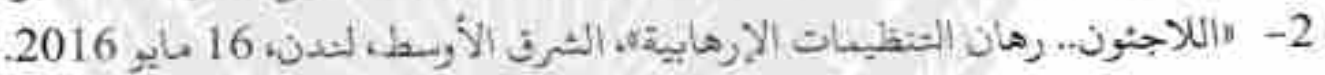

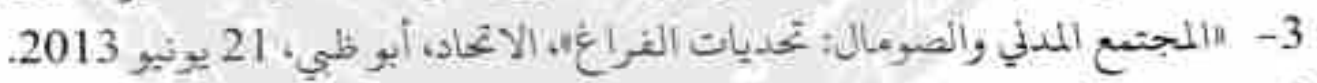

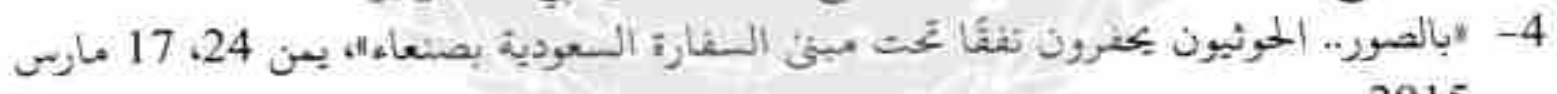
.2015

5- الجيش الجزائر يخوض حربًا لمنع تهريب الأسلحة عبر الحدود الليبيةلا، القدس العربي، لندن. 14 نوفنبر 2015.

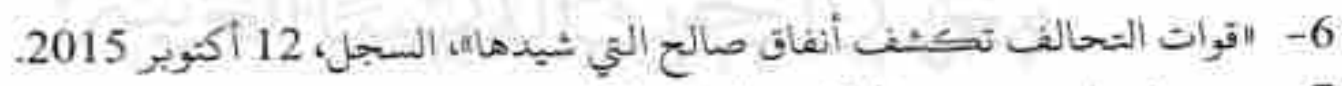

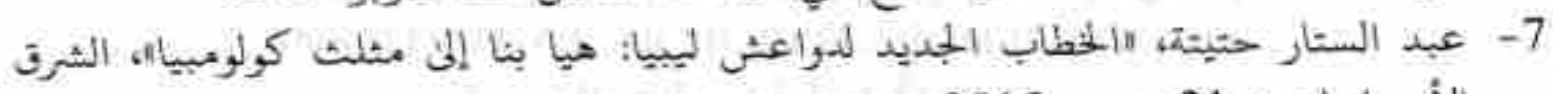
الأوسط، لندن، 21 دينسبر 2015.

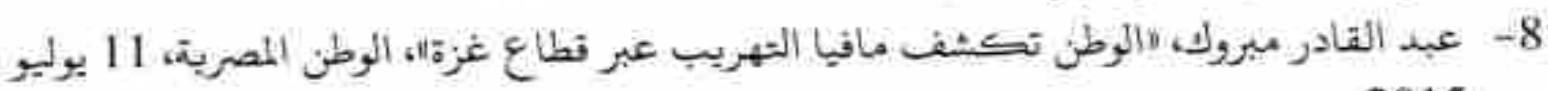
.2015

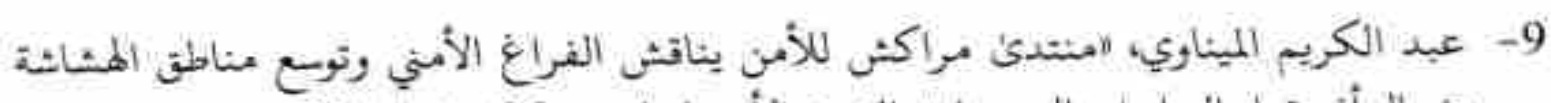

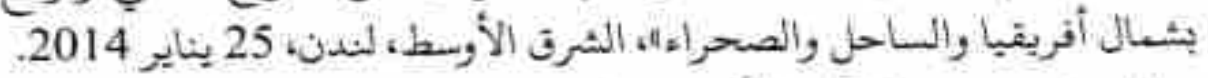

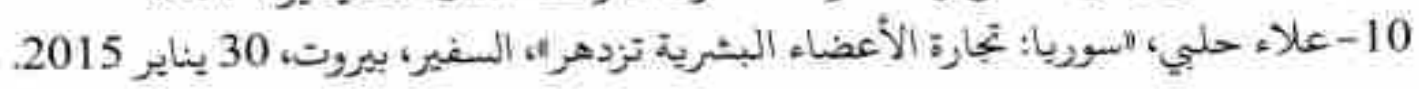


11-لاهافيا تجارة البئر تتوحش: نساء للبغاء. أرحام للإيجار.. أطفال للبيع، صحيفة التقرير، 23 أكتوبر 2014.

12-محبد العبسي، لاخطلف الأجائب في اليبن: سوق سوداء لتنظيم القاعدةّه، السفير، بيروت، 25 مايو 2014. 13-مركز الخليج للدراسيات الإستراتيجية لامناطق الفراغ والميلشيات المسلحة في الوطن العربيك،

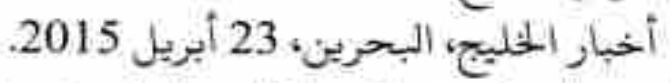

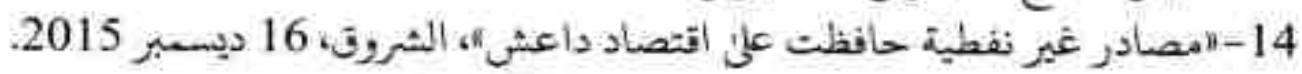

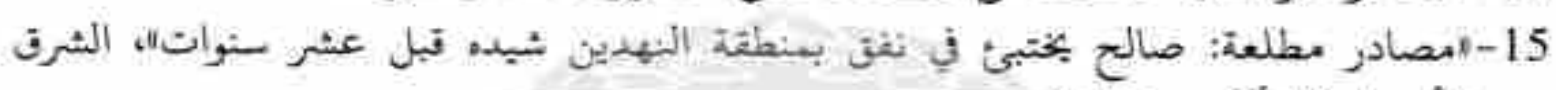
الأوسط ، 12 أكتوبر 2015.

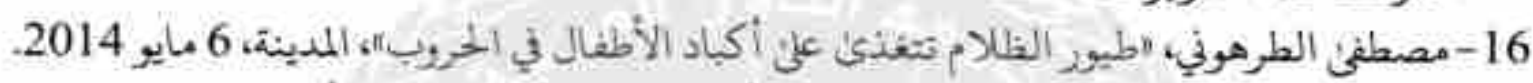

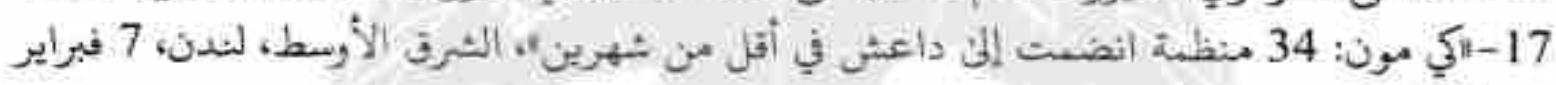
.2016

\section{7- المواقع الإخباريترا.}

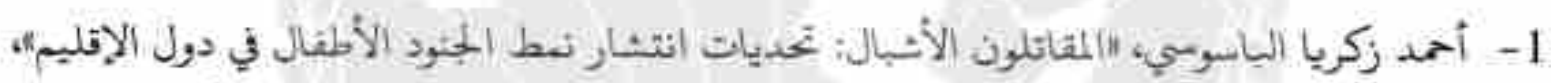

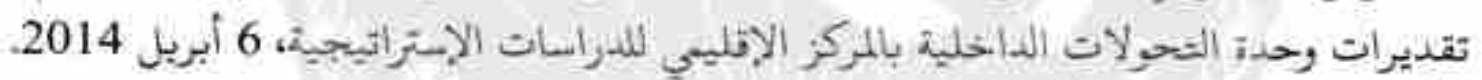

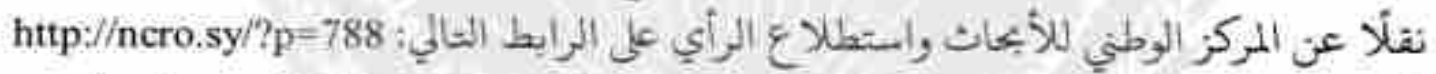

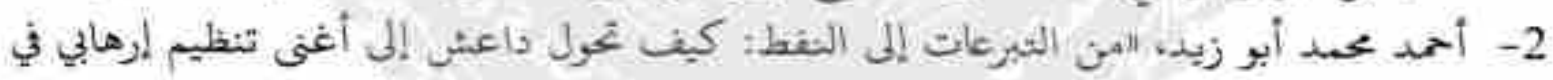

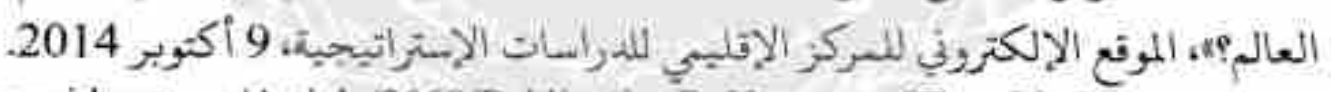
www:rcssmideast.org/Article/2668/PublicationByYear.aspx? Typeld=3 3- أسامة مهي، لادولة الخلافة لداعث تتشكل من حلب السورية لينيوي العراقية، إيلاف، 9

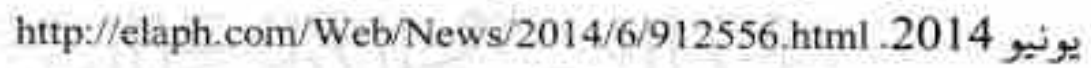

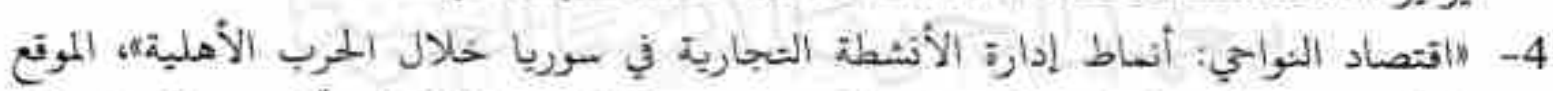

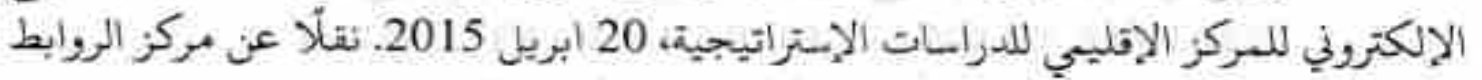

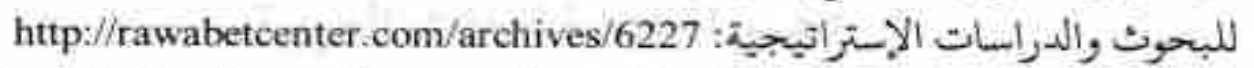

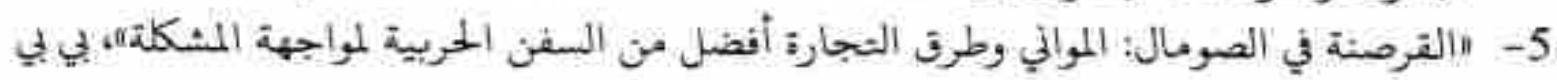
بي البريطانية، 10 يولير 2014. http://www.bbc.com/arabic/worldnews/2014/07/140710_facing_somali_piracy_by_dev elopment

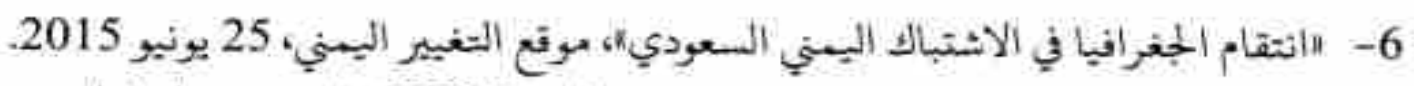
http://www.al-tagheer.com/art32321.html 
7- التجنيد داعثب للمراهفات يتزايد.. وثوة من الأطفال الجهاديين باسم أشبال الملافةال، سي إن إن عربي، 25 فبراير 2015. http:/arabic,cnn.com/middleeast/2015/02/25/me-250215-michael-holmes-isis-kidspropaganda

$$
\text { 8- تشارلز ليستر، "اقطع السيولة عن دأعث"، مركز بروكنجز الدوحة، } 24 \text { أكتوبر } 2014 .
$$

https: $/ /$ www.brookings,edu/blog/markaz/2014/10/24/\%d9\%82\%d8\%b7\%d8\%b9. $\%$ d8\%a $7 \%$ d9 $\% 84 \%$ d8\%b3\%d9\%8a \%d9\%88\%d9\%84\%d8\%a9-\%d8\%b9\%d9\%86$\%$ d8 $\%$ af $\%$ d $8 \%$ a $7 \%$ d8 $\%$ b9\%d8\%b4l

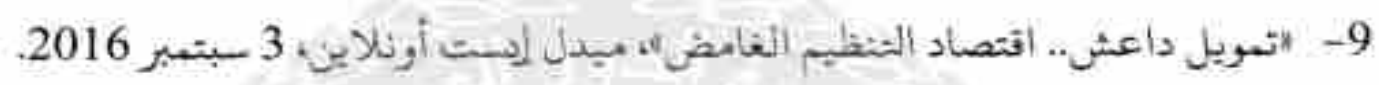

http: //www, middle-east-online.com/?id $=183407$

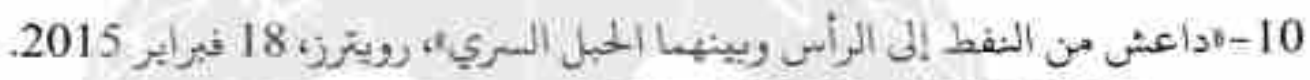

https://arabic.rt.com/news $774439-\%$ D $8 \%$ AA $\%$ D8\%AC $\%$ D $\%$ A7\%D8\%BI\% D8\%A9-\%D8\%A3\%D8\%B9\%D8\%B6\%D8\%A7\%D8\%A1-\%D8\%A8\%D8\% B4\%D8\%B1\%D $9 \% 8$ A $\%$ D8\%A9- $\%$ D8\%AF\%D8\%A7\%D8\%B9\%D8\%B4/

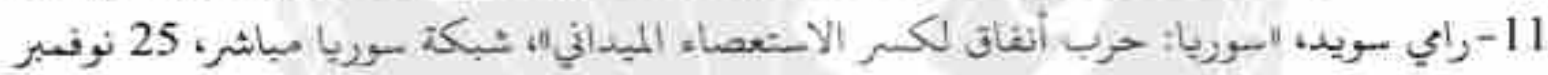
http: $/ /$ slnnews.co $/ \mathrm{m}=2014$ \& \&paged $=89.2014$

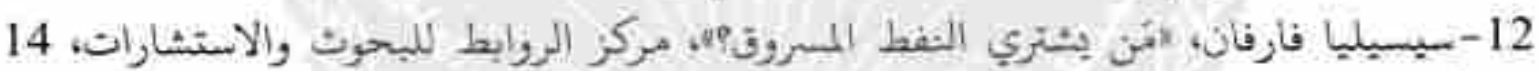

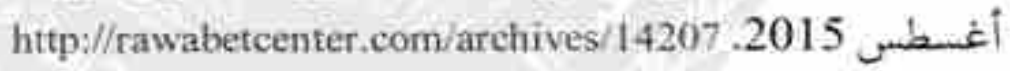

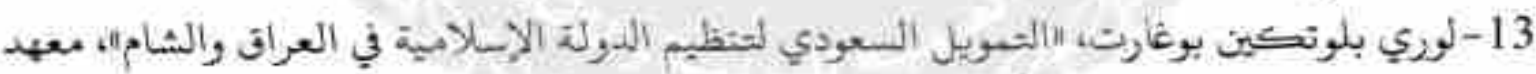

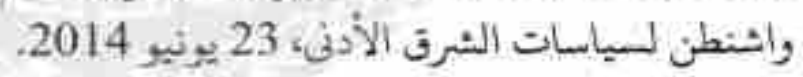

http://www.washingtoninstitute.org/ar/policy-analysis/view/saudi-funding-of-isis

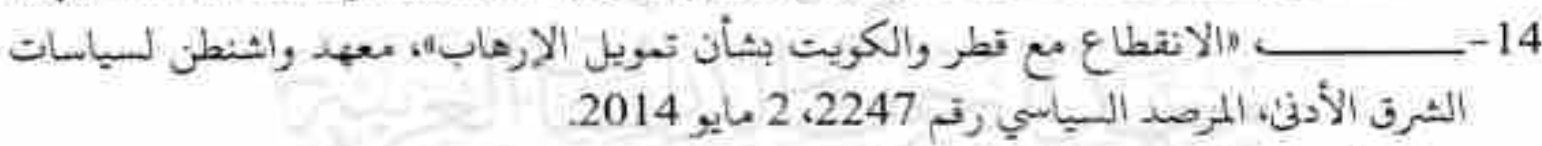

http:/www.washingtoninstitute.org/ar/policy-analysis/view/the-terrorist-fundingdisconnect-with-qatar-and-kuwait

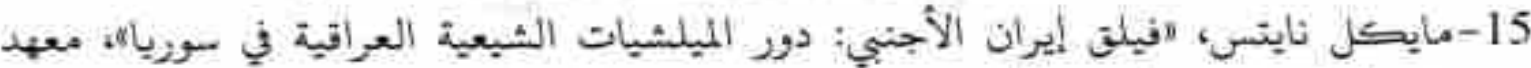

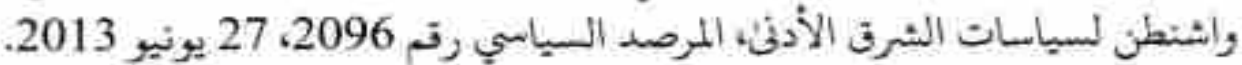

http://www_washingtoninstitute.org/ar/policy-analysis/view/irans-foreign-legion-therole-of-iraqi-shiite-militias-in-syria

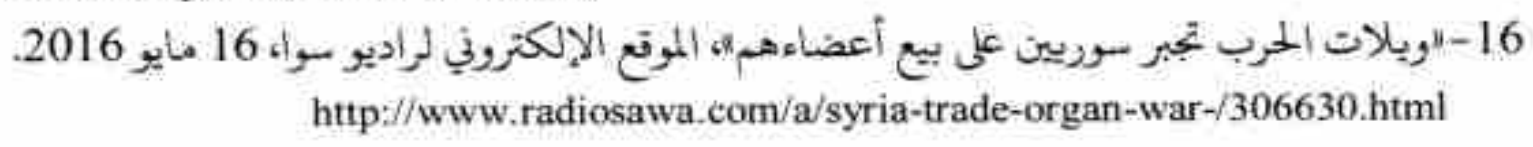




\section{ثانيا - باللفت الإنجليزيتي:}

\section{Books:}

- Micheal Hudson, The crisis of the Arab states, (Washington: Belfer center for studies and International Affairs, February 2015).

\section{Periodicals:}

- Nathan E. Shields, "Unrest in the middle east: potential implication for international terrorism and counterterrorism policy), Global Security Studies, volume 3, issue 2, Spring 2012.

- Patrick M. Regan, «Interventions with civil war: A retrospective survey with prospective ideas", Civil Wars, Vol.12, No.4, December 2010.

\section{Papers:}

- Marc R. Roseblum, Jerome P. Bjelopera \& Kristin M. Finkleg, uBorder security: understanding threats at US borders', Congressional Research Service, 21 February. 2013. 


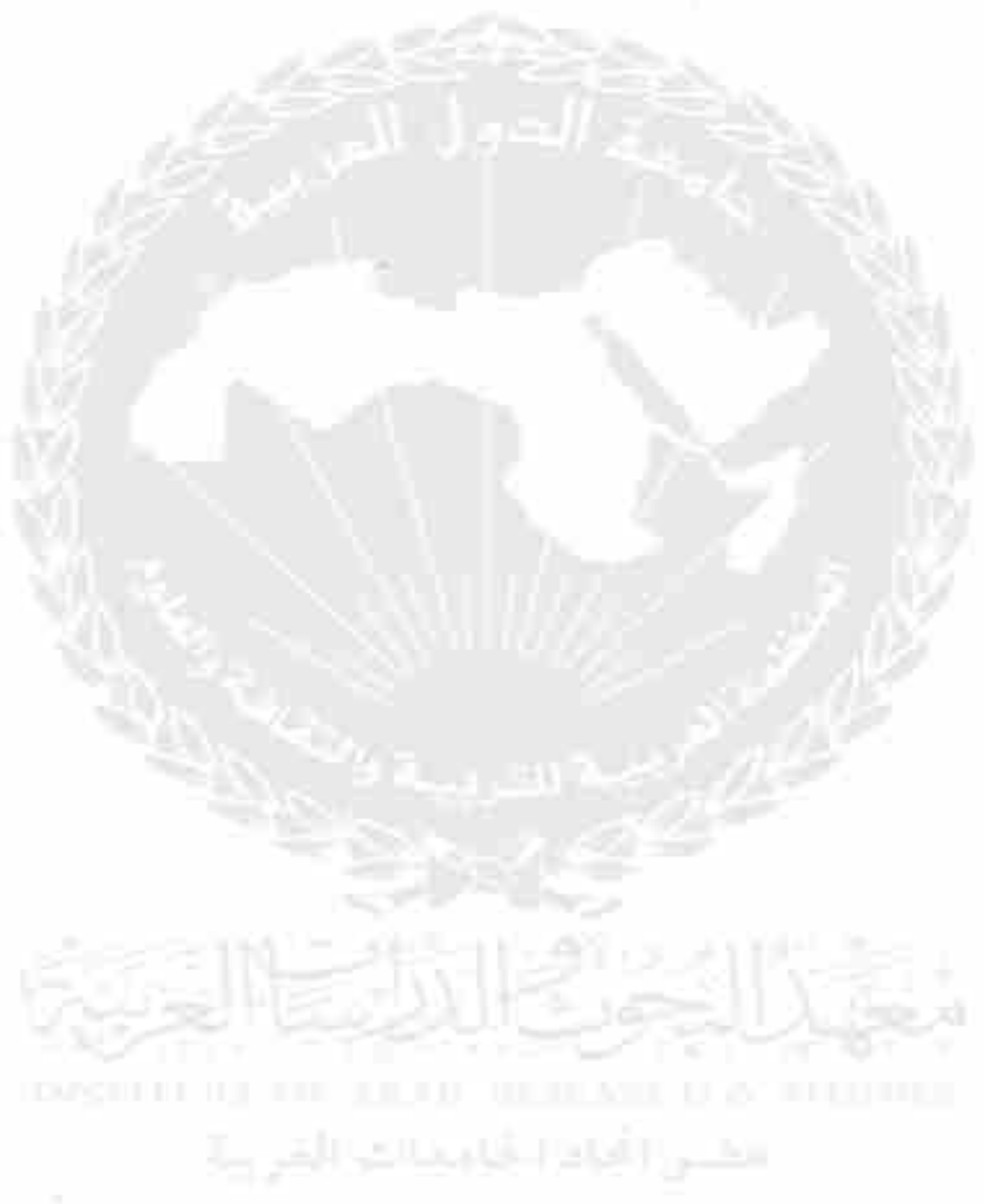

